\title{
3 Gallipoli: Planungen, Landungen, Verzweiflung
}

Nachdem sich das Osmanische Reich dazu entschlossen hatte, auf deutscher Seite in den Krieg einzugreifen, veränderte das die geostrategische Situation an der südlichen Flanke des Zarenreiches. Die Verbindung zu seinen Verbündeten auf dem Seeweg war unterbrochen, Exporte konnten nicht mehr getätigt werden und die russische Armee hatte nun mit einem weiteren Feind zu rechnen, der von Süden her aktiv werden konnte, um beispielsweise die Krim zu bedrohen. Diese Gegebenheiten, in Verbindung mit der festgefahrenen Situation an der Westfront stimulierten schließlich den Plan der Ententemächte, die Dardanellen einzunehmen und das Osmanische Reich aus dem Krieg zu drängen. Im Folgenden wird deshalb zunächst die Planungsphase der Gallipoli-Kampagne eingehender betrachtet, bevor im Anschluss daran die Operationen der britisch-französischen Flotte an den Dardanellen sowie die Landung der alliierten Truppen auf der Gallipoli Halbinsel genauer analysiert werden sollen. Dabei geht es nicht allein darum, zu zeigen, wie die einzelnen Operationen verlaufen sind, sondern gleichzeitig zu beantworten, weshalb diese von Beginn an dazu bestimmt waren, katastrophal zu enden. Gekennzeichnet waren nämlich sämtliche Planungen und schlussendlich auch deren Ausführung durch verhängnisvolle Vorurteile und Fehleinschätzungen: Überheblichkeit der Alliierten, Ungenauigkeit bei den eigenen Vorbereitungen und ein bis an die Grenze des Erklär- bzw. Vertretbaren gesteigerter Optimismus, der keinen Zweifel am Gelingen der Operationen zuließ, bis es zu spät war, denn die Einsicht folgte erst im Angesicht der endgültigen Niederlage.

\subsection{Die Planungsphase}

Gallipoli steht für eine der kontroversesten Kampagnen des Ersten Weltkrieges. Zum einen wurde sie lange Zeit als unwichtiger Nebenkriegsschauplatz betrachtet und erhält in heutigen Darstellungen zum Ersten Weltkrieg noch selten ausreichend Raum, zum anderen wurden bei den Planungen und späteren Ausführungen so viele Fehler begangen, dass sich zwangsläufig die Frage stellen muss, wie es dazu kommen konnte. ${ }^{1}$ Mit dem Eintritt des Osmanischen Reiches in den Krieg erhielt die deutsche Militärmission, deren Anwesenheit, wie oben beschrieben, bereits zu außenpolitischen Komplikationen geführt hatte, einen anderen Charakter und war noch einmal intensiviert worden, sodass schließlich

1 Doyle u. Bennett, Geography, S. 12.

Ә OpenAccess. ( 2020 Frank Jacob, publiziert von De Gruyter. (cc) BY-NC-ND Dieses Werk ist lizenziert unter der Creative Commons Attribution-NonCommercial-NoDerivatives 4.0 License.

https://doi.org/10.1515/9783110694772-003 
einige Tausend deutsche Soldaten und Offiziere am Bosporus eingetroffen waren, um den Verbündeten im Zuge der weiteren Operationen zu unterstützen. ${ }^{2}$ Ausgelöst wurde die britische Fokussierung auf Gallipoli und die Meerengen allerdings durch Geschehnisse auf einem anderen Kriegsschauplatz.

Die britische Armee und deren Führung agierten zwar ganz im Sinne einer Kontinentaltheorie, die vorsah, an der Westfront mit allen möglichen Mitteln gegen das Deutsche Kaiserreich vorzugehen. Die Entwicklung der letzten Monate 1914 und der ersten 1915 hatte jedoch gezeigt, dass die britisch-französischen Truppen unter erhöhtem Materialeinsatz vermutlich nicht dazu fähig sein würden, die deutschen Stellungen zu überwinden. Es hatte sich der Graben- und Abnutzungskrieg, diese schier endlose Materialschlacht, eingestellt. Churchill, wie ebenfalls andere Beobachter, kam zu dem Schluss, dass ein Sieg an dieser Stelle nicht erreicht werden konnte und begann deshalb, nach Alternativen $\mathrm{zu}$ suchen. Hinzu kam, dass nun das deutsche Kaiserreich, zusammen mit dem osmanischen Verbündeten, in der Lage war, die vitalen Interessen des britischen Empires in Ägypten, Persien oder Afghanistan zu bedrohen. Es musste folglich nach einer Möglichkeit gesucht werden, um dieser Gefahr entgegenzutreten und wenn möglich, das Bündnis zu zerschlagen. Ein Vorhaben, das im Erfolgsfall zudem dafür hätte sorgen können, dass sich die bisher noch neutralen Balkanstaaten ebenfalls zum Krieg auf Seiten der Entente entschlossen. ${ }^{3}$

An der Westfront schien jegliche Aktivität unangebracht, zumal Maschinengewehre und Haubitzen den Charakter des Krieges gänzlich verändert hatten. ${ }^{4}$ Sicherlich, es waren schon vor dem Ersten Weltkrieg Diskussionen über die $\mathrm{Zu}$ kunft der Kriegsführung geführt und Visionen zukünftiger Schlachtfelder beschrieben worden, ${ }^{5}$ aber die Realität des Jahres 1914 lieferte Einsichten, von denen der moderne aber immer noch kriegswütige Mensch schlichtweg überfordert schien. Die vielen Gefallenen, die erstarrten Fronten und die Ratlosigkeit der militärischen Führung, beunruhigten die britischen Entscheidungsträger, besonders da die Verlustmeldungen so hoch waren, dass sie jenseits dessen rangierten, was man sich in den schlimmsten Szenarien ausgemalt hatte. ${ }^{6}$ Bereits gegen Ende 1914 war klar, dass ein langwieriger Grabenkrieg zu erwarten war, sodass in London zunehmend nach Alternativen für die weitere Kriegsführung gesucht wurde.

2 Richter, Krieg, S. 37-43 u. S. 75.

3 Bean, History, S. 764.

4 Carlyon, Gallipoli, S. 36.

5 Vgl. Förster (Sprung).

6 Moorehead, Gallipoli, S. 25. 
Notwendig wurde dieses Vorgehen auch, weil Großfürst Nikolai Nikolajewitsch Romanow (1856-1929), der Oberkommandeur der russischen Armee, um eine Machtdemonstration des Britischen Empire gegen das Osmanische Reich gebeten hatte, um den Druck auf Russlands Flanke zu vermindern. ${ }^{7}$ Aufgrund der Niederlagen gegen die deutschen Truppen an der russischen Westfront und die Operationen im Kaukasus schien Russland nicht dazu in der Lage, sich durch militärische Operationen an seiner Flanke, selbst Entlastung zu verschaffen und hatte sich deshalb an seine Verbündeten gewandt. Im Zuge dieser Anfrage begann die Diskussion um eine mögliche Intervention bei den Dardanellen, wobei zunächst nur klar war, dass gehandelt werden sollte, allerdings nicht wie. ${ }^{8}$ Wichtig war dabei, dass ein Sieg das Ziel sein musste, um die alliierte Moral in der aussichtslosen Situation, welche von der modernen Kriegsführung geschaffen wurde, zu heben. Es begann schließlich eine Diskussion im War Council, das neben Churchill aus Premierminister Herbert Henry Asquith (1852-1928), Arthur Balfour (1848-1930), Sir Edward Grey (1862-1933), David Lloyd George (1863-1945), Herbert Kitchener (1850 - 1916), Lord John Fisher (1841-1920) und Sir James Wolfe Murray (1853-1919) bestand. Diese Männer waren, so der kanadische Historiker Tim Travers, „Amateur-Strategen und -Taktiker. Es war anzunehmen, dass wer auch immer als erster einen Plan zusammenstellen konnte, der einigermaßen akzeptabel war, den Sieg davontragen würde.“9

Zunächst wurde über die Einnahme der Gallipoli-Halbinsel durch griechische Soldaten nachgedacht, die dabei von Schiffen der britischen Marine unterstützt werden könnten. Diese Idee basierte auf der Offerte des griechischen Premierministers Eleftherios Venizelos (1864-1936), der dabei gegen die Wünsche seines pro-deutschen Königs Konstantin I. (1868-1923) agiert hatte. Die griechischen Soldaten blieben folglich aus, die Idee einer Aktion gegen die Meerengen war aber schon einmal im Raum. ${ }^{10}$ Die Mitglieder des War Council nahmen diese Idee auf und regten eine Operation der Flotte gegen die Dardanellen an, wobei etliche Fragen zunächst und auch später, ungeklärt blieben:

1. Wie würde man die Minenfelder beseitigen, die die Durchfahrt durch die Meerengen versperrten?

2. Konnte man diese überhaupt beseitigen, solange die Befestigungsanlagen noch feuerten?

3. Was würde die britische Flotte nach einem Durchbruch durch die Meerengen tun?

7 Travers, Gallipoli, S. 19.

8 Moorehead, Gallipoli, S. 26-29.

9 Travers, Gallipoli, S. 20.

10 Carlyon, Gallipoli, S. 73; Prior, Gallipoli, S. 7. 
4. Sofern ein Fall Konstantinopels allein durch eine derartige Flottenaktion herbeizuführen war, welche Konsequenzen hätte dieses Ereignis auf den Krieg gegen das Deutsche Kaiserreich?

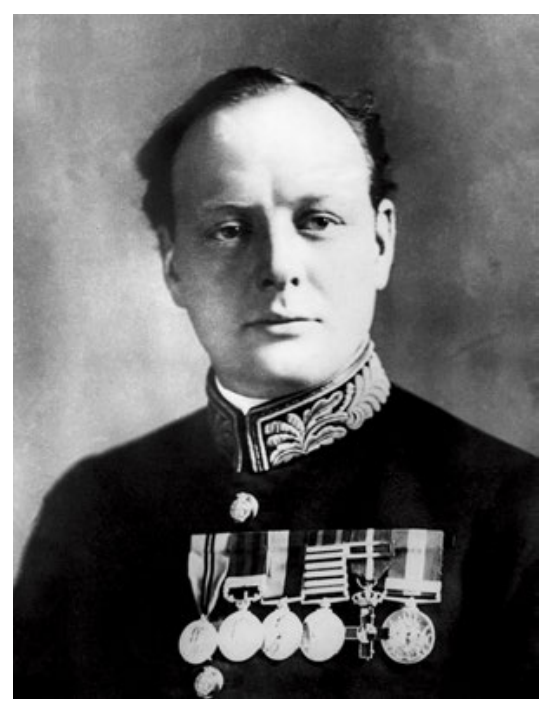

Abb. 3: Winston Churchill auf einer Aufnahme von 1914.

Tragischerweise fanden diese Fragen nur wenig Beachtung. ${ }^{11}$ Wie hungrige Hunde, die endlich und nach langer Wartezeit einen alten Knochen gefunden hatten, balgten sich die Mitglieder des War Council um einen Plan, der bei näherer Betrachtung alles andere als vielversprechend war. Dem Hauptproblem, nämlich, dass die Minen geräumt werden mussten, um die Befestigungsanlagen attackieren zu können, erstere allerdings nicht beseitigt werden konnten, solange letztere noch intakt waren, zollte niemand wirklich Aufmerksamkeit. Die Entscheidungsträger waren sich stattdessen sicher, endlich einen Plan ersonnen zu haben, der das Desaster der Westfront überwinden und den Krieg beenden würde. Hinzu kam, dass alle Beteiligten ihre eigene Vorstellung von der Operation gehabt haben dürften. Während der Premierminister eine Idee sah, die, sollte sie sich als Fehlschlag erweisen, wieder fallengelassen werden konnte, war es für Churchill die Idee überhaupt. Andere, wie Kitchener, der unwillig war, die Armee an der Operation zu beteiligen, mögen ihre Zweifel gehabt haben, blieben jedoch stumm als es darum ging, die verheißungsvolle Illusion eines schnellen Sieges bei Gallipoli

11 Carlyon, Gallipoli, S. $74 \mathrm{f}$. 
und die mit ihr einhergehende, die Sinne vernebelnde Siegesgewissheit in Frage zu stellen.

Churchill, der die politische Verantwortung für die britische Marine trug und für den das Scheitern Gallipolis eine seiner schwersten Niederlagen bedeutete, rechtfertigte sich später für seine Rolle, indem er versuchte, die Entstehungsgeschichte der Operationen genauestens zu beschreiben. ${ }^{12}$ Dabei hat seine Darstellung der Ereignisse, für die die Entscheidungsträger laut Churchill „[i]m Ausland, in alliierten, neutralen und vor allem feindlichen Staaten [...] mit Respekt und sogar Bewunderung" ${ }^{13}$ betrachtet, die in Großbritannien aber so kritisiert wurden, sicherlich zumindest teilweise apologetischen Charakter. So gibt Churchill an, dass es ihm in erster Linie um die Situation auf dem Balkan gegangen sei, wo die deutschfreundlichen Kräfte mit denen rangen, die sich der Entente anschließen wollten. Churchill erkannte zudem das Problem der Beschlagnahmung der osmanischen Schiffe an, ${ }^{14}$ relativierte aber die Bedeutung eines hypothetischen Bündnisses mit Konstantinopel einige Seiten später, weil man das Osmanische Reich mit griechischer Unterstützung durch gemeinsame Operationen an den Meerengen hätte in die Knie zwingen können. ${ }^{15}$ Zunächst hat Churchill also durchaus mit einer kombinierten Aktion der britischen Flotte und griechischen Landungstruppen gerechnet, um den britischen Schlachtschiffen die Durchfahrt durch die Dardanellen ins Marmarameer zu ermöglichen und Konstantinopel selbst zur Kapitulation zu zwingen. Dabei hoffte Churchill auf Unterstützung der russischen Schwarzmeerflotte und zaristischer Truppen von Norden her. ${ }^{16}$

Es schien ihm von Anfang an klar zu sein, dass neben der Flotte mindestens 50.000 Mann an Truppen benötigt würden, um dieses Ziel zu erreichen. ${ }^{17}$ Trotzdem war das Unterfangen für Churchill wichtig, denn, wie er in einem Brief an Sir Edward Grey bereits Ende September 1914 betont hatte, leide die Britische Marine unter der osmanischen Herrschaft über die Dardanellen, da Teile der Flotte an den Meerengen gebunden seien. ${ }^{18}$ Noch bevor das Osmanische Reich offiziell auf Seiten des Deutschen Kaiserreiches in den Krieg eintrat, empfahl Churchill deshalb Aktionen gegen den potentiellen Gegner. Zudem hoffte er wohl dadurch, die Balkanstaaten gegen das Osmanische Reich zu mobilisieren und sie stärker an die

12 Churchill, World Crisis, S. vii.

13 Ebd., viii.

14 Ebd., S. 525.

15 Ebd., S. 529.

16 Ebd., S. 533.

17 Ebd., S. 534.

18 Ebd., S. 536. 
Entente binden zu können. ${ }^{19}$ Für den späteren Premierminister stand fest, dass „England, ohne Armee, ohne einen Soldaten, den es erübrigen konnte, ja ohne Gewehr, das man schicken konnte, nur mit seiner Marine und seinem Geld, im Nahen Osten eher wenig zählte." ${ }^{20}$ Es waren folglich geostrategische Überlegungen und der Wunsch, den zermarternden Stellungskrieg der Westfront zu überwinden, die Churchill handeln ließen.

Darüber hinaus wurde er von seinen eigenen Ambitionen getrieben. Er wollte die Britische Flotte nutzen, um den Krieg möglichst ohne große weitere menschliche Verluste $\mathrm{zu}$ beenden und sich durch sein Handeln auf ewig einen Platz in den Geschichtsbüchern zu sichern. ${ }^{21}$ Allerdings war Churchill nicht der einzige, der einen Angriff auf das Osmanische Reich favorisierte. Premierminister Asquith erhielt im Dezember 1914 gleich mehrere Vorschläge - unter anderem von Lloyd George -, die ihm von einer Alternativstrategie zur Kriegsführung an der Westfront überzeugen wollten, wobei neben einer Operation gegen die Meerengen und die Gallipoli-Halbinsel unter anderem die Landung von Truppen bei Saloniki oder in Syrien als Option offeriert wurden. Churchill arbeitete jedoch hinter den Kulissen unentwegt daran, den Plan zur Flottenaktion gegen die Meerengen populär zu machen. Dabei war „sein ungeduldiges Verlangen der Vater seiner Beurteilung“ ${ }^{22}$, sodass er meist nicht gewillt schien, kritische Kommentare zu berücksichtigen.

Er war eher an dem interessiert, was erreicht werden sollte, sodass ihn das ,Wie' weniger beschäftigte als das ,Ob’. Churchill war schlicht „geneigt, den Krieg eher als Epos denn als Tragödie zu betrachten“23 und setzte seine ganze Hoffnung auf einen erfolgreichen Durchbruch der britischen Flotte an den Dardanellen und deren anschließende Fahrt nach Konstantinopel, der das Osmanische Reich siegreich in die Knie zwingen würde. Heinz A. Richter hat diese Kurzsichtigkeit, allein durch eine Flottenoperation etwas erreichen zu hoffen, zu Recht kritisiert, denn eine solche „war zur Zeit des Ersten Weltkrieges angesichts des technischen Fortschritts selbstmörderisch [...]. Die von Churchill und der Marineführung geplante Beschießung der Dardanellen-Forts war ebenfalls völlig verfehlt, denn sie musste den Gegner warnen, dass er dort später größere Angriffe zu erwarten hatte, womit das Überraschungselement für eine amphibische Operation verloren ging." 24

19 Ebd., S. 537.

20 Ebd., S. 538.

21 Carlyon, Gallipoli, S. 72; Prior, Gallipoli, S. 8.

22 Bean, History, S. 764.

23 Carlyon, Gallipoli, S. 37.

24 Richter, Krieg, S. 70 f. 
Ungeachtet dessen erhielt der Dardanellen-Plan immer mehr Zustimmung und gewann an Popularität, selbst wenn nicht alle dieser Idee von Anfang an zugetan waren und Churchill bei manchen seiner Kollegen hart daran arbeiten musste, um sie umzustimmen bzw. zu einem widerwilligen Miteinander zu überreden. Lord Fisher kannte den späteren Premierminister von der Zusammenarbeit im Marineministerium. Beide hatten sich im Zuge derselben gut miteinander verstanden. Jedoch waren der Altersunterschied - Fisher war über 30 Jahre älter als Churchill - sowie die unterschiedlichen Ansichten im Hinblick auf den Einsatz der Marine gelegentlich spürbar. ${ }^{25}$ Fisher hatte die Ambitionen Churchills und seinen daraus resultierenden Drang nach einer historischen Tat erkannt und versuchte, diesem während der Diskussionen des War Councils etwas entgegenzusetzen. Es schien dem Ersten Lord der Admiralität aber stets zu gelingen, Fisher zu überzeugen, dass es keine andere Option geben konnte, als den Angriff auf die Dardanellen. Der Konflikt zwischen den beiden beruhte dabei nicht zwingend auf dem Grundgedanken, die Flotte einzusetzen, doch hatte Fisher „seine Reputation darauf aufgebaut Schiffe zu erhalten; Churchill wollte seine Karriere darauf begründen Schiffe für das greater good zu versenken. “26 Es war zwar vorgesehen, nur alte Schiffe an die Dardanellen zu entsenden, Fisher hielt die Aktion dennoch für eine Verschwendung wichtiger Ressourcen, die besser für die finale Auseinandersetzung mit der deutschen Flotte Verwendung finden sollten.

Die Pläne zur Bildung einer Balkanallianz, die zur Einkreisung des Osmanischen Reiches führen würde, begeisterten Fisher, aber er ging dabei von einer Involvierung griechischer Truppen aus. Er plädierte für eine gemeinsame Operation, bei der die Marine durch Landungen von Truppen verbündeter Balkanstaaten - und keinesfalls englischer Soldaten - unterstützt werden würde. ${ }^{27}$ Mit Blick auf den Einsatz der Royal Navy befürwortete Fisher hingegen eine Flotte in der Nordsee, um eine der deutschen Inseln, z. B. Borkum, zu besetzen. Mitunter deshalb, war der Admiral nicht willens, Churchills „südliche Pläne“ zu befürworten. Zunächst reagierte Churchill auf den Widerstand und berief für den 3. Januar 1915 eine Sitzung der Admiralty War Group ein, die im Marineministerium weitere Möglichkeiten ausloten sollten. Dieses Treffen und weitere Diskussionen scheinen aber nicht stattgefunden zu haben und letztendlich hielt Churchill an seinem Plan fest. ${ }^{28}$

25 Carlyon, Gallipoli, S. 71; Moorehead, Gallipoli, S. 36.

26 Carlyon, Gallipoli, S. 76.

27 Fisher an Hankey, 1. Februar 1915, Hankey Papers, CAB 63/4, National Archives, Kew, zitiert nach Prior, Gallipoli, S. 12.

28 Prior, Gallipoli, S. 15-19 gibt einen Überblick über die weiteren Diskussionen. 
Die Entscheidung fiel in einer Sitzung des War Councils am 13. Januar 1915. In dieser Sitzung sollte Fisher nicht nur den internen Streit mit Churchill endgültig verlieren; die Mitglieder des Gremiums bestimmten damit auch entscheidend den weiteren Verlauf der Operation. Kitchener war zwar immer noch nicht bereit, Truppen zu bewilligen, doch ungeachtet dessen verhallte Fishers Kritik. Dieser wies darauf hin, dass er glaubte, die Flotte sei besser in der Nordsee einzusetzen und lehnte einen großangelegten Angriff der britischen Marine an den Dardanellen ab, da sich diese auf die große Auseinandersetzung mit dem Deutschen Reich vorzubereiten habe. Er wiederholte also seine Ansichten, die er zuvor schon Churchill mitgeteilt hatte. Während der Sitzung zeichnete sich ab, dass der rhetorisch begabtere Erste Lord der Admiralität dazu in der Lage war, die anderen Mitglieder von seinem Plan zu überzeugen. Als Fisher zornig den Tisch verließ, musste ihn Kitchener besänftigen. Es war abzusehen, dass Fisher dieses Wortgefecht nicht gewinnen konnte, doch eine Rücktrittsdrohung scheiterte am Redetalent Churchills, der seinen Kollegen geschickt für sich einnehmen konnte. Letzten Endes stimmte Fisher, wenn auch unter Druck, der Operation gegen die Dardanellen zu. Die Aktion der Flotte wurde also autorisiert. Allerdings war damit noch nicht geklärt, welchen Effekt eine Attacke der britischen Schiffe, ohne die Unterstützung von Landungstruppen haben konnte. Während Fisher darin lediglich eine Machtdemonstration des Britischen Empire zu sehen glaubte, waren andere Mitglieder des War Councils geneigt, in dieser Entscheidung den ersten Schritt zum Ende des Krieges zu erblicken.

Eine gewisse Euphorie griff um sich, wollten einige doch den Zusammenbruch des Osmanischen Reiches am Horizont erkennen. Die Bereitschaft der russischen Verbündeten, Truppen zu entsenden sowie Versicherungen aus Paris, dass man gewillt war, sich ebenfalls an der Flottenoperation zu beteiligen, bewirkten eine Art hochmütiger Zuversicht. Admiral Sackville Carden (1857-1930) hatte einen Plan für die Flotte vorbereitet, der schon am 13. Januar diskutiert worden war und demzufolge nun agiert werden würde. Kritisch anzumerken sind mit Blick auf diesen Plan zwei Dinge: Carden galt in der Marine nicht nur als „langsam [und] ineffektiv“29 und er äußerte sich zudem nicht dazu, was mit der Aktion der Marine an den Dardanellen eigentlich erreicht werden konnte oder sollte.

Fisher war wütend, dass man im War Council für die Ausführung der Aktion gestimmt hatte, sodass Churchill wiederum aktiv werden musste, um ihn erneut von der Richtig- bzw. Notwendigkeit der Dardanellen-Operation zu überzeugen. Am 28. Januar 1915 überredete er Fisher, das Konzept zusammen mit ihm und dem

29 Travers, Gallipoli, S. 21. 
Premierminister noch einmal zu diskutieren. Churchill wusste, dass er Fishers Zustimmung brauchte, um die Aktion nicht zu gefährden, da Asquith nur gewillt war, zur Tat zu schreiten, wenn alle an einem Strang zogen. ${ }^{30}$ Im Gegensatz zu Calden und Fisher hatten inzwischen alle anderen Mitglieder des War Councils sehr genaue Vorstellungen davon, was mit der Flottenoperation bei den Dardanellen erreicht werden würde. Sie erhofften sich, dass

1. die osmanische Armee in zwei Teile gespalten,

2. Konstantinopel unter alliierte Kontrolle gebracht,

3. eine Verbindung für Versorgungslieferungen nach Russland geschaffen,

4. der russische Exportmarkt revitalisiert und dadurch das Land innerlich stabilisiert sowie

5. eine Passage in Richtung Donau geöffnet würde. ${ }^{31}$

Für die meisten Anhänger des Planes war es schlichtweg unmöglich, sich eine andere Operation, die nur annähernd so effektiv wäre, vorzustellen. Etwas, das hier verantwortungslos missachtet wurde, war einer der Grundsätze der Kriegsführung, nämlich dass zum Sieg in einer Schlacht auch die Kontrolle bzw. Inbesitznahme des gegnerischen Terrains notwendig ist. Eine Flottenoperation allein - ähnlich wie Luftschläge in der heutigen Zeit - kann den Gegner zwar attackieren, aber weder einen umfassenden Sieg noch ein Ende der Feindseligkeiten erzwingen. Es hätte klar sein müssen, dass „der einzige Weg, um sicherzustellen, dass die feindlichen Befestigungs- und Geschützanlagen ausgeschaltet würden, darin bestand, Truppen zu landen um sie zu zerstören.“32

Es scheint beinahe tragisch, dass die Mitglieder des War Councils tatsächlich an den Plan glaubten, wohl weil sie von der ausweglosen Situation an der Westfront derartig beeinflusst waren, dass sie gewillt waren, ihre Hoffnung auf eine Möglichkeit wie Gallipoli zu setzen, um durch einen militärischen Erfolg endlich das Ende des Krieges herbeiführen zu können. Die Entscheidungsträger gingen schlichtweg davon aus, dass der osmanische Gegner angesichts der mächtigen britischen Flotte kapitulieren würde und Truppen erst notwendig werden würden, wenn es um die Besetzung des gegnerischen Territoriums und die Gefangennahme des sich ergebenden Feindes ging.

Eine erfolgreiche Zusammenarbeit aller Waffengattungen wurde im Fall von Gallipoli in erster Linie von Kriegsminister Kitchener verhindert. Dieser hatte sich vor allem durch seine harte Kriegsführung gegen die südafrikanischen Buren

30 Moorehead, Gallipoli, S. 39f.

31 Prior, Gallipoli, S. 28.

32 Ebd. 
einen großen Bekanntheitsgrad erworben und galt als Verkörperung britischer Kriegskunst, denn „die eine Sache, die die Briten über Kitchener wussten, war die, dass er den Krieg besser verstand als irgendjemand sonst auf der Welt." ${ }^{\text {"W3 }} \mathrm{Er}$ war zudem ein Machtmensch, jemand der lieber handelte als lange zu reden. Dennoch war er 1914 jedoch nicht bereit, Truppen zur Verfügung zu stellen, um die vom russischen Verbündeten geforderte Machtdemonstration gegen das Osmanische Reich auszuführen. Trotzdem wurde zu Beginn des Jahres 1915 über eine Entsendung von Truppen beraten und Ian Hamilton zum Befehlshaber auserkoren. Hamilton hatte unter dem späteren Kriegsminister während des Burenkrieges als Stabschef gedient und befolgte getreu die Befehle seines Vorgesetzten. ${ }^{34}$ Kitchener stellte seinem Untergebenen gegenüber klar, dass die Armee nicht zwingend an den Meerengen zum Einsatz kommen müsse, da die Marine davon ausging, alleine erfolgreich sein zu können. Die Armee würde nur dann zum Zuge kommen, wenn die britische Flotte versagte. Der Kriegsminister versicherte zudem sofort, dass Gallipoli lediglich eine Station auf dem Weg in die Hauptstadt des Osmanischen Reiches war und dass es darum gehen müsse, dieses aus dem Krieg zu zwingen. Kitchener erkundigte sich deshalb voller Optimismus bei Hamilton, wie er gedenke, Konstantinopel mit seinen Truppen abzusichern. Wie viele andere sah demnach Kitchener nicht voraus, „dass die gelbe Erde der Gallipoli-Halbinsel aufgeworfen würde, um ein Netz aus Gräben und Tunneln, denen in Frankreich gleich, zu bilden. Dieser kleine Krieg würde schnell und leicht sein. Frankreich sei eine Schlammschlacht, Gallipoli hingegen Schach.“" ${ }^{35}$ Kitchener, dessen militärische Karriere in erster Linie aus Einsätzen an kolonialen Kriegsschauplätzen bestanden hatte, brachte durch solche Annahmen seine rassistisch-arrogante Weltsicht zu Tage. Zur Adressierung von Hamiltons Anweisungen benutzte er die Benennung „Konstantinopel-Expeditionskorps“, welche ausschließlich auf Wunsch Hamiltons zur Verschleierung der Ziele in „Mittelmeer-Expeditionskorps“ geändert wurde. ${ }^{36}$

Die Nachlässigkeiten innerhalb der Planungsphase waren damit nicht beendet. Während die Verteidiger wussten, dass sie sich auf eine Landungsoperation vorbereiten mussten und daran gingen, die eingrenzbare Zahl möglicher Landungsplätze abzusichern und auf ein Gefecht vorzubereiten, lief die Heeresoperation in London schleppend an. Während „der kranke Mann Europas sein Bett verließ und seine Krücken wegwarf“" ${ }^{37}$ um sich auf einen „blutigen Tanz“ ein-

33 Carlyon, Gallipoli, S. 32.

34 Ebd., S. $38 \mathrm{f}$.

35 Ebd., S. 41.

36 Ebd., S. 42.

37 Ebd., S. 111. 
zustellen, herrschte im Kriegsministerium und bei Hamiltons Stab nur eines: Unwissen. Der Kommandeur des Expeditionskorps wusste zu Beginn überhaupt nicht, wo er mit seinen Soldaten - die 29. Armee mit 17.649 Mann, die ANZACTruppen mit 30.638 Mann, ein französisches Kontingent mit 16.762 Mann sowie die Royal Naval Division mit 10.007 Mann ${ }^{38}$ - landen sollte. Hamilton konnte bloß von ungenauen Schätzungen der gegnerischen Stärke, die von 40.000 bis 80.000 Mann ausgingen, ausgehen. Der Befehlshaber der alliierten Truppen in Ägypten, John Maxwell (1859-1929), war nicht bereit, Hamilton mit Truppen zu unterstützen, sodass dieser auf keinerlei Reserven setzen konnte. Eine Geheimhaltung der eigenen Vorbereitungen wurde ebenfalls nicht gewährleistet, sodass Hamilton ebenso wie der Gegner in ägyptischen Zeitungen regelmäßig über den Stand der Vorbereitungen informiert wurde. Damit war jedes Überraschungsmoment zerstört und der Befehlshaber des Mittelmeer-Expeditionskorps musste mit einer blutigen Landung rechnen, sofern diese denn überhaupt gelänge. Generalmajor Aylmer Hunter-Weston (1864-1940), der die 29. Division befehligte, wollte das fehlende Überraschungsmoment mit Moral und Courage ausgleichen, wobei für ihn alle militärischen Planungen auf eine simple Formel reduziert werden konnten: Attacke. General William Birdwood (1865-1951), der die Führung der ANZAC-Truppen übernehmen würde, wollte hingegen lieber auf der asiatischen Seite der Meerengen landen, um von dort aus gegen die osmanische Armee vorzugehen. Maxwell hatte Birdwood am 3. April 1915 wissen lassen, dass er selbst davon ausginge, dass sich Gallipoli zu einer Art „Miniatur Flandern“ entwickeln würde; eine Vorhersage, die sich aus der Retrospektive als richtig erweisen sollte.

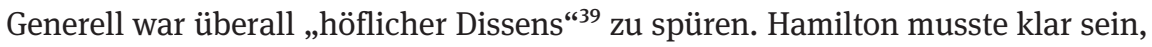
auf welche Form von Operation er sich eingelassen hatte. Ihm und seinem Stab blieb dennoch die Hoffnung, diese erfolgreich meistern zu können. Doch bevor die Landungsoperationen beschlossen, geplant und ausgeführt werden konnten, hatten die Marine und damit Churchill ihre Chance, Historisches zu leisten.

38 Ebd., S. 112.

39 Ebd., S. 122. 


\subsection{Das Scheitern der Marine und der Fluch Gallipolis}

Der australische Militärhistoriker Robin Prior hat die Attacken der britischen Flotte auf die Befestigungsanlagen an den Dardanellen als eine der ,am schlechtesten durchdachtesten Operationen des Krieges “40 bezeichnet. Die Planer hatten sich, ebenso wie bei den Landungsoperationen, überhaupt nicht mit den geographischen Beschaffenheiten des Operationsgebietes ${ }^{41}$ auseinandergesetzt, sodass man nicht nur organisatorisch schlecht vorbereitet, sondern ebenso schlecht informiert in ein Unternehmen startete, das von der Hoffnung eines Ausweges aus dem westeuropäischen Stellungskrieg getrieben war. Die Aussicht, im Osmanischen Reich einen einfacheren Gegner als die Deutschen gefunden zu haben, beflügelte die Ambitionen der Politiker, vernebelte aber gleichzeitig die Wahrnehmung derer, die zu entscheiden hatten, wann und wie vorzugehen sei. Das Osmanische Reich hatte mit dem Kriegseintritt begonnen, die bereits mit meist guten Geschützen versehenen Befestigungen weiter zu verstärken und war dabei durch deutsche Offiziere und Mannschaften unterstützt worden. ${ }^{42}$ Zudem war ein umfassendes Minenfeld angelegt worden, um feindliche Schiffe am Durchbruch zu hindern. ${ }^{43}$

Dieses Verteidigungsbollwerk konnte laut Ansicht der britischen Planer von einer zweitklassigen Flotte überwunden werden. Die britischen Schiffe, die entsandt werden sollten, waren fast alles Auslaufmodelle, die zwar mit 30-Zentimeter-Geschützen ausgestattet waren, aber innerhalb der Royal Navy, seitdem die Dreadnought-Klasse eingeführt worden war, nicht mehr auf dem neuesten Stand waren. Lediglich ein modernes Schiff, das Schnelle Schlachtschiff Queen Elizabeth mit 38 Zentimeter-Geschützen wurde bereitgestellt. Jedoch war es Admiral Carden nicht erlaubt worden, mit der Queen Elizabeth die Meerengen zu durchqueren. Ein Duell mit der auf der anderen Seite der Meerengen wartenden Goeben wäre folglich schwierig geworden. Bei dieser Entscheidung wird erneut deutlich, dass Halbherzigkeit den Kurs der britischen Aktionen bestimmt hat. Offenbar musste Admiral Fisher dem Plan im War Council notgedrungen und halb erzwungen zustimmen, aber er wollte nicht Großbritanniens Schlachtschiffe zum Ruhme Winston Churchills opfern. Auch die Besatzungen der bereitgestellten Schlachtschiffe dürften nicht unbedingt die besten Kontingente der verfügbaren

\footnotetext{
40 Prior, Gallipoli, S. 58.

41 Zur geographischen Beschaffenheit der Meerengen siehe Moorehead, Gallipoli, S. 43.

42 Zur Beschaffenheit der Befestigungsanlagen siehe Ebd., S. 44f. und Rudenno, Gallipoli, S. $26-30$.

43 Zum Minenfeld in der Durchfahrt siehe Prior, Gallipoli, S. 35 und Rudenno, Gallipoli, S. $28-30$.
} 
Seeleute umfasst haben. ${ }^{44}$ Die britische Flotte, die nach Gallipoli entsandt wurde, war eine aus internen Konflikten geborene Notlösung.

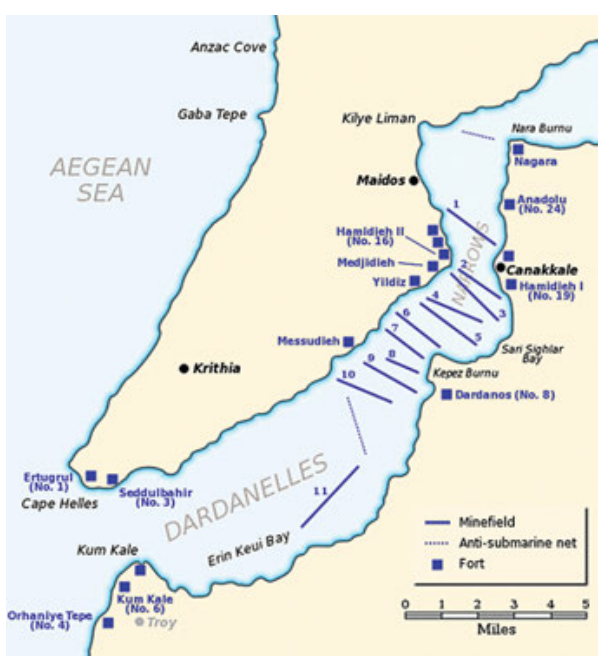

Abb. 4: Die osmanischen Verteidigungsanlagen.

Diese Kompromissflotte sollte zunächst aus großer Distanz durch ein Bombardement die äußeren Festungsanlagen am Eingang der Meerengen ausschalten, sodass umfunktionierte Fischerboote in der Lage wären, die Minen Schritt für Schritt zu räumen. Dadurch wiederum sollte ein Beschuss aus kürzerer Distanz zu den Festungsanlagen ermöglicht werden, durch den dann die mobilen Geschütze der osmanischen Armee unschädlich gemacht werden konnten. Essentiell für diesen Plan war demnach die Räumung der Minen im Bereich der Durchfahrt, wobei die Strömungen und die herrschenden Witterungsverhältnisse bei den ersten Planungen wenig Beachtung fanden. Ungeachtet dessen begann am 19. Februar die Operation der britisch-französischen Flotte bei den Dardanellen mit einem ersten Bombardement der äußeren Befestigungen. ${ }^{45}$ Ein achtstündiger Beschuss hatte kaum Auswirkungen: Lediglich sechs Tote waren auf osmanischer Seite zu beklagen und von den 27 fest installierten Geschützen der äußeren Anlagen wurde keines zerstört. Die zur Minenräumung bereitgestellten Boote waren aufgrund der Strömung kaum vorangekommen, aber stetig beschossen worden, während die alliiierten Schiffe eine so niedrige Treffgenauigkeit besaßen, dass sie

44 Prior, Gallipoli, S. 44.

45 Carlyon, Gallipoli, S. 78f.; Moorehead, Gallipoli, S. 46 f. 
nicht in der Lage waren, den gegnerischen Beschuss zu unterbinden oder Geschütze ganz auszuschalten. Die Problematik der zu räumenden Minen setzte sich deshalb in den nächsten Tagen und Wochen fort.

Hinzu kam, dass es Probleme mit dem Wetter gab, das eine konsequente und konstante Fortsetzung der Aktion der Flotte beeinträchtigte, sodass ein erneuter Angriff erst am 25. Februar 1915 unternommen werden konnte. Diese war vermutlich die erfolgreichste, da die Schlachtschiffe an diesem Tag vier osmanische Geschütze zerstörten, sodass ,eine Stimmung der Euphorie durch die gesamte Flotte fegte. “46 Am folgenden Tag wurden erstmals Einheiten der Marineinfanterie an Land gebracht, um die Schiffe bei der endgültigen Zerstörung von Geschützanlagen von Land aus zu unterstützen. Während dieser frühen Angriffe waren die osmanischen Befestigungsanlagen nur unzureichend geschützt, sodass Verluste zu verzeichnen waren und einen Eindruck davon vermittelten, wie eine kombinierte Kampagne der Armee und Marine hätte aussehen müssen, um erfolgreich zu sein. Allerdings wurden hier ausschließlich die festen Geschützanlagen der osmanischen Armee außer Gefecht gesetzt, die mobilen Geschütze blieben weiterhin aktiv und konnten nicht beseitigt werden. ${ }^{47}$

Der stete Beschuss sowie die Witterungsverhältnisse machten das Vorankommen der Boote, die die Minenräumung übernehmen sollten, beinahe unmöglich. Die umgerüsteten Fischkutter wurden durch Beschusses schnell dezimiert. Solange die Forts intakt blieben, konnten die Minen nicht geräumt und somit die Festungen nicht aus kürzerer Distanz beschossen werden. Ein Teufelskreis, den die alliierte Flotte bis zum Ende der Operationen nicht durchbrechen konnte. Zudem war nicht bedacht worden, dass wesentlich mehr Munition benötigt wurde, um bei der extrem niedrigen Treffgenauigkeit der Schlachtschiffe einen Effekt zu erzielen. Obwohl im Zuge der Operationen 20.000 Geschosse von den Schiffen aus auf die Fortanlagen abgefeuert worden waren, blieben die Zerstörungsmeldungen gering. ${ }^{48}$ Auch im März 1915 sollte sich an dieser Bilanz nur wenig ändern. ${ }^{49}$

Unabhängig davon meldete Admiral Carden noch am 2. März 1915 nach London, dass er in den nächsten 14 Tagen in das Marmarameer durchbrechen würde, die Operation also zu vollster Zufriedenheit und vollem Erfolg führen werde. Als jedoch zwei Tage später eine erneute Landung von Marineinfanteristen eingeleitet wurde, trafen diese nun auf heftigen Widerstand der osmanischen Verteidiger. Dessen Führung hatte schnell und konsequent auf die neue Situation

46 Prior, Gallipoli, S. 46.

47 Carlyon, Gallipoli, S. 80 f.; Moorehead, Gallipoli, S. 47.

48 Prior, Gallipoli, S. 40.

49 Rudenno, Gallipoli, S. 41-56 liefert einen Überblick der Märzoffensive. 
reagiert und die Mannstärken an den äußeren Befestigungsanlagen erhöht, um eventuellen Landungs- bzw. Zerstörungsoperationen effektiv entgegentreten zu können. Es war klar, dass sich die Operation nicht so entwickeln konnte, wie Carden das nach London gemeldet hatte, wenn nicht ein entschiedenerer Kurs gewählt würde, der auf einem aktiven Angriff auf die Fortanlagen basieren musste. Carden ersann deshalb einen Plan für einen Generalangriff, welcher am 15. März von der britischen Führung in London abgesegnet wurde. Das langsame Herantasten war beendet, zumal mit jedem verstreichenden Tag mit weiteren osmanischen Verstärkungen der Mannschaften und weiteren Munitionslieferungen für den Gegner zu rechnen war.

Carden schien nicht mehr bereit, die Aktion fortzuführen und wurde aufgrund eines drohenden Nervenzusammenbruchs durch seinen Stellvertreter Konteradmiral John de Robeck (1862-1928) ersetzt, der die Attacke am 18. März leitete. ${ }^{50}$ Dazu standen ihm 17 Schlachtschiffe sowie der Schlachtkreuzer Inflexible zur Verfügung. Der Plan hatte sich seit Beginn der Flottenoperation nicht wesentlich verändert. Ziel war es, zunächst die äußeren Befestigungsanlagen zu zerstören, um den Minenräumern in der Nacht die Möglichkeit zu verschaffen, das Minenfeld zu räumen. Am Folgetag sollten dann die verbliebenen und noch intakten Verteidigungsbollwerke der osmanischen Armee aus kurzer Distanz beschossen werden. Es war das Ziel, Schritt für Schritt die Befestigungsanlagen außer Gefecht zu setzen, bis die Flotte das Ende der Meerengen erreicht hätte. Die Schlachtschiffe wurden dazu in drei Gruppen eingeteilt:

1. Queen Elizabeth, die Linienschiffe der Lord-Nelson Klasse Agamemnon und Lord Nelson sowie der Schlachtkreuzer Inflexible, flankiert von dem Schlachtschiff der Majestic-Klasse Prince George und dem Linienschiff der Swiftsure-Klasse Triumph auf europäischer bzw. asiatischer Seite.

2. Eine Meile dahinter die französischen Linienschiffe der Charlemagne-Klasse Gaulois und Charlemagne, die Linienschiffe Bouvet und Suffren, flankiert von den Linienschiffen der britischen Majestic-Klasse und Swiftsure-Klasse $M a-$ jestic und Swiftsure.

3. Die Schlachtschiffe der Canopus-Klasse Albion, Ocean und Vengeance sowie das Schlachtschiff der Formidable-Klasse Irresistible.

Als Reserve verblieben noch das Linienschiff Canopus (Typschiff der CanopusKlasse) und das Linienschiff der Duncan-Klasse Cornwallis. ${ }^{51}$ Da einen Monat

50 Zum Angriff der Flotte am 18. März siehe Carlyon, Gallipoli, S. 87-101; Moorehead, Gallipoli, S. 52-61; Prior, Gallipoli, S. 54-58; Travers, Gallipoli, S. 32-36.

51 Carlyon, Gallipoli, S. 90; Moorehead, Gallipoli, S. 53. 
zuvor bereits mit den Operationen gegen die Dardanellen begonnen worden war, konnte der Angriff nicht mehr auf einen Überraschungseffekt vertrauen. Die osmanischen Verteidiger waren sehr gut mit dem Gegner vertraut und man wusste genau, was das Ziel der am 18. März beginnenden Operation sein würde.

So war dem Angriff auf die Meerengen kein Erfolg beschieden, auch wenn de Robeck die osmanischen Verteidigungsanlagen an das Limit ihrer Leistungskraft und an die Grenzen ihrer Munitionsreserven brachte. De Robeck brach den Angriff aufgrund mangelnder Erfolgsaussichten schließlich ab. Die Minenräumer konnten wegen der Suchscheinwerfer der osmanischen Verteidiger nicht erfolgreich im Dunkeln agieren, was die alliierte Flotte drei Schiffe kostete: Irresistible, Ocean und Bouvet waren auf Minen gelaufen und sanken, zwei weitere - Inflexible und Gaulois - liefen auf Grund und die Suffren wurde durch steten Beschuss stark beschädigt. Insgesamt verloren die britische und französische Marine 700 Seeleute, obwohl es nicht gelungen war, die Minen zu beseitigen. ${ }^{52}$ De Robeck war der Einsatz an Leben zu hoch, um die Aktion fortzuführen. Roger Keyes (1872-1945), der Stabschef Cardens wollte durch einen erneuten Angriff am gleichen Tag bis in das Marmarameer vorstoßen, da er ahnte, dass die Munition der osmanischen Verteidiger für einen weiteren Angriff unter Umständen nicht mehr ausreichte, de Robeck teilte diese Einschätzung allerdings nicht und zügelte die Ambitionen seines Kollegen.

Churchill begrüßte Keyes' Initiative, denn für ihn war klar, dass eine Durchfahrt durch die Dardanellen nicht ohne immense Verluste zu bewerkstelligen sein würde. Dem Ersten Seelord war es gleichgültig, Schiffe zu verlieren, solange dieses Ziel erreicht werden konnte. Die Vertreter der Marine teilten diese Ansicht jedoch nicht und mahnten die Gegebenheiten zu überdenken und zu einer stärkeren Einbeziehung des Heeres in die Operation. Die alliierte Flotte hatte versagt, da keines der gesteckten Ziele auch nur annähernd erreicht worden war. Die Ineffektivität der Schiffsartillerie beim Beschuss der osmanischen Befestigungsanlagen, das Scheitern beim Ausschalten der mobilen Geschütze und bei der Räumung der Minen markierten das Ende aller Ambitionen der Flotte, ohne Unterstützung der Armee erfolgreich sein zu können. Heinz A. Richter nennt als Ursachen dieser Niederlage drei Faktoren, nämlich 1) die „durch Artillerie und Scheinwerfer gesicherten Minensperren“, 2) die Annahme, „dass man mit Flachbahngeschützen Festungen vernichten könnte“ und 3) die „amateurhafte Führung“ des Flottenkontingents durch Carden und de Robeck. ${ }^{53}$

52 Carlyon, Gallipoli, S. 93f.; Prior, Gallipoli, S. 57.

53 Die Zitate stammen aus Richter, Krieg, S. 130. 
Wesentlich erfolgreicher waren im Gegensatz dazu U-Boot-Operationen der britischen Marine im Marmarameer. ${ }^{54}$ Diesen war zunächst ein Durchbruch durch die Dardanellen gelungen und somit war es ihnen möglich, osmanische Schiffe zu versenken. Das verzögerte das Eintreffen von Nachschub auf der Halbinsel, da Transporte als Folge der Torpedoangriffe nun über den Landweg, der wesentlich mehr Zeit in Anspruch nahm, abgewickelt werden mussten. Dass ein Erfolg der britischen Marine durchaus eine Wendung der Lage hätte bringen können, wird deutlich, wenn man die Reaktionen in Konstantinopel auf die Erfolge der feindlichen Unterseeboote betrachtet: Die Verantwortlichen fürchteten nun tatsächlich einen Durchbruch der alliierten Flotte. Da die Führung der Jungtürken auch innenpolitisch nicht unangefochten war, hätte eine feindliche Flotte im Hafen von Konstantinopel durchaus einen Zusammenbruch der Regierung und eine Neuorientierung der osmanischen Politik bedeuten können. ${ }^{55}$

Doch die Planer und Entscheider in London hielten am Dardanellen-Plan fest, statt über andere Möglichkeiten nachzudenken. Verblieben war, wie in der Büchse der Pandora, die stete Hoffnung, den Krieg und das Sterben an der Westfront zu beenden. Das Scheitern Cardens und de Robecks hatte deutlich gemacht, dass eine alleinige Operation der Marine nicht ausreichen würde, das Vorhaben zum Abschluss zu bringen und dadurch das Osmanische Reich in die Knie zu zwingen. Der einzige Aspekt, der die meisten Befürworter der Dardanellen-Kampagne, vor allem Kitchener, überzeugt hatte, war die Tatsache gewesen, dass das Ziel bei einer Marine-Aktion ohne großen Truppeneinsatz auf dem Lande erreichbar schien. Mit dem Ende dieser Illusion hätten eigentlich kritische Stimmen einsetzen müssen, denn eine erfolgreiche Landungsoperation musste schon aufgrund des fehlenden Überraschungsmomentes einen ähnlich hohen Blutzoll fordern wie ein weiteres Vorgehen gegen die deutschen Stellungen an der Westfront. Besonders, da das osmanische Heer aufgrund des Ausbleibens weiterer Attacken gegen die Befestigungsanlagen durch die alliierten Schlachtschiffe davon ausgehen konnte, dass eine Landungsoperation in naher Zukunft bevorsteht. Durch die späte Einsicht der britischen Führung, dass auch Landungstruppen bereitgestellt werden müssten, hatten die osmanischen Verteidiger nun etwa acht Wochen Zeit, sich auf die Landungen der britischen, französischen, australischen und neuseeländischen Soldaten vorzubereiten und in Ruhe alle Maßnahmen einzuleiten, die später so viele Verluste auf Seiten der Alliierten fordern würden.

Nach dem Scheitern der Flotte wurde aus der Operation schließlich eine kombinierte Aktion der Marine und Armee. Bis sich Kitchener aber entschloss, ein

$54 \mathrm{Zu}$ den Aktionen der Unterseeboote im Marmarameer vgl. Rudenno, Gallipoli, S. 154-191. 55 Moorehead, Gallipoli, S. 62-67. 
größeres Truppenkontingent - vor allem die 29. Division aus England - zur Verfügung $\mathrm{zu}$ stellen, verstrich $\mathrm{zu}$ viel Zeit und das Überraschungsmoment ging verloren. Zudem war es fraglich, ob die bereitgestellten knapp 75.000 Mann ausreichen würden, das gesetzte Ziel zu erreichen. Es fehlte von Anfang an an ausreichender Koordination zwischen den beiden Waffengattungen, die eher nebeneinander als miteinander agierten. Churchill wollte die Flotte nach ihrem Scheitern am 18. März zwar noch einmal zu einer Aktion nutzen, um die Durchfahrt durch die Dardanellen zu erzwingen, aber scheiterte damit am Widerstand der Admiralität, sodass danach aus einer reinen Flottenoperation eine Aktion geworden war, in der die Hauptoffensive nun in Händen des Heeres lag. Liman von Sanders hatte dahingegen acht Wochen Zeit, sich ausreichend auf die Alliierten und ihre Landungsoperationen einzustellen, denn die Armee hatte noch keine Vorbereitungen getroffen, da Kitchener von einem schnellen Sieg der Royal Navy ausgegangen war.

Schon im Februar 1915 waren erstmals Pläne diskutiert worden, die Armee stärker einzubeziehen. Im September 1914 war Churchill bei anfänglichen Überlegungen noch davon ausgegangen, dass bei einer Beteiligung des Heeres etwa 50.000 Mann ausreichen würden, die Landungsoperation auszuführen. Das mag durchaus realistisch gewesen sein, wenn man den Zustand der osmanischen Truppen zu diesem Zeitpunkt bedenkt. Aber gegen einen gut vorbereiteten, sich in der vorteilhafteren defensiven Position befindlichen Feind war eine Landungsoperation mit einer so geringen Zahl von Truppen schlichtweg unmöglich. Kitchener, der schließlich über die Entsendung von Truppen für eine Landung auf der Gallipoli-Halbinsel entscheiden musste, schien zudem lange nicht gewillt, die so dringend an der Westfront benötigten Verstärkungen an einen Nebenkriegsschauplatz zu senden. Erst Ende März 1915 genehmigte er schließlich die Abstellung der 29. Division für dieses Vorhaben, nachdem er bereits zu Beginn des Monats von Lieutenant General Birdwood, der sich vor Ort einen Eindruck verschafft hatte, informiert worden war, dass die Dardanellen-Operation ohne Unterstützung von Landstreitkräften nicht durchzuführen war.

Im Gegensatz zu den akkuraten Schätzungen des griechischen Vorschlages einer Landung auf Gallipoli, der von 150.000 Mann ausgegangen war, wollte Kitchener lediglich 75.000 Soldaten bewilligen. Wie viele andere unterschätzte er dabei die Verfassung der osmanischen Truppen, die Bedeutung des geographischen Faktors für den Charakter der Landungsoperation sowie die logistischen Schwierigkeiten - z. B. die Wasserversorgung der Soldaten -, die ein solches Unternehmen verursachen würde. Trotz der Hinweise von Birdwood und dem Befehlshaber in Ägypten, Maxwell, die beide unterstrichen, dass das Unternehmen einer großen Armee bedürfe, ließ sich Kitchener nicht überzeugen und hielt an seinen numerischen Überlegungen fest. Der Oberbefehlshaber der Lan- 
dungstruppen Hamilton erhielt zudem nur wenig konkrete Informationen, als er am 12. März den Befehl erhielt, das Kommando der Operation zu übernehmen: „Wir senden jetzt Truppen um die Flotte an den Dardanellen zu unterstützen und Sie haben das Kommando“, ${ }^{56}$ war alles, was Kitchener zu sagen hatte. Für Hamilton war diese Art der Befehlserteilung nicht neu und er wusste aus dem Burenkrieg, was Kitchener von ihm erwartete: „In diesem Moment wünschte Kitchener, dass ich mich verbeuge, den Raum verlasse und den Befehl ausführe, so wie ich es vor dreizehn Jahren getan habe. ${ }^{\text {"57 }}$ Doch so einfach würde es in diesem Fall nicht sein, denn Hamilton wusste nichts über die Dardanellen, nichts über die Osmanen und fast nichts über die Stärke der eigenen Truppen. ${ }^{58}$ Die beiden mussten ihr Gespräch also, entgegen dem bisherigen Procedere, intensivieren. Dabei erfuhr Hamilton, dass die 29. Division nur leihweise unter seinen Befehl unterstellt wurde und sobald sie verzichtbar geworden war, umgehend zurückgeschickt werden musste. Es war auch klar, dass alle Reserven, die an diesen östlichen Kriegsschauplatz gesandt würden, in London und an der Westfront kritisch betrachtet wurden, da der Eindruck vorherrschte, diese würden letztlich der Westfront gestohlen. ${ }^{59}$ Hamilton wusste, dass er vor einer schwierigen Aufgabe stand und das nicht nur in militärstrategischer Hinsicht.

Während dieses Treffens, bei dem Hamilton mit seiner Aufgabe betraut wurde, wird auch Kitcheners Überheblichkeit deutlich, scherzte er doch, dass bloß ein einziges britisches U-Boot im Marmarameer, aus dem dreimal der Union Jack geschwenkt werde, ausreichte, um eine Fluchtbewegung aller osmanischen Truppen auf der Halbinsel auszulösen. ${ }^{60}$ Zudem fragte er Hamilton nach seiner Meinung im Hinblick auf die Möglichkeiten, auf Konstantinopel vorzurücken. Ein Scheitern der Landungsoperationen wurde nicht in Erwägung gezogen. Es gab keinen Plan B, denn dieser würde nicht notwendig sein. Das Heer des britischen Empire würde landen und die Halbinsel so einfach überqueren wie Moses das Volk Israel durch das Rote Meer geführt hatte. Das Gefühl zivilisatorischer Überlegenheit war es, die derlei Hirngespinste entstehen ließ. Besonders tragisch ist, dass Kitchener, als Veteran des Burenkrieges, wissen musste, wohin falsche Überlegenheitsgefühle führen konnten, hatten die Briten doch im Kampf gegen die südafrikanischen Buren zunächst eine durchaus ähnliche Erfahrung machen müssen.

56 Hamilton, Diary, Bd. 1, S. 1.

57 Ebd., S. 2.

58 Ebd.

59 Ebd., S. 5.

60 Ebd., S. 7. 
Hamilton wurde nicht die Wahl seines eigenen Stabes gewährt, sondern ihm wurde ein „wilder Haufen“ zusammengewürfelten Personals zugeteilt. Seinen Stabschef Oberst Walter Braithwaite (1865-1945) traf Hamilton beispielsweise erst auf dem Weg nach Gallipoli und auch dieser konnte dem Kommandeur nur wenig konkrete Informationen liefern. ${ }^{61}$ Alles, was dem Stab zur Verfügung stand, waren einige „vage Notizen; das Ausbildungsbuch der osmanischen Armee und zwei kleine Reiseführer“. ${ }^{62}$ Erst von seinem Stabschef erfuhr Hamilton, dass er über keinerlei Reserven verfügen konnte. Nun, auf dem Weg nach Gallipoli, beunruhigte ihn das doch, zumal er wusste, dass es schwierig werden würde, bei Kitchener um etwas zu bitten. ${ }^{63}$ Erst in Ägypten traf er schließlich die meisten Mitglieder seines Stabes, von denen er die wenigsten persönlich kannte. Seine eigene Situation beschrieb Hamilton dabei noch recht positiv:

Nur zwei Arten von Kommandeuren könnten möglicherweise die Zeit finden, auf dem Weg zu ihrem Unternehmen, das in vielerlei Hinsicht unvorhergesehen ist, [einen Plan] hinzukritzeln - ein Deutscher und ein Brite. Der erste, weil jede Eventualität vorher von ihm durchdacht worden ist; der zweite, weil er nichts, wirklich gar nichts in seiner Aktenmappe hat als einen Blankoscheck mit den großen aber einfachen Worten John Bull. Der deutsche General ist das Produkt einer organisierenden Nation. Der britische General ist das Produkt einer improvisierenden Nation. ${ }^{64}$

Wie wenig er seinem organisierten deutschen General-Kollegen, Liman von Sanders mit seiner Improvisation entgegensetzen konnte, sollte Hamilton im Verlauf der weiteren Operationen bitter erfahren.

Was die Entscheidungsträger in London anbelangt, muss festgehalten werden, dass der Militäroperation standardmäßig zugestimmt wurde, ohne dass es eine Diskussion, einen Plan, oder eine politische Autorisierung des Unternehmens gegeben hätte. Ebenso wie die Qualen und das Leid aus der geöffneten Büchse der Pandora entwichen waren, wurde hier fast beiläufig eine Operation bewilligt, die für viele Soldaten Leid und Tod bedeuten würde. Im War Council gab es scheinbar kein Gegengewicht zum „Optimismus eines Churchill, der Arroganz eines Kitchener und der Sorglosigkeit eines Asquith.“65 Der Plan war einfach. Geographische und logistische Probleme wurden nicht weiter in Betracht gezogen. ${ }^{66}$

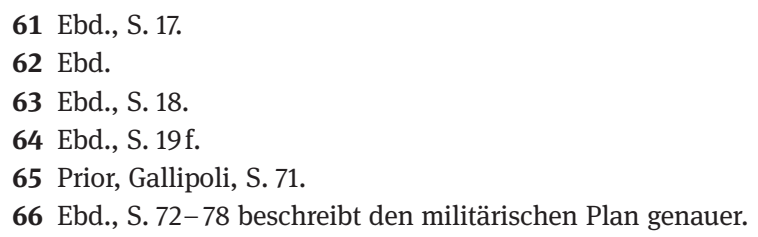


Gerade die geographischen Bedingungen sollten jedoch entscheidend zur Niederlage der Alliierten beitragen. Hamilton wurde das Problem klar, als er auf dem Kriegsschauplatz eintraf und die Lage vor Ort in einem Schreiben an Kitchener wie folgt kommentierte: „Hier sieht Gallipoli wie eine Nuss aus, die viel härter hart zu knacken sein wird, als die auf der Karte in Ihrem Büro. "67 Lieutenant General Birdwood und Major General Hunter-Weston, die die Landungen der ANZAC-Truppen und der 29. Division kommandieren sollten, hatten den gleichen Eindruck. Keiner von ihnen war wirklich vom Gelingen der hoch gesteckten Ziele, also der Einnahme der Gallipoli-Halbinsel innerhalb weniger Tage, überzeugt. Die Meinungen waren in Hamiltons Stab gespalten, was die grundsätzlichen Perspektiven betraf: Während Hunter-Weston die Gefahr eines weiteren Stellungsbzw. Belagerungskrieges antizipierte, war Stabschef Braithwaite davon überzeugt, dass man die gesetzten Ziele letztlich doch erfüllen konnte. In den nächsten Wochen wurden hastig Befehle ausgeführt. Allerhand Material und Truppen wurden zunächst nach Ägypten verschifft, wo sich das Expeditionskorps sammelte, bevor man Ende April 1915 endlich mit der Eroberung der Gallipoli-Halbinsel beginnen wollte. In dieser Zeit waren die Kommandeure der osmanischen Armee nicht untätig und Liman von Sanders ging daran, die Verteidigungsanlagen noch verbessern $\mathrm{zu}$ lassen, seine Truppen im Gelände $\mathrm{zu}$ drillen und sich genau zu überlegen, wie er seine Einheiten verteilen sollte, um möglichst allen alliierten Operationen effektiv entgegentreten zu können.

\subsection{Die Landungsoperationen}

Die Landungen auf der Gallipoli-Halbinsel eröffneten an dieser fernen Front eine neue Form des Krieges: Nicht nur das fremde Terrain unwegsam, sondern der Freund verfügte hier auch über ein modernes Waffenarsenal. ${ }^{68}$ Am 25. April 1915, dem ersten Tag der Landungsoperationen, kollidierten „Romantik und Realismus auf dem Schlachtfeld“. ${ }^{69}$ Selbst dem letzten Träumer war die Realität dieses Kriegsschauplatzes schlagartig bewusst geworden. ${ }^{70}$ Die osmanische Armee war wesentlich besser auf die kommenden Ereignisse eingestellt und deshalb klar im Vorteil. Als Vorsichtsmaßnahme waren die Dardanellen bereits im September 1914

\footnotetext{
67 Hamilton, Diary, Bd. 1, S. 27.

68 Hamilton, Diary, Bd. 1, S. 326.

69 Carlyon, Gallipoli, S. 132.

70 Vgl. dazu auch Tagebuch Lieut. Alexander B. McColl, Taranaki Company, Wellington Inf. Regt., Alexander Turnbull Library, Wellington, New Zealand, MSX-8204, Eintrag vom 25. April 1915.
} 
vermint worden, allerdings kann das noch als Teil der regulären Mobilmachung im Zuge der vorhandenen Verteidigungspläne betrachtet werden. Noch vor dem Eintritt in den Krieg hielt die Regierung in Konstantinopel „einen Gewaltschritt der Ententeflotte gegen Konstantinopel nicht für ausgeschlossen und wollte sich dagegen sichern. " ${ }^{\text {71 }}$ General von Usedom übernahm daraufhin das Amt des Generalinspekteurs der Küstenartillerie und begann, die Befestigungsanlagen zu verstärken, um im Falle eines solchen Angriffes die Meerengen effektiv schützen zu können. Diese Maßnahmen waren erfolgreich, schließlich konnten die Attacken der alliierten Flotte, wie sie oben beschrieben wurden, abgewehrt werden, selbst wenn die Knappheit an Munition beinahe einen Durchbruch der britischen und französischen Schiffe bedeutet hätte. Mit dem Ausgang der Schlacht am 18. März 1915 war entschieden, dass sich die osmanische Armee auf eine bald anlaufende Landungsoperation vorzubereiten hatte.

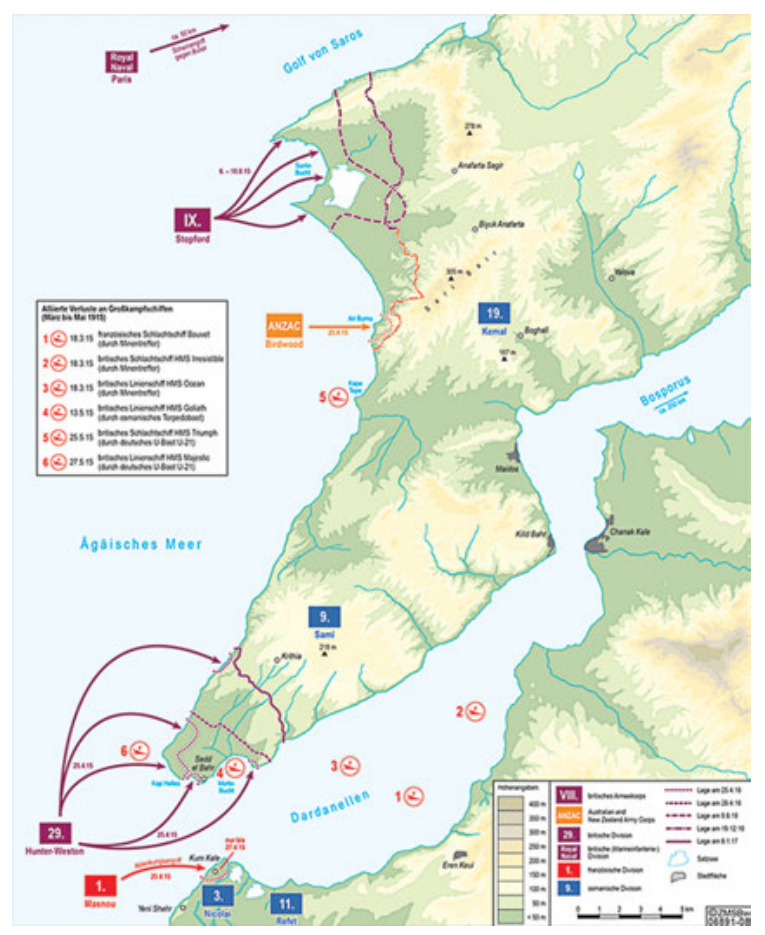

Abb. 5: Die Landungsoperationen im April 1915, Infografik des ZMSBw.

71 Sanders, Türkei, S. 47. 
Carl Mühlmann, Adjutant General Liman von Sanders, beschreibt die Lage nach dem gescheiterten Angriff der britischen Marine aus osmanischer Sicht wie folgt:

\begin{abstract}
Als die erste Freude über den großen Erfolg vorüber war, hatten Enver und seine deutschen Ratgeber [...] sich mit der voraussichtlichen weiteren Entwicklung der Lage zu beschäftigen. Auch sie hielten, nachdem die Flotte weder am 19. noch in den folgenden Tagen die Beschießung wieder aufgenommen hatte, eine Fortsetzung der bisherigen Angriffstaktik nicht für wahrscheinlich. Noch unwahrscheinlicher aber schien es ihnen schon aus Prestigegründen, daß England sich mit diesem negativen Ergebnis zufrieden geben würde. Eher war anzunehmen, daß das, was der Flotte nicht gelungen, nunmehr der Armee übertragen werden würde, oder, mit anderen Worten, daß die Werke und Batterien der Meerengen, die dem Angriff vom Wasser aus widerstanden hatten, jetzt durch einen Landangriff zu Fall gebracht werden sollten. ${ }^{72}$
\end{abstract}

Hinzu kam, dass in Konstantinopel Meldungen über Truppenkonzentrationen in Ägypten eingetroffen waren, sodass die Verteidiger der Dardanellen durchaus darüber im Bilde waren, wie schnell das Landungskorps zusammengestellt wurde. Erste Schätzungen reichten von 50.000 bis 100.000 Mann. Auch die Namen der Führungsoffiziere waren bekannt. Die fünf osmanischen Divisionen, die sich bei den Dardanellen befanden, wurden zur Fünften Armee zusammengefasst und durch die 3. Division aus Konstantinopel noch verstärkt. Am 24. März, also weniger als eine Woche nach dem Ende der alliierten Flottenangriffe, erhielt Liman von Sanders den Oberbefehl über die Fünfte Armee und begab sich am Folgetag nach Gallipoli, wo er am 26. März eintraf. ${ }^{73}$ Der deutsche General „stimmte sofort zu, machte ihn [den Kriegsminister] aber darauf aufmerksam, daß die jetzt dort befindlichen Truppen schnell verstärkt werden müßten, da keine Zeit zu verlieren sei“74, weil neben der Gallipoli-Halbinsel auch die asiatische Seite der Meerengen geschützt werden müsse, zumal dortige Landungsoperationen ebenfalls nicht ausgeschlossen waren. Liman von Sanders erwartete viel Arbeit, aber, wie er berichtet, hatten ihm die Briten ausreichend Zeit gelassen, alle Vorbereitungen abzuschließen. ${ }^{75}$ Die geographische Beschaffenheit des Landungsgebietes war ihm dabei aber nicht entgangen: „Die Dardanellenstraße auf der europäischen Seite von Norden begrenzende schmale Halbinsel Gallipoli ist ein ausgesprochenes Bergland mit schroffen Höhenketten, deren Hänge durch tiefe Schluchten und scharfe Spalten zerrissen sind.“76 Aus militärischer Perspektive handelte es

72 Mühlmann, Kampf, S. 79.

73 Moorehead, Gallipoli, S. 94.

74 Sanders, Türkei, S. 77.

75 Ebd., S. 78.

76 Ebd., S. 79. 
sich folglich um ein Terrain, welches den Verteidigern einen gewissen Vorteil bot, dessen Beschaffenheit jedoch jegliche Aktion erschweren musste, weshalb es essentiell war, sich genauestens mit diesen Gegebenheiten vertraut zu machen. ${ }^{77}$

Die wichtigste Frage war die nach den Landungspunkten der Alliierten, die sich aufgrund mangelnder Alternativen recht schnell eingrenzen ließ. Es war davon auszugehen, dass Hamilton an den verfügbaren Stränden landen würde. Prinzipiell kamen Bulair, Suvla, Ari Burnu und Kap Helles für eine Landung auf der Halbinsel in Frage. Aus Sicht Liman von Sanders war klar, dass nicht alle möglichen Landungspunkte verteidigt werden konnten, weshalb „die Gruppierung der für die große Ausdehnung der Küste nur schwachen Kräfte“78 $z u$ ordnen war. Er war darauf bedacht, seine Truppen an zentralen Punkten zu konzentrieren, um sie dann ganz nach Bedarf gegen die stattfindenden Landungsoperationen Hamiltons einsetzen zu können. Mühlmann kommentiert die Entscheidung des deutschen Befehlshabers wie folgt:

Zunächst galt es, die Kräfte zweckentsprechend zu gruppieren. Ihm schienen zu viel Kräfte für die vorderste Front verwendet worden zu sein, in dem Bestreben, möglichst alle für eine Landung in Betracht kommenden Uferpartien zu besetzen. Gewiß stieß der landende Angreifer bei diesem Prinzip überall auf Widerstand, aber dieser Widerstand konnte nur schwach sein, und es fehlte zudem die Möglichkeit schneller Verstärkung. ${ }^{79}$

Er wollte demnach seine Truppen nicht ausdünnen bzw. zu weit voneinander entfernt zerstreuen, da ein solches Vorgehen die Schlagkraft derselben minimiert hätte. Des Weiteren war es nicht wichtig, jeden Landungspunkt sofort zu verteidigen, sondern flexibel genug zu sein, auf eben solche Landungen schnell und mit möglichst überlegenen Kräften zu reagieren. Er verteilte seine Truppen deshalb auf die asiatische und europäische Seite der Meerengen, um möglichst viele Operationsgebiete abzudecken. Eine Division unter dem Kommando von Mustafa Kemal wurde als Reserve zurückbehalten, um sie nach Bedarf einsetzen zu können.

Um seine Pläne auf eigenen Eindrücken fußen zu lassen, „verließ [er] sich nicht auf das Studium der Karte, sondern besichtigte persönlich den ganzen Sicherungsabschnitt. Erst dann glaubte er in der Lage zu sein, die Aussichten der einzelnen Landungsoperationen gegeneinander abwägen und danach die eigene Kräfteverteilung vornehmen zu können. “80 Liman von Sanders erkannte bei die-

77 Kannengießer, Gallipoli, S. 54-62 liefert eine geomilitärische Beschreibung der Halbinsel Gallipoli und der Dardanellen.

78 Sanders, Türkei, S. 79.

79 Mühlmann, Kampf, S. 81.

80 Ebd. Für eine genaue Analyse der Landungsoptionen siehe ebd., S. 82-84. 
sen Besichtigungen die taktischen Probleme der Verteidigung der GallipoliHalbinsel, denn die ,technische Möglichkeit für das Landen großer Truppenmengen war an vielen Stellen der Küste gegeben. Sie konnten unmöglich alle besetzt werden. Es mußten daher taktische Gründe entscheiden. “81 Mit seinem flexiblen Operationsplan trat er dieser Problematik aber entgegen. Zudem wurden seine Einschätzungen über die wahrscheinlichen Operationen des Feindes durch ägyptische Tageszeitungen bestätigt. Eine Geheimhaltung oblag denselben nicht. Außerdem konnte Großbritannien nicht gegen die Veröffentlichung von Nachrichten über Pläne und Truppenbewegungen vorgehen, da Ägypten offiziell ein neutrales Land war und daher nicht mit einer Pressezensur bedacht werden durfte. Die britischen Befehlshaber hofften schlicht, dass die osmanischen Planer derlei Meldungen nicht wahrnehmen würden. ${ }^{82}$

Liman von Sanders sollte aber noch weitere Informationen durch eine viel wichtigere Quelle erhalten. ${ }^{83}$ Er hatte drei mögliche Landungszonen auf der asiatischen Seite ausgemacht: die Bucht von Besika, Kum Kale und Karanlik, das aber aufgrund vorhandener Minen eher ungeeignet erschien. Im Zuge der Operation war vorgesehen, erfahrene Offiziere in das Gebiet der möglichen Landungen zu entsenden, um im Falle britischer Aktionen abzuschätzen, ob es sich um ein Täuschungsmanöver oder um eine tatsächliche Landung von Truppen des Gegners handelte. Auf der südlichen Gallipoli-Halbinsel wurden Kap Helles sowie Gaba Tepe als potentielle Ziele ausgemacht. Einen dritten Fokus legte Liman von Sanders auf Bulair am Golf von Saros im Norden der Halbinsel. Zwar wäre ein langer Landmarsch der britischen Truppen notwendig, um gegen die Befestigungsanlagen auf der anderen Seite der Halbinsel vorzugehen, aber gleichzeitig konnte eine dortige Landung auch dazu dienen, die osmanische Armee von ihren Nachschubrouten abzuschneiden. Er stellte deshalb drei Divisionen zur Verteidigung Bulairs ab. Es schien jedoch unwahrscheinlich, dass Hamilton beabsichtigte, so weit im Norden zu landen.

Der Militärattaché des Osmanischen Reiches in Rom meldete bereits am 22. März 1915, dass die alliierte Führung den Angriff gegen die Dardanellen nach der gescheiterten Flottenaktion durch Landungsoperationen des Heeres fortsetzen würde. Liman von Sanders hatte also Gewissheit, dass der Feind kommen würde. Zudem war er gut über die Zusammensetzung der Truppen informiert worden und wusste aus Athen, dass die Briten damit begonnen hatten, Schiffe für den Truppentransport zu erwerben. Ende März wurde Bewegung auf Lemnos

81 Sanders, Türkei, S. 80.

82 Moorehead, Gallipoli, S. $109 \mathrm{f}$.

83 Die Beschreibung der Begebenheiten im Zusammenhang mit Leutnant Palmer folgt, falls nicht anders angegeben, Travers (Liman von Sanders). 
gemeldet, wo die ersten Truppen eintrafen. Es wurde offensichtlich, von wo aus Hamilton zu operieren gedachte. Der wichtigste Vorfall im Hinblick auf die Informationen, die die deutsch-osmanische Heeresleitung besaßen, ereignete sich am 17. April, also nur knapp eine Woche vor den Landungen der Alliierten. Das britische Unterseeboot E-15 versuchte, die Dardanellen zu passieren, um in das Marmarameer zu gelangen, wurde dabei aber entdeckt, beschossen, lief auf Grund und sank. Einige der Besatzungsmitglieder starben im Geschosshagel, einige konnten sich ans Ufer retten, wo sie gefangen genommen wurden. Einer der Gefangenen war Leutnant Palmer, der Britische Vizekonsul in Chanak und ein Mitglied der Freiwilligenreserve der Royal Navy. Seine Befragung lieferte wichtige Informationen, die vom befehlshabenden Offizier Djevad Bey direkt an die Heeresleitung weitergereicht wurden. ${ }^{84}$

Palmer wurde als Spion betrachtet, dem die Hinrichtung drohte. Dieses Ende vor Augen, erklärte sich der Leutnant bereit, Informationen zur Verfügung zu stellen. Gefragt nach der alliierten Landung, teilte er mit, dass etwa 100.000 Mann unter dem Kommando General Hamiltons bereitstünden, um die Attacke auszuführen. Er gab an, dass diese Truppen bei Gaba Tepe und Sedd el Bahir (Kap Helles), also im Süden der Halbinsel gelandet werden sollten, dass die Pläne aber aufgrund der Befürchtung, dass die osmanischen Verteidiger darüber ins Bild gesetzt worden wären, geändert werden mussten. Die Landungen würden deshalb im Norden, im Golf von Saros erfolgen. Palmer sagte zudem aus, dass er keine Informationen über die genauen Planänderungen besitze, sondern nur sagen könne, dass eine Änderung der vorgesehenen Landeplätze erfolgt war. Djevad Bey wies auf die Wichtigkeit dieser Meldung hin, denn sie bedeutete für die osmanischen Verteidiger, sofern man der Nachricht vertrauen wollte, dass ein eher unbeachtetes Landungsgebiet stärkere Aufmerksamkeit verdiente. Palmer hatte in der Verhörsituation schnell reagieren müssen und sich entschieden, die wahren Ziele zu nennen, um im Anschluss daran durch eine falsche Ergänzung das Augenmerk des Gegners auf ein anderes Operationsgebiet zu lenken. Gewiss wollte er durch die Preisgabe von Informationen sein Leben retten, versuchte aber gleichzeitig, größeren Schaden von den Landungsoperationen abzuwenden.

Es ist schwierig auszumachen, welchen Einfluss die Meldung über Palmers Aussagen auf die Führung der osmanischen Armee hatte, aber Liman von Sanders schien beinahe eine Obsession zu entwickeln, dass Bulair der Schauplatz des Geschehens würde. Er war im Laufe der Landungsoperationen ab dem 25. April

84 Colonel Djevad Bey an Supreme Command, 20. April 1915 und 21 April 1915, „Correspondence of Fifth Army and the Supreme Command, “ Record 780, File 182, Shelf 5, Cabinet 105, General Staff Archives, Ankara, Turkey, zitiert nach ebd., S. 974. 
zunächst nicht bereit, seine Truppen in den Süden zu entsenden, weil er immer noch mit einer Aktion in diesem Operationsgebiet rechnete. Erst am 28. April, als er von Verstärkungen der feindlichen Brückenköpfe im Süden erfuhr, beorderte er seine Truppen zur Unterstützung der Verteidiger dorthin. Mühlmann hatte Liman von Sanders schon eher gebeten, diesen Schritt zu unternehmen. Ob es allein Palmers Informationen waren, die den General zu diesem Ausharren im Norden veranlassten oder ob Liman von Sanders selbst bereits zuvor der Überzeugung war, dass eine Landung bei Bulair erfolgen musste, hat offen zu bleiben. Die späte Verstärkung gab den alliierten Landungstruppen im Süden der Halbinsel aber ausreichend Zeit, sich festzusetzen. Diesen Fehler kann man dem deutschen Befehlshaber anlasten, der allerdings ungeachtet seines Beharrens auf Bulair einen Plan ausgearbeitet hatte, der während der Operationen gegen die feindlichen Truppen in der Anfangsphase der Gallipoli-Kampagne bestens funktionierte:

Es wurde von mir befohlen, daß jede Division ihre Kräfte zusammenzuhalten habe und nur die allernotwendigsten Sicherungen in ihrem Abschnitt an die Küste vorschieben dürfe. Wie es auch kommen mochte, so war mit unseren schwachen Kräften nicht das starre Festhalten, sondern die Beweglichkeit der drei Kampfgruppen das einzige Mittel zum endgültigen Erfolg! $!^{85}$

Sobald dieser Plan angewiesen und die entsprechenden Offiziere ins Bild gesetzt worden waren, musste sich Liman von Sanders um die Stellungen der Verteidiger kümmern, um dem alliierten Angriff eine schlagkräftige Erwiderung entgegensetzen zu können. Carl Mühlmann wies ebenfalls auf derlei Notwendigkeiten hin: „Zwangen die taktische Lage und die in Anbetracht des großen Raumes geringen Kräfte zu einer schwachen Bemessung des eigentlichen Küstenschutzes, so war es doppelt angebracht, die geringe aktive Kraft durch fortifikatorische Anlagen zu erhöhen. Auch hier blieb viel zu tun“. ${ }^{86}$ Und Liman von Sanders fasst die ergriffenen Maßnahmen in seinen Memoiren bündig zusammen:

An der Verstärkung der Feldbefestigungen auf den besonders gefährdeten Uferstrecken wurde mit allen verfügbaren Kräften, und zwar zumeist auch bei Nacht, gearbeitet. Die vorhandenen türkischen Hindernismittel waren ebenso knapp wie das Handwerkszeug, aber wir halfen uns, so gut wie es ging. Torpedoköpfe wurden als Tretminen neben solchen verwendet, und die Umzäunungen der Gärten und Felder mußten öfters Holz und Draht für die Hindernisse liefern. An den für den Feind besonders günstigen Landungsstellen wurde nahe am Ufer Stacheldraht unter dem Wasserspiegel gespannt. ${ }^{87}$

85 Sanders, Türkei, S. 82.

86 Mühlmann, Kampf, S. 85.

87 Sanders, Türkei, S. 83. 
Dabei arbeitete Liman von Sanders mit seinem Stab und den auf Gallipoli befindlichen Truppen unter hohem zeitlichen Druck:

Um so mehr war anzuerkennen, daß in kurzer Zeit bei wenig Arbeitskräften und wenig Material an den einer Landung am meisten ausgesetzten Küstenpunkten starke Verteidigungsanlagen entstanden, die die schwer zu vereinigenden Forderungen miteinander zu verbinden suchten, gute Feuerwirkung auf die voraussichtliche Landungsstelle zu gestatten und dabei dem Feinde keine günstigen Ziele zu bieten. ${ }^{88}$

$\mathrm{Zu}$ diesem Zweck wurden Geschütze und Maschinengewehre in die Verteidigungsanlagen eingelassen, sodass sie die Landungszonen unter Feuer nehmen konnten, ohne von See aus gesichtet und folglich beschossen werden zu können. Die „Drahthindernisse, [die] an einzelnen Stellen im flachen Wasser versenkt [wurden], sollten den landenden Gegner im Feuer festhalten, Tretminen dem Feinde beim Betreten des Bodens Verluste zufügen. “89 Gleichzeitig wurden kleine Depots für Munition und Verpflegung an den verschiedenen Verteidigungsabschnitten errichtet, um die Logistik zu vereinfachen und den Truppen ausreichend Material und Nahrungsmittel zur Verfügung zu stellen, damit diese möglichst lange die besetzten Positionen gegen den heranstürmenden Feind verteidigen konnten. Nach vier Wochen umtriebigen Geschehens und „angestrengtesten Dienstes" ${ }^{\text {900 }}$ waren die Verteidigungsanlagen errichtet und es konnte auf den Beginn der feindlichen Operationen gewartet werden. Liman von Sanders hatte eine alleinige Vorbereitung der Stellungen nicht genügt.

Im Gegensatz zu Hamilton ging der deutsche Befehlshaber nicht von einer generellen Unterlegenheit der osmanischen Soldaten aus, sondern lediglich davon, dass diese eine solide Ausbildung und fähige Kommandeure benötigen:

Es ist ein großer Irrtum, wenn behauptet wird, daß der anatolische Soldat nur beschränkt in seiner Ausbildung gefördert werden kann. Es dauert nur lange bei ihm, bis die Ausbildung für offensive Zwecke in Fleisch und Blut übergeht und verstanden wird. Unter guten, frischen Unterführern wird er alles leisten, was im Stellungskrieg, bei kurzen Angriffen, und im Patrouillendienst verlangt werden kann. ${ }^{91}$

Den im November 1914 von der Regierung in Konstantinopel ausgerufenen Djihad, der die Muslime gegen die britische Kolonialherrschaft mobilisieren sollte, hielt Liman von Sanders für unnötig, zumal diese Maßnahme kaum Erfolg zei-

88 Mühlmann, Kampf, S. 86.

89 Ebd., S. 86.

90 Ebd.

91 Sanders, Türkei, S. 124. 
tigte. Bei seinen eigenen Truppen konnte Liman von Sanders ebenfalls kaum eine Wirkung dieser Proklamation feststellen:

Für den tiefgläubigen anatolischen Soldaten war der heilige Krieg nicht notwendig; er ging auch ohne diesen für seinen Padishah tapfer und vertrauensvoll in den Tod. Bei den unter türkischer Herrschaft stehenden mohammedanischen Arabern hat der heilige Krieg nicht vermocht, die tief eingewurzelten Gegensätze zwischen Türken und Arabern und die allgemeine, durch Generationen erwachsene und genährte Unzufriedenheit mit der türkischen Verwaltung auszugleichen. ${ }^{92}$

Die Moral seiner Truppe war, ungeachtet des ausbleibenden Erfolges der religiös intendierten Radikalisierung, gut,

[e]s fehlte aber noch mehr an der Marschfähigkeit der Truppe, die in dem Küstenschutz fast erstarrt war. Deshalb wurde die Ausbildung jetzt auf ganz andere Grundlagen gestellt. Nachtund Gewaltmärsche wurden angeordnet und Geländeübungen mit Entwicklungsaufgaben abgehalten, um der Truppe die nahezu verlorengegangene Geschmeidigkeit im Bewegungskriege zurückzugeben. ${ }^{93}$

Am Anfang plante Liman von Sanders folglich keinen Stellungskrieg, in dem die osmanische Armee lediglich die Defensive zu übernehmen gedachte, sondern einen direkten Gegenangriff, um die Landungstruppen der Alliierten direkt wieder ins Meer zu werfen. Der Oberbefehlshaber verstand es zudem, fähigen Offizieren, wie Mustafa Kemal, im Laufe der Operationen größere Verantwortung zuteil kommen $\mathrm{zu}$ lassen. ${ }^{94}$

Woran es mangelte war das Kriegsmaterial. So standen kaum Sandsäcke zur Verfügung, um die Vereidigungsanlagen weiter zu befestigen und es fehlte oft an einfachen Dingen wie Stacheldraht, der beispielsweise durch Weidezaun ersetzt wurde. Liman von Sanders bemerkt, dass diese Entbehrungen „[n]ur infolge der stoischen Ruhe und der Kaltblütigkeit des anatolischen Soldaten und seiner absoluten Bedürfnislosigkeit“95 überwunden werden konnten. Diese half jedoch nur

92 Ebd., S. 48.

93 Mühlmann, Kampf, S. 85.

94 Die Entscheidung, Mustafa Kemal im August den Oberbefehl im Kampfgebiet zu übergeben, begründet Sanders wie folgt: „Mustapha [sic!] Kemal, der seine ersten kriegerischen Lorbeeren in der Cyrenaika gepflückt hatte, war eine verantwortungsfreudige Führernatur. Am 25. April morgens hatte er mit der 19. Division selbständig entschlossen zugegriffen, den vordringenden Feind bis an die Küste zurückgeworfen und hatte dann über 3 Monate in Front [...] gestanden, allen heftigen Angriffen in zähem, ungebrochenem Widerstand erfolgreich die Stirn bietend. Ich konnte zu seiner Tatkraft vollstes Vertrauen haben." Sanders, Türkei, S. 112.

95 Ebd., S. 98. 
wenig, wenn es darum ging, die Geschütze ohne ausreichend Munition abzufeuern. Von Anfang an kam es zu Engpässen bei der Artilleriemunition, die auch durch die Übernahme einer Fabrik durch Kapitän Waldemar Pieper, die in Konstantinopel eingerichtet worden war, um Artilleriemunition zu produzieren, nicht dauerhaft beseitigt werden konnten, „da weder das zur Verarbeitung vorhandene Material, noch die Maschinen vollwertig waren." "96 Bisweilen musste sogar Manövermunition verschossen werden, damit die eigenen Truppen weiterhin an die Unterstützung durch die Artillerie glaubten. Erst im November $1915 \mathrm{kam}$ aus Deutschland „die längst ersehnte deutsche Artilleriemunition [...], [die] die Hoffnung auf ein glückliches Ende des Feldzuges wesentlich zuversichtlicher“ werden ließ. ${ }^{97}$ Neben der schlechten Ausstattung mit Munition stellten die osmanischen Lazarette ein echtes Problem dar. Bis Ende August 1915 waren sie kaum dazu in der Lage, die mehr als 20.000 Verwundeten aufzunehmen, sodass viele Soldaten einfach an Ort und Stelle liegen blieben, verbluteten oder in der Hitze verdursteten. Andere wurden auf Karren und Schiffen in Richtung Hauptstadt verbracht, wo sie, sofern sie die Reise überlebten, in Massenlazaretten endlich Behandlung fanden.

Dennoch war die Lage der osmanischen Truppen wesentlich organisierter als das bei den Alliierten unter Hamiltons Kommando der Fall war, selbst wenn Liman von Sanders den Feind dafür lobte und, ähnlich wie die erste Generation der Vertreter der Gallipoli-Historigraphie, der Operation durchaus Erfolgsaussichten einräumte, zumal eine starke Darstellung des Gegners auch den eigenen Ruhm vermehrt haben dürfte:

Die Vorbereitungen des Feindes müssen als vortrefflich anerkannt werden. Sie hatten nur den Fehler, daß sie auf zu alten Erkundungen basierten, und daß sie die zähe Widerstandsfähigkeit der türkischen Truppen unterschätzten. Daher blieb ihnen der durchschlagende Erfolg in den ersten Tagen versagt, der die großangelegte Aktion zu einer entscheidenden, in kurzer Zeit durchzuführenden Waffentat hätte gestalten müssen. ${ }^{98}$

Eines war allen Beteiligten klar: Zeit war ein vitaler Faktor. Etwas, das auch Carl Mühlmann in seinen Erinnerungen betonte: „Alles sprach vom taktischen und strategischen Standpunkt für sofortiges Handeln; jeder Tag Aufschub gab dem Dardanellenverteidiger Zeit, sich zu verstärken, erschwerte also Landung und Angriff. “99 Trotz der, dem Gegner gewährten, langen Vorbereitungszeit sollte mit

96 Ebd., S. 99.

97 Ebd., S. 125.

98 Ebd., S. 86.

99 Mühlmann, Kampf, S. 89. 
einem minimalen Truppenaufwand das erreicht werden, was der Flotte versagt geblieben war. Dabei unterschätzte man im britischen Stab weiterhin die osmanische Armee. Insbesondere die in Ägypten eintreffenden Soldaten nutzten ihre Zeit in erster Linie dazu, das ägyptische Nachtleben zu erkunden und die touristische Seite des Krieges zu genießen. ${ }^{100}$ Die Abenteuerlust spielte bei vielen britischen Soldaten, die bei Gallipoli erstmals zum Einsatz kamen, eine durchaus bedeutende Rolle. Hinzu kommt, dass die Kampagne freudig erwartet wurde, da es viele der jungen britischen Soldaten als ihre Pflicht betrachteten, Heimat, Nation und Empire in diesem Krieg zu repräsentieren und gegen den osmanischen Feind zu verteidigen. Ungeachtet solcher Gefühle versammelte sich in Ägypten letztlich eine sehr heterogene Truppe, die aus Franzosen, Fremdenlegionären, afrikanischen Soldaten, Sikhs, Gurkhas, Australiern und Neuseeländern sowie Arbeitsbataillonen, deren Mitglieder sich aus Männern levantinischer oder griechischer Herkunft rekrutierten, bestand. Insgesamt betrachtet waren „die Truppen des Mittelmeer-Expeditionskorps ein bunt gemischter Haufen aus Formationen des britischen Empire, die einzig zu dem spezifischen Zweck zusammengebracht worden waren, auf der Gallipoli-Halbinsel zu landen und diese einzunehmen." ${ }^{\text {"101 }}$

Nicht selten kam es zu Reibungen, etwa wenn sich australische Soldaten weigerten, britische Offiziere militärisch zu grüßen. Der schottische Schriftsteller Compton MacKenzie (1883-1972), der selbst in Ägypten Halt machte, bevor er nach Gallipoli geschickt wurde, traf einen jungen Offizier eines Australian Light Horse Regiments und sprach mit ihm über die australische Haltung gegenüber englischen Offizieren: „Er bestätigte, dass er den Anblick englischer Offiziere einfach nicht ertragen konnte und dass er, wenn er die Wahl hätte, entweder gegen die Engländer oder die Osmanen zu kämpfen, geteilter Meinung sei, ob er sich nicht entscheiden würde gegen die Engländer zu kämpfen. “102 Darüber hinaus waren fast alle Freiwilligen für Gallipoli rekrutierte Zivilisten gewesen, weshalb zunächst ein intensives Training einsetzen musste, um diese schlachttauglich zu machen. Besonders die ANZAC-Kontingente konnten dabei nur bedingt auf Offiziere zurückgreifen, die ausreichend Schlachterfahrung besaßen. Trotzdem waren gerade diese Formationen für ihren Enthusiasmus und den Elan der darin dienenden Soldaten bekannt, die sich zudem durch Initiative und Individualismus auszeichneten. Kritiker hingegen, sprachen von einem Mangel an Disziplin, schlechter Führung und unzulänglicher Ausbildung.

100 Moorehead, Gallipoli, S. 102.

101 Erickson, Strength, S. 1002.

102 MacKenzie, Gallipoli, S. 23. 
Die britische 29. Division war eine Kreation der Armee, die während des Krieges erst geschaffen worden war. Sie bestand aus elf regulären Bataillonen der Infanterie und war gut ausgebildet worden, auch wenn viele der Rekruten zuvor noch keinen Kampfeinsatz miterlebt hatten. ${ }^{103}$ Die Franzosen hatten ihr OrientExpeditionskorps (Corps Expeditionnaire d'Orient) bereitgestellt, das für die ersten Landungen aus einer Division bestand. Diese war in Nordafrika geformt worden und bestand aus französischen und nordafrikanischen Einheiten, u. a. einem senegalesischen Regiment. Gut geführt und mit hervorragender Artillerie ausgestattet, aber doch aufgrund der hastigen Zusammenstellung vielleicht von schlechter Funktionalität, gehörte es zu den erfolgreicheren Einheiten der Gallipoli-Kampagne, in deren Zuge eine weitere Division ähnlicher Zusammensetzung von Paris entsandt wurde. Problematisch erschien im Gegensatz zum französischen Verbündeten ausgerechnet die Zusammenarbeit der Briten mit der eigenen Marine, denn oft machte es den Anschein, als würden diese und das Heer unterschiedliche Schlachten ausfechten. Die britische Generalstabsschule hatte es nämlich versäumt, kombinierte Operationen zu studieren oder genauer zu planen. Oft entstand dadurch der Eindruck, dass die Armee während des Angriffs zur Einnahme der Gallipoli-Halbinsel nicht koordiniert mit der Marine vorging.

Alles in allem waren Mannschaften und Führung des alliierten Heeres schlechter vorbereitet als der osmanische Gegner unter deutschem Kommando. Die britischen Kommandeure besaßen selbst zum Zeitpunkt der Landungen keine genauen Karten der Gebiete, in denen sie operieren sollten. ${ }^{104}$ Ganz einfache, aber doch essentielle, Fragestellungen waren bisher nicht bedacht, geschweige denn geklärt worden:

\footnotetext{
Gab es Trinkwasser an der Küste?

Welche Straßen existierten?

Mit wie vielen Verwundeten musste man rechnen?

Sollte in Grabenanlagen oder in offener Feldschlacht gekämpft werden?

Welche Waffen würden benötigt werden?

Wie tief war das Wasser im Landungsgebiet?

Welche Art von Booten würde benötigt werden, um die Männer zu transportieren?

Würden sich die Feinde zurückziehen oder Widerstand leisten ${ }^{105}$
}

103 Erickson, Strength, S. 1003.

104 In der Retrospektive wurde vor allem auf die schlechte Leistung der verantwortlichen Kommandeure verwiesen, um die Niederlage zu erklären. Vgl. etwa Br.-Gen. J.G. King-King an an Cecil F. Aspinall-Oglander, Nr Bournemouth, 5. Februar 1931, TNA-CAB 45/243, S. 3.

105 Moorehead, Gallipoli, S. 108. 
Zudem herrschte auf alliierter Seite Knappheit an fast allem. Es gab zu wenig Männer, Gewehre, Munition, Flugzeuge... Hamilton hatte versucht, weitere Verstärkungen aus Ägypten, u. a. ein Regiment nepalesischer Gurkhas, die als Elitetruppen des Britischen Empire galten, zu erbitten; seine Anfrage war aber unbeantwortet geblieben. Die Alliierten begannen also Ende April 1915 eine Landungsoperation, die verspätet und schlecht vorbereitet war, keinen genau studierten Plänen folgte und einen Verteidiger zum Gegner hatte, der bestens darüber informiert war, was zu erwarten und wie auf die Ereignisse zu reagieren war.

Am 25. April begannen schließlich die verschiedenen Landungsoperationen der britischen (Kap Helles), französischen (Kum Kale) und ANZAC Truppen (nördlich von Gaba Tepe) an den vorgesehenen Küstenabschnitten zu beiden Seiten der Meerengen. Bei Kap Helles zeigte sich, dass es, nicht anders als an der Westfront, ein schwerer Kampf der Alliierten gegen gut verschanzte Verteidiger werden würde, die aus „kurzer Distanz in eine kompakte Masse schreiender, angestrengter Männer in ihren Booten feuerten."106 Dort, wo britische Marineeinheiten zwei Monate zuvor noch ohne großen Widerstand gelandet waren, entstand jetzt ein Schlachtfeld, das nur wenig Platz für militärischen Hochmut ließ. Hier starben die jungen Männer, wo sie fielen. Von ursprünglich vier Landungsoptionen - Bulair, Gaba Tepe, Kap Helles und Kum Kale - waren die letzten drei ausgewählt worden, um von verschiedenen Seiten auf das Kilid Bahr Plateau vorzustoßen und die Halbinsel innerhalb weniger Tage einzunehmen. ${ }^{107}$ Es war klar, dass es das Ziel der Landungstruppen sein musste, die unmittelbaren Höhenzüge $\mathrm{zu}$ besetzen, um einen Brückenkopf für die folgenden Operationen zu etablieren. Die flächenmäßig kleinen Strandabschnitte boten nämlich kaum Möglichkeiten für weitere Truppenbewegungen und für die Trinkwasserversorgung, sofern nicht schnell vorgerückt wurde.

Eine umfangreichere Operation auf der asiatischen Seite wurde von Hamilton aus zwei Gründen abgelehnt: Zum einen wäre die Versorgungslage erschwert worden und die Truppen hätten leicht vom eigentlichen Ziel der Kampagne abgedrängt werden können und zum anderen benötigte die alliierte Armee Zugang zu den Höhenzügen Gallipolis, um die Durchfahrt der Flotte aktiv durch Artilleriebeschuss der osmanischen Festungsanlagen $\mathrm{zu}$ unterstützen. ${ }^{108}$ Es wurden zudem so viele Landungsoperationen zur gleichen Zeit ausgeführt, um Liman von

106 Ebd., S. 133.

107 Doyle u. Bennett, Geography, S. 14; Moorehead, Gallipoli, S. 135-142. Lediglich Hamilton hatte zu Beginn der Operationen über eine fünfte Option bei Suvla nachgedacht, welche im August 1915 zu einer zweiten Landung führen würde.

108 Doyle / Bennett, Geography, S. 14. 
Sanders zu zwingen, mit der Entsendung von Verstärkungen möglichst lange zu warten, bis ihm klar war, welcher Strandabschnitt nicht nur zu Täuschungszwecken angelaufen worden war. Im Idealfall wurde erhofft, dass die britischen Truppen schon gelandet wären, bevor die osmanischen Verstärkungen einträfen. Dass die Operation nur auf eine kurzfristige Auseinandersetzung angelegt war, wird deutlich, wenn man die Ausrüstung der Landungstruppen eingehender betrachtet. Jeder Mann war mit nur 200 Schuss Munition, Grabwerkzeug und drei Tagesrationen ausgestattet worden. Eine langwierige Operation war also aus logistischer Perspektive nicht vorgesehen. ${ }^{109}$

Die 29. Division, die bei Kap Helles an Land gebracht wurde, sollte Achi Baba einnehmen, während die ANZAC-Truppen angehalten waren, die an deren Landungsgebiet angrenzenden Höhenzüge zu besetzen, um dem osmanischen Heer den Rückzugsweg abzuschneiden. Die französischen Kontingente bei Kum Kale sollten derweil die feindlichen Geschütze auf asiatischer Seite ausschalten. ${ }^{110} \mathrm{Zur}$ Aufnahme von Verwundeten standen dabei lediglich zwei Hospitalschiffe zur Verfügung. Es ist also davon auszugehen, dass Hamilton nur mit wenig Gegenwehr rechnete, zumal er selbst nur die Küste auf und ab fuhr, ohne wirklich selbst ins Geschehen einzugreifen. Die Koordination der Operationen oblag folglich den Offizieren, die die Landungstruppen befehligten. Hamilton selbst notierte, fern vom aktuellen Geschehen, am Landungsmorgen noch optimistisch: „Wir haben unseren taktischen Coup gelandet und den Kommandierenden des Feindes überrascht." ${ }^{111}$

Doch kaum hatten die ersten Männer die Landungsboote verlassen, begann ein Sturm aus Geschossen über sie hereinzubrechen. Hamilton beschreibt an Bord seines Schiffes eine Szenerie, bei der „die Maschinengewehre und Gewehre an der Küste nie ihr Feuern unterbrachen [...] Alle paar Sekunden durch unsere gewaltigen Salven unterbrochen, kehrte dieses reizende Geräusch beharrlich in unsere Ohren zurück. [...] wir waren machtlos, nicht in der Lage etwas anderes zu tun als zu warten. “112 Hamilton betonte zwar die Courage der Truppen, die unentwegt gegen dieses „Stahlgewitter“113 vorrückten, aber er muss in dieser Situation erstmals erkannt haben, welchen Realitäten er wirklich gegenüberstand. ${ }^{114}$ Beim osmanischen Oberkommando in Gallipoli überstürzten sich ab 5 Uhr morgens die

109 Moorehead, Gallipoli, S. 115.

110 Zum Verlauf der Landungen vgl. Carlyon, Gallipoli, S. 127 f.; Hamilton, Diary, Bd. 1, S. 126 159; Masefield, Gallipoli, S. 37-39; Prior, Gallipoli, S. 89-109; Rudenno, Gallipoli, S. 77-83.

111 Hamilton, Diary, Bd. 1, S. 129.

112 Ebd., S. 132.

113 Die Bezeichnung stammt von Ernst Jünger. Vgl. dazu Jünger (Stahlgewitter).

114 Hamilton, Diary, Bd. 1, S. 138f. 
Meldungen über die alliierten Truppenlandungen im Süden der Halbinsel. Liman von Sanders versuchte ruhig und besonnen zu reagieren, auch wenn viele seiner Offiziere von der großen Anzahl von Landungen doch schockiert schienen:

Aus den vielfach bleichen Gesichtern der meldenden Offiziere in früher Morgenstunde war ersichtlich, daß, obwohl eine feindliche Landung mit Sicherheit erwartet wurde, ihr Eintreten an so vielen Stellen manche überraschte und mit Besorgnis erfüllte. Mein erstes Gefühl war, daß in unseren Maßregeln nichts geändert zu werden brauchte. Dies war eine große Genugtuung! Die feindliche Landungsarmee hatte diejenigen Punkte ausgewählt, welche wir selbst als die wahrscheinlichsten Landungsstellen besonders geschützt hatten. ${ }^{115}$

Ungeachtet der guten Vorbereitungen war Liman von Sanders aber beunruhigt über die Unterstützung der gelandeten Truppen durch die Flotte, da diese den Verteidigern an Feuerkraft mehr als überlegen war:

Die feindlichen Schiffe schützten im besten Sinne des Wortes ihre gelandeten Truppen. Wir verfügten in jenen Tagen dort nur über Feldartillerie, die zur Abwehr der feindlichen Landangriffe dringend benötigt wurde und bereits jetzt mit ihrer Munition haushalten mußte. Gegen die feindlichen Kampfschiffe konnten sie weder nach Wirkung noch nach Reichweite in Betracht kommen. Es [blieb] nur der Versuch, die gelandeten Truppen in nächtlichem Angriff auf ihre Schiffe zurückzuwerfen. ${ }^{116}$

Dennoch versuchten die osmanischen Verteidiger mit aller Macht, die Landungen der alliierten Truppen $\mathrm{zu}$ verhindern und eröffneten an den verschiedenen Strandabschnitten das Feuer, sobald die Landungsboote in Reichweite waren. Es begann für die britischen Truppen der 29. Division ein Marsch durch Wasser und über den Strand, bis sie endlich geschützte Stellungen erreichten. Die Zahlen der Gefallenen auf dieser Strecke waren ebenso hoch wie derer, die an der Westfront auf einem Abschnitt vergleichbarer Länge das Niemandsland zu überqueren hatten.

Dabei waren im Süden der Halbinsel bei Kap Helles gleich fünf Landungsoperationen ausgeführt - die Strandabschnitte S, V, W, X, und Y. Dabei wurden ein dreiviertel Bataillon auf den Landungsabschnitt S, zweieinviertel Bataillone auf V, ein Bataillon auf W, sowie zweieinviertel Bataillone auf Y verteilt. ${ }^{117}$

115 Sanders, Türkei, S. 84.

116 Ebd., S. 93.

117 Im Folgenden werden mit W und Y nur zwei der Landungen etwas eingehender vorgestellt, wobei Verluste an allen Strandabschnitten zu beklagen waren - insgesamt 3800 Mann also etwa $20 \%$ der für die Landungen bei Kap Helles zur Verfügung stehenden Truppenkontingente -, selbst wenn an einigen der Widerstand der Verteidiger nicht ganz so heftig ausfiel. 
Die Stellungen an Strandabschnitt W waren bereits als Grabenanlagen angelegt worden und unter Wasser war in der Landungszone Stacheldraht verlegt worden. Sobald die Truppen in Reichweite gelangten, begannen Maschinengewehre das Feuer zu eröffnen. ${ }^{118}$ Die britischen Soldaten konnten zwar schlussendlich landen, allerdings waren die gesteckten Operationsziele nicht zu erreichen. Major John Graham Gillam beschreibt in seinem Gallipoli Diary die Landungen in diesem Bereich. Von Deck des Panzerkreuzers Essex aus konnte er die Landungszone sehen, in der für ihn ,alles Hölle und Verwirrung [zu sein] schien. " ${ }^{119}$ Er selbst betrachtete den Krieg dabei wie aus einer Loge im Theater und spricht später mit einem Verwundeten Soldaten, der ihm die Situation schildert. Der junge Mann war auf dem Weg an den Strand von Stacheldraht und Maschinengewehrfeuer leicht verwundet worden, hatte aber noch genug Leben in sich, um diese Situation leichtfertig als lustig $\mathrm{zu}$ beschreiben. ${ }^{120}$ Am 26. April begab sich der Major selbst an Land, wo es extrem gefährlich war, sich über offenes Gelände zu bewegen. Scharfschützen erschwerten solche Bewegungen und überall lagen Leichen herum. ${ }^{121}$ Der Krieg offenbarte sich in dieser Situation, am Strand der Gallipoli-Halbinsel für viele zum ersten Mal mit all seiner Grausamkeit. Darüber hinaus wurde bei den ersten Attacken auf die osmanischen Stellungen ersichtlich, dass der Gegner erhebliche Verlust erlitten hatte. In den Schützengräben fanden sich „Tote, die in grotesken Haltungen daliegen“. ${ }^{122}$ Gegen Abend des zweiten Tages konnte erstmals Ordnung in dem Strandabschnitt geschaffen werden, an dem „überall Gewehre, Munition und Männer [waren]. “123 Ein Versorgungssystem wurde eingerichtet, um die vordersten Stellungen mit allem Notwendigen versorgen zu können. Eines war aber schon jetzt offensichtlich. Das Ziel, möglichst schnell die gegnerischen Höhen $\mathrm{zu}$ besetzen, war nicht erreicht worden.

Am Strandabschnitt Y bot sich ein ähnliches Bild. Die britischen Truppen mussten ohne ausreichende Deckung aus den Landungsbooten heraus über den Strand. Die osmanische Gegenwehr, die von Maschinengewehrfeuer begleitet war, erschwerte diese Operation wie an anderen Abschnitten auch, u. a. Z. ${ }^{124}$ Hamilton erkannte das Potential dieses Landungsbereiches, da es weniger Widerstand zu geben schien als an anderen Strandabschnitten, wie beispielsweise V. Er ver-

118 Prior, Gallipoli, S. 105-108.

119 Gillam, Diary, S. 32.

120 Ebd., S. 33.

121 Ebd., S. 44.

122 Ebd.

123 Ebd.

124 Prior, Gallipoli, S. 97-103. 
suchte deshalb um 9:20 Uhr von der Queen Elizabeth aus, Hunter-Weston zu kontaktieren und fragte an, ob dieser mehr Männer benötige. Es ging keine Antwort ein. 45 Minuten später sendete Hamilton eine weitere Nachricht, in der er seine Frage wiederholte und darauf hinwies, dass ausreichend Boote vorhanden wären, um Verstärkungen an Land bringen zu lassen. Hunter-Weston antwortete eine Stunde später mit dem Hinweis darauf, dass das Marinekommando darauf hingewiesen hätte, eine solche Aktion würde die Landungen der Truppen an den anderen Landungsabschnitten verzögern. So verzichteten beide darauf, sich weiter mit dem Strandabschnitt zu befassen, und die Truppen saßen nach der Landung untätig herum, um auf einen weiteren Vormarsch der Gesamtstreitkräfte zu warten. ${ }^{125}$ Eine gute Gelegenheit war damit vertan worden. Für dieses Versagen mitverantwortlich war die Einstellung vieler britischer Offiziere, die durch die Ausbildung an der Generalstabsschule maßgeblich bestimmt wurde. Die Aufgabe der Führungsoffiziere bestand demnach darin, die Schlacht zu planen, diese aber nicht auszuführen und dabei so wenig wie möglich in ablaufende Aktionen einzugreifen, um die Initiative der untergeordneten Offiziere nicht zu bremsen. ${ }^{126}$ Der britische Historiker Robert Rhodes James spricht gar von einem „Fetisch des Nichteingreifens“127, welcher für die passive Haltung Hamiltons verantwortlich $\mathrm{zu}$ machen sei. Die Nachrichten des Oberkommandierenden waren als Fragen formuliert und deswegen vermutlich nur wenig bindend für Hunter-Weston, dessen Antwort an Hamilton erahnen lässt, dass es keine klaren Kommandostrukturen gegeben zu haben scheint. Der für die Landungen bei Kap Helles verantwortliche Kommandeur hatte zudem selbst nur selten klare Anweisungen formuliert, sondern von seinen Männern stattdessen verlangt, so weit wie möglich vorzurücken. Ohne klare Zielvorgaben, entwickelten die Soldaten im Angesicht von Tod und Vernichtung daher ganz eigene Ambitionen und redefinierten, was die Führung für erstrebenswert gehalten hatte. ${ }^{128}$ Im Juli wurde Hunter-Weston schließlich aufgrund eines Hitzschlags ersetzt, wobei andere Stimmen, u. a. der britische Journalist Ellis Ashmead-Bartlett (1881-1931), die Führung für ihre fehlende Koordination kritisierten und davon ausgingen, dass Widerstand in den eigenen Reihen für die Abberufung des Kommandierenden der Truppen bei Kap Helles verantwortlich war.

Die Landungen dort hatten schließlich nur einen kleinen Raumgewinn erzielt. Die Vorwärtsbewegung endete in der Nähe von Krithia, wo die Frontlinie bis zum Abzug der Truppen im Januar 1916 unbeweglich verblieb. Insgesamt er-

125 Travers, Command, S. 413.

126 Ebd. S. 414

127 James, Gallipoli, S. 319.

128 Travers, Command, S. 416. 
reichten die Landungen bei Kap Helles nur wenig. Zwar mussten osmanische Verstärkungen dorthin verlagert werden, allerdings war das nur ein kleiner Trost für den hohen Blutzoll. Als Compton MacKenzie die Szenerie zum ersten Mal sah, empfand er den Anblick als beinahe surreal: „Ich fühlte mich als würde ich das Arrangement einer Schlachtenszene im Fenster eines Spielzeugladens betrachten, eine künstlerische Methode Spielzeugsoldaten und Spielzeugboote auszustellen, alle Spielzeug-Zelte und Bäume und Forts vorrätig, zu ihrem besten Vorteil [...]; und wir [...] dort oben in den Booten wie Passagiere auf dem Dach eines haltenden Omnibusses, die auf dieses Ladenfenster hinabstarrten“. ${ }^{129}$ Der britische Autor John Masefield hat derweil eine ganz eigene Erklärung, weshalb die Truppen nicht weiter vorrückten. „Wir rückten nicht weiter vor, weil wir es nicht konnten, denn zwei erholte Männer, fest verschanzt, mit Maschinengewehren, werden einen müden Mann mit Gewehr in neun von zehn Fällen stoppen. Unsere Männer hatten das Unvorstellbare erreicht, indem sie gelandet waren. Sie konnten am selben Tag nicht das Unmögliche tun. “130 Die nervliche Belastung nagte an den Soldaten in dieser Situation ebenso sehr, wie der Durst und die Erschöpfung.

Viele Probleme der Alliierten waren durch die Landungen bei Kap Helles offensichtlich geworden. Zum einen wurde die Armee von ihren eigenen Befehlshabern gehemmt, denn die Führungsoffiziere hatten es versäumt, die Initiative zu ergreifen und an den Stellen vorzustoßen, wo der osmanische Widerstand nicht auf eine so umfangreiche Landungsoperation vorbereitet war. Hinzu kommt, dass die Führungsoffiziere alle fern vom Einsatzgebiet waren und damit nicht zeitnah mit klaren und gezielten Entscheidungen reagieren konnten, sofern sie das überhaupt beabsichtigten. Auch die Kommunikation zwischen den Offizieren selbst sowie zwischen den unterschiedlichen Waffengattungen war mangelhaft. Die medizinischen Versorgungsmöglichkeiten waren darüber hinaus desaströs, sodass viele Soldaten starben, die bei besseren Vorbereitungen und Planungen vielleicht hätten gerettet werden können. ${ }^{131}$

Ähnlich desaströs verliefen die Landungsoperationen der ANZAC-Truppen weiter nördlich. Australien hatte während des Ersten Weltkrieges knapp 200.000 Mann Verluste zu beklagen, wobei etwa 60.000 der rund 330.000 Soldaten gefallen waren. ${ }^{132}$ Dabei waren 30\% derer, die sich zur Waffe meldeten, in Großbritannien geboren worden. Eine gewisse Begeisterung für den Krieg, der beinahe mit einem sportlichen Wettkampf gleichgesetzt wurde, bei dem es um Ruhm, Ehre

129 MacKenzie, Gallipoli, S. 32.

130 Masefield, Gallipoli, S. 79.

131 Travers, Command, S. 411-413.

132 Carlyon, Gallipoli, S. 134 u. 140. 
und den Beweis von Männlichkeit durch Tapferkeit auf dem Schlachtfeld ging, sei den australischen Soldaten eigen gewesen, heißt es. ${ }^{133}$ William Throsby Bridges (1861-1915) erwarb sich als Kommandeur der australischen Militärakademie einen Namen und sorgte dafür, dass die australischen Truppen erstmals als eigenständiges Kontingent in den Krieg zogen. Er selbst sollte die Kampagne nicht überleben und wurde damit zum ersten australischen General, der in einem Krieg fiel, und maßgeblich an der Begründung des ANZAC-Mythos, beteiligt war. Die hohen Rekrutenzahlen wurden zudem als Spiegelbild der australischen Abenteuerlust gedeutet. Allerorten war der Sold der Freiwilligen aus Down Under wesentlich höher als der ihrer britischen Kameraden. Lediglich ein Sechstel der australischen Offiziere hatte im Zuge des Burenkrieges in Südafrika (1899-1902) Kampferfahrungen sammeln können. Insgesamt betrachtet war das australische Kontingent ein eher unerfahrenes, bei denen 20\% der Rekruten jünger als 21 Jahre, $40 \%$ zwischen 21 und 25 Jahren, und 40\% älter als 25 Jahre waren. Etwa $90 \%$ aller Soldaten waren alleinstehend, nur ein Viertel der Offiziere war verheiratet. ${ }^{134}$ Am 1. November 1914 wurden die australischen Kontingente ähnlich denen aus Neuseeland ${ }^{135}$ verschifft und gelangten zunächst nach Ägypten.

Von dort wurden sie schließlich ins Landungsgebiet gebracht, wo sie mit ihrer Ankunft am 25. April 1915 den Beginn der ANZAC-Legende markieren sollten. Die angeblich glorreiche Landung bestand ähnlich denen im Süden der Halbinsel zu großen Teilen aus Verwirrung. So waren beispielsweise die australischen Einheiten auf unterschiedliche Transportschiffe verteilt worden, sodass eine Koordinierung nach der Landung erschwert wurde, mussten sich doch die Einheiten erst einmal zusammenfinden. Hinzu kam, dass die geplante Landungszone um etwa eine Meile in nördlicher Richtung verfehlt wurde und die Truppen aus Australien und Neuseeland deshalb anstelle eines Strandes ein Terrain vorfanden, bei dem die Soldaten von hohen Klippen umgeben waren und sich in einer sehr gefährlichen Position befanden. ${ }^{136}$ Bis heute ist ungeklärt, weshalb die Landungszone verfehlt wurde, vielleicht war es der militärischen Führung nicht wichtig genug gewesen, für die Präzision der Abläufe Sorge zu tragen. ${ }^{137}$

Der englische Kriegskorrespondent Ellis Ashmead-Bartlett, der durch seine Berichte ebenfalls maßgeblich an der Entstehung der ANZAC-Legende beteiligt gewesen war, beschreibt die Landung der australischen und neuseeländischen

133 Ebd., S. $146 \mathrm{f}$.

134 Ebd., S. $148-152$.

$135 \mathrm{Zu}$ den Truppenaushebungen in Neuseeland vgl. ebd., S. 160-162.

136 Ebd., S. 179 bezeichnet das Schlachtfeld als eine „Wildnis“.

137 Zur ANZAC-Landung Ashmead-Bartlett, Dardanelles, S. 44-61; Carlyon, Gallipoli, S. 169176; Moorehead, Gallipoli, S. 127 f. 
Einheiten in seinem Werk The Uncensored Dardanelles genauer. Am Abend des 24. April 1915 erhielten die Truppen an Bord der Transportschiffe noch eine warme Mahlzeit und nach einer letzten Pfeife oder Zigarette ${ }^{138}$ schliefen sie, um sich für den Morgen und die anstehende Aufgabe zu erholen: „Es war der letzte Schlaf für viele der tapferen Krieger aus ,Down Under'. “139 Am Morgen wurden alle Lampen gelöscht und die Männer „segelten langsam durch die Nacht einem unbekannten Ziel, einem unbekannten Schicksal entgegen. “ ${ }^{140}$ Die Soldaten begaben sich in die Landungsboote und machten sich auf den Weg zur Halbinsel, wo sie, sobald die Boote den Strand erreicht hatten, von osmanischem Maschinengewehrfeuer empfangen wurden. Die jeweils 40-50 Mann pro Landungsboot gaben leichte Ziele für die Verteidiger ab, doch „die australischen Freiwilligen zeigten sich der Lage gewachsen. Sie warteten weder auf Befehle, noch darauf, dass die Boote den Strand erreichten, sondern sprangen in die See, wateten an die Küste, und, indem sie eine Art grober Linie formten, stürzten direkt auf das Blitzen der Gewehre ihrer Feinde zu." ${ }^{141}$ Gleichzeitig mussten die Verwundeten wieder aus dem Landungsbereich evakuiert werden und ein „endloser Strom“142 verletzter Soldaten wurde zurückgebracht. Die minimalen Schätzungen der möglichen Zahl Verwunderter bei den Landungstruppen wurden durch den Beschuss der osmanischen Verteidiger aus ihrer überlegenen Stellung weit übertroffen.

Selbst am folgenden Tag endete das Feuer der osmanischen Gewehre nicht. Die Verteidiger attackierten die ANZAC-Stellungen ohne Unterlass. ${ }^{143}$ Dennoch wurden die Landungsoperationen fortgesetzt; zusehends mehr Männer und Material kamen an Land. Ashmead-Bartlett fasst die Szenerie dieser Tage zusammen:

Die ANZAC-Szenen in diesen frühen Tagen haben einen unauslöschlichen Eindruck bei denen hinterlassen, die Zeugen derselben wurden. Indem man inmitten dessen, was einer Lawine zerberstender Schrapnellgeschosse gleichkam, auf die Küste zuhielt, landete man an einem etwa 30 Meter breiten sandigen Strand, zwischen dem Wasser und den Klippen, die dann auf etwa 30 bis 60 Meter ansteigen. Dort fand man, konzentriert auf diesen engen Raum, Regimenter, die darauf warteten auf die Schützengräben vorzurücken, müde Gruppen, die dabei waren die Boote und Fahrzeuge zu entladen, solche die große Pyramiden aus Fleischkonserven und Keksen errichteten, andere die Wasser holten, von dem zu dieser Zeit nur eine moderate Menge an der Küste zu finden war. ${ }^{144}$

138 Zum Rauchen im Ersten Weltkrieg siehe Schindelbeck (Zigaretten).

139 Ashmead-Bartlett, Dardanelles, S. 45.

140 Ebd.

141 Ebd., S. 47.

142 Ebd., S. 48

143 Ebd., S. 53.

144 Ebd., S. 56. 
Chaos regierte folglich auch diesen Strandabschnitt und Ashmead-Bartlett erinnerte die Situation an ein riesiges Schiffswrack, das an der Küste zerschellt war, da die Landungstruppen eher aussahen, als wären sie an Land gespült und nicht geplant dorthin gebracht worden. ${ }^{145}$ Lieutenant General Birdwood erkannte sehr wohl, dass die Landungen nicht am ursprünglich vorgesehenen Ort stattgefunden hatten. Er musste nun eine Truppe kommandieren, die regelrecht eingekesselt war und keinesfalls einer Armee glich, die im Zuge war, die Gallipoli-Halbinsel leichten Schrittes zu überqueren, um Konstantinopel zu erstürmen. Er meldete Oberbefehlshaber Hamilton, dass seine Offiziere Bedenken ob der Situation geäußert hätten und die Moral der Truppen stark unter der belagerungsartigen Situation und dem steten Feuer der Osmanen leide. ${ }^{146}$

Birdwood bat darum, seine Männer evakuieren zu dürfen, da er nicht davon ausging, dass die momentane Lage genutzt werden konnte, um eine erfolgversprechende Offensive einzuleiten. Hinzu kam, dass sich das vorhandene Kartenmaterial als vollends nutzlos herausstellte. Hamilton ließ Birdwood mitteilen, dass er mit seinen Truppen ausharren solle und gab ihm die Anweisung „zu graben, graben, graben““ ${ }^{147}$ Die Australier gruben sich also, ähnlich wie die alliierten Truppen an der Westfront tief ins Gelände ein, in dem ein Tunnel- und Schützengrabensystem entstand und harrten der weiteren Entwicklungen. Aufgrund dieses Grabens (engl. to dig) wurden die australischen Soldaten in der Zukunft oft als „Gräber“ (digger) bezeichnet. ${ }^{148}$ Viele Alternativen blieben den ANZAC-Truppen nicht, denn durch die verfehlte Landung waren nun die Höhenzüge von Chunuk Bair und Sari Bair entscheidend, die allerdings vom Gegner gehalten wurden. Dass diese in osmanischer Hand blieben, war vor allem Mustafa Kemal zu verdanken, der deren Wert sofort erkannt hatte und seine ganzen Kräfte gegen die Landungstruppen mobilisierte. Er entschied sich auch, die für die Reserve vorgesehenen Einheiten in den Kampf zu werfen, wobei er eine riskante Wahl traf, denn zu diesem Zeitpunkt hatte sich noch nicht gezeigt, welche Landungen die eigentlichen Angriffe waren und welche nur zur Ablenkung des Feindes angedeutet werden sollten. Liman von Sanders musste lediglich seinen gut durchdachten Plan ausführen lassen. Die Kommandostrukturen, die Logistik sowie die Verteilung der Truppen an die notwendigen Schauplätze funktionierten auf osmanischer Seite wesentlich besser als bei den Alliierten.

145 Ebd. S. 57

146 Hamilton, Diary, Bd. 1, S. 143.

147 Ebd., S. 144.

148 Moorehead, Gallipoli, S. 147. Bean, History, S. 45 - 48 beschreibt die Aufstellungen der ANZAC Truppen nach der Landung und den ersten Gefechten. 
Im ANZAC-Gebiet waren die Stellungen des Feindes bald so nah, dass die australischen und neuseeländischen Soldaten die Gespräche des osmanischen Gegners in den Schützengräben hören konnten. ${ }^{149}$ Letztere waren in der Lage, auf der gesamten Frontlinie nach Belieben Verstärkungen heranzuziehen, da die Höhen nicht von den Australiern, Briten, Franzosen, Indern, Nepalesen und Neuseeländern eingenommen werden konnten. Die Osmanen erreichten bisweilen sogar eine numerische Überlegenheit, die sie zu nutzen gedachten, um die Angreifer wieder zurück ins Meer zu treiben. Nach den Landungen begannen deshalb schwere Kämpfe, bei denen sich die osmanischen Soldaten der ,grundsätzlichen Einstellung zum Angriff“150 verschrieben hatten. ${ }^{151}$

Hamilton betrachtete die geglückten Landungen jedoch als ersten großen Erfolg, der mit „Blut, Schweiß und Feuer“ erkauft worden sei. ${ }^{152}$ In seinen Aufzeichnungen klingt zu diesem Zeitpunkt immer noch hindurch, dass der Kommandeur an einen schnellen Sieg glaubte, durch den die Flotte befähigt würde, das Osmanische Reich letztendlich zum Eingeständnis der eigenen Niederlage zu zwingen. Die Einschätzung der deutschen Offiziere, hier beispielsweise durch Carl Mühlmann zum Ausdruck gebracht, wich stark von der Hamiltons ab, denn man war durchaus bereit, den Briten weiterhin Paroli zu bieten, auch wenn das in erster Linie durch Nachtangriffe erfolgen musste:

In dem wenig Deckung bietenden Gelände war der Angreifer der vollen Feuerwirkung des an Land befindlichen Gegners und dessen die Halbinsel umrahmenden Flotte ausgesetzt. Jeder Angriff bei Tageslicht mußte daher unter den furchtbarsten Verlusten zusammenbrechen. So blieb nur die Möglichkeit eines Nachtangriffs mit allen seinen Schattenseiten, der schwierigen Orientierung und der erschwerten Gefechtsleitung. Zusammengefaßt ergab sich also vom türkischen Standpunkt die gebieterische Forderung, zu einem möglichst nahen Zeitpunkt durch Nachtangriff den Gegner bei Sedd ul Bahr ins Meer zu werfen. ${ }^{153}$

Es wurden in der Folge Versuche unternommen, den alliierten Feind durch gezielte Attacken aus seinen Stellungen zu vertreiben, diese scheiterten aber. Beide Seiten beklagten den Mangel an Geschossen und Munition. Anfang Mai 1915 notierte Hamilton kritisch seine Sorge über diesen Umstand in seinem Tagebuch und betonte dabei, „dass [ihn] das Kriegsministerium dazu zwingt [s]eine tapferen Truppen erneut gegen Maschinengewehre in die Schanze zu schicken; es auf die günstige Art zu tun; es zu tun, ohne nach den Geschossen zu fragen, die der

149 Ebd., S. 48.

150 Mühlmann, Kampf, S. 106.

151 Ebd., S. 105-122.

152 Hamilton, Diary, Bd. 1, S. 158.

153 Mühlmann, Kampf, S. 109. 
Attacke eine sportliche Chance verleihen würde." 154 Trotzdem hoffte er weiter und wenn er doch nur ein Regiment Gurkhas aus Ägypten bekommen hätte, dann wäre er zu allem in der Lage gewesen. Kurzum, Hamilton war demselben Erklärungsmuster verfallen, wie die Generäle an der Westfront: mehr Männer, mehr Geschosse, größere Kanonen, dadurch schließlich ein Sieg.

Neben Hamilton äußerte Hunter-Weston, der die britischen Landungstruppen kommandierte, ähnliche Bedenken und monierte, dass man in Flandern nie verlangen würde, was man auf Gallipoli von den britischen Soldaten forderte. ${ }^{155}$ Die Materialengpässe auf Seiten der Alliierten wurden von den deutschen Offizieren jedoch nicht erkannt. So schreibt beispielsweise Mühlmann nicht ohne Neid auf die Ressourcen des Britischen Empire: „Im Verlauf des Stellungskrieges trat immer deutlicher in Erscheinung, daß der Engländer für seine Materialausstattung den Reichtum der ganzen Welt, der Türke dagegen nur die so begrenzten Hilfsmittel Konstantinopels zur Verfügung hatte. “156 Der Mangel an Munition wurde oft beklagt; die eigenen Truppen mussten „mit vermehrten Blutopfern die Unterlegenheit an Material wettmachen. “157 Weshalb diese Kritik immer wieder auftaucht, wird deutlich, wenn bedacht wird, dass bereits bis zum 5. Mai 1915 elf Millionen Schuss Munition, 23.000 Schrapnellgeschosse sowie 5.000 Geschosse für die Haubitzen verbraucht worden waren. ${ }^{158}$ Schließlich mussten die Osmanen aufgrund der physischen Erschöpfung sowie der hohen Verlustzahlen ihrer Truppen die Angriffe auf alliierte Stellungen beenden. Trotz des Verlustes von „kostbarem Menschenmaterial“ und ungeachtet „vermehrte[r] Blutopfer“159 war es nicht gelungen, die gegnerischen Brückenköpfe zu vernichten. Das osmanische Heer begann schließlich damit, sich ebenfalls auf einen längeren Stellungs- und Grabenkrieg vorzubereiten und grub sich weiter ein. Die Gallipoli-Kampagne schien sich, wie von Maxwell und anderen vorhergesagt, in ein „orientalisches Flandern“ zu verwandeln. Ohne eine Verstärkung der Artillerie schienen Angriffe deshalb von vornherein aussichtslos zu sein:

Beide Teile mußten erkennen, daß ganz besonders in diesem schwierigen Angriffsgelände, das den beiderseitigen Stellungen, namentlich aber den türkischen Linien, schon eine natürliche Stärke verlieh, die Überlegenheit an schwerer Feuerkraft mit guter Wirkung auf die vorderste Kampflinie eine unerläßliche Vorbedingung des Erfolges war. ${ }^{160}$

154 Hamilton, Diary, Bd. 1, S. 198.

155 Ebd., S. 200.

156 Mühlmann, Kampf, S. 126.

157 Ebd. S. 129.

158 Hamilton, Diary, Bd. 1, S. 204.

159 Die Zitate stammen aus Mühlmann, Kampf, S. 124.

160 Ebd., S. 122. 
Hamilton war nicht bereit, schon aufzugeben, wusste er doch, dass kein Erfolg zumindest nicht in kurzer Zeit - zu erwarten sein würde, wenn die Flexibilität der Frontlinie erst einmal verloren war. Für ihn schien deshalb klar, dass ,resolut und um jeden Preis vorgerückt und dieses neue Spinnennetz aus Stahl zerstört werden musste, bevor dessen [...] unzerbrechliche Teile [...] miteinander verbunden würden."161 Zunächst war das Überraschungsmoment verschwunden und die Soldaten auf beiden Seiten von den Ereignissen und den immens hohen Verlustzahlen erschüttert.

Und doch war die britische Seite bestrebt, diese Entwicklung zu unterbinden. Immer wieder versuchten die Briten Krithia, das ein Ziel am Landungstag gewesen war, einzunehmen. In insgesamt vier Schlachten zwischen Ende April ${ }^{162}$ und Anfang August 1915 sollte auf dieses Dorf vorgestoßen werden, um den Brückenkopf bei Kap Helles weiter ins Innere der Halbinsel zu schieben. Dabei wurde von den Soldaten verlangt, sich mit aller Kraft gegen den Feind zu werfen, selbst wenn dieser mit Maschinengewehren und in gut verschanzten Stellungen auf einen solchen Angriff wartete. ${ }^{163}$ Hamilton beschreibt einen dieser Angriffe unter dem Datum des 8. Mai 1915 in seinem Tagebuch: „Als der Moment [des Angriffes] hereinbrach, erwachte die weite Ebene vor uns zum Leben. Bajonette blitzten überall in der weiten Ebene. Unter unseren Ferngläsern nahm diese vage Bewegung Form und menschliche Gestalt an: Männer erhoben sich, fielen, rannten, brandeten in Wellen, brachen, sprangen zurück, zerfielen und verschwanden. “164 Nachdem dieser Angriff im Mai gescheitert war, schien hier aber schon klar, dass Gallipoli nicht zum erhofften schnellen Sieg werden würde, sondern sich vielmehr genauso entwickelte, wie so viele andere Operationen des Ersten Weltkrieges. Nach dem Verlust vieler Menschenleben setzte Schritt für Schritt ein Stillstand ein, eine Entwicklung, die aus dem zu Beginn mit so vielen Hoffnungen verbundenen Unternehmen einen Nebenkriegsschauplatz machen sollte. Umso heftiger wurde die Kritik, dass die militärische Führung bei den Dardanellen wertvolle Menschenleben und Ressourcen für ein sinnloses und vermutlich nicht $\mathrm{zu}$ erreichendes Ziel opfere. ${ }^{165}$ Es setzte die Einsicht ein, dass es sich um eine lange und blutige Kampagne handeln würde, die nur unter höchstem Einsatz von Mensch und Material vielleicht noch zu entscheiden war.

Am 8. Mai 1915 musste Hamilton in einer Meldung an Kitchener eingestehen, dass er ohne Verstärkungen kaum dazu in der Lage sein würde, weiter vorzu-

161 Hamilton, Diary, Bd. 1, S. 201.

162 Zum ersten Versuch am 28. April vgl. Aspinall-Oglander, Operations, S. 236-283.

163 Hamilton, Diary, Bd. 1, S. 208.

164 Ebd., S. 211.

165 Ashmead-Bartlett, Dardanelles, S. 94. 
stoßen, sondern auch einen Grabenkrieg zu führen hatte. Dieses Eingeständnis kam der Anerkennung einer Niederlage nahe, denn Hamilton gestand ein, dass das Unternehmen gescheitert war. In London waren weder die militärische noch die politische Führung bereit, dieses Scheitern zu akzeptieren. Jetzt galt es für Hamilton, das zu tun, was er Birdwood zuvor geraten hatte: auszuharren und sich einzugraben.

Auf Seiten der Osmanen war die militärische Führung ebenfalls noch nicht bereit, den Stillstand der Front zu akzeptieren. Es wurde eine Offensive gegen den ANZAC-Brückenkopf geplant. Diese sollte mit einem Nachtangriff, der am 18. Mai erfolgte, beginnen. Erneut mussten die Planer der Operation einsehen, dass es keinen Sinn ergab, mit noch so vielen Truppen gegen einen Feind anzustürmen, der seine Position mit schwerer Artillerie und Maschinengewehren verteidigen konnte. Die eingesetzten Divisionen erlitten extrem hohe Verluste - die 2. Division hatte 9.000 Gefallene zu beklagen - und Liman von Sanders bekannte in seinen Memoiren, dass dieses Vorgehen eher dem der Gegner geglichen hatte: „Ich muß den genannten Angriff im übrigen als einen von mir gemachten Fehler, der auf der Unterschätzung des Feindes beruhte, bezeichnen. “166 Nach dieser gescheiterten Aktion endeten die osmanischen Angriffe und man beschränkte sich darauf, die angelegten Schützengräben auszubauen.

Die einzigen nennenswerten Aktionen Ende Mai 1915 wurden von U-Booten ausgeführt. Das deutsche U-21 versenkte am 25. und 27. Mai die britischen Linienschiffe Triumph und Majestic. Diese hatte zur Folge, dass „[d]er Feind [...] nun vorübergehend den größten Teil seiner Schlachtschiffe nach den gesicherten Häfen von [...] Lemnos zurück[zog] und [...] für die nächsten Wochen die artilleristische Unterstützung der Landungsarmee im wesentlichen den Destroyers und den Torpedobooten [überließ]." 167 Im Gegenzug waren britische U-Boote im Marmarameer aktiv und erschwerten durch ihre Versenkungen die Versorgung mit Nachschub für die Truppen Liman von Sanders, da diese vom See- auf den Landweg verlagert werden mussten. Das britische Unterseeboot E-11 versenkte in seiner dreimonatigen Operationsphase mehr als 100 Schiffe, darunter auch einen Kohletransporter im Hafen von Konstantinopel, sodass bis Ende 1915 keine osmanischen Schiffe mehr bei Tag fuhren. ${ }^{168}$ Die britische Marine intensivierte diese Aktionen aber nicht mehr, zumal die Verteidiger an den Meerengen daran gingen, ein großes Stahlnetz zu spannen, um die Durchfahrt weiterer U-Boote durch die Meerengen zu unterbinden. Zwar waren derlei Aktionen nicht kriegsentschei-

166 Sanders, Türkei, S. 100.

167 Ebd., S. 101.

168 Moorehead, Gallipoli, S. $206 \mathrm{f}$. 
dend, sie zeigten aber, welche Bedeutung den Unterseebooten in Zukunft zukommen würde und welche Rolle sie in einem modernen Krieg spielen konnten. ${ }^{169}$

Im Juni und Juli versuchten die alliierten Truppen erneut, einen Vorstoß zu initiieren, wobei die Attacken meist ein bis zwei Tage andauerten, aber kaum erfolgreich waren. In fünf Angriffen (4. Juni, 21. Juni, 28. Juni, 5. Juli und 12. Juli 1915) wurde selten mehr Raum gewonnen als eine halbe Meile, wobei die Zahlen der Gefallenen auf Seiten der Alliierten zwischen 2.000 und 6.000 lagen. ${ }^{170}$ Diese Operationen verliefen stets gleich, wiederholten sie doch einen Frontalangriff in der Hoffnung, mit ausreichend Soldaten in der Lage zu sein, den Feind und dessen Stellungen zu überwinden. Prinzipiell hätte Hamilton in dieser Situation die auch noch nicht verfügbaren Panzer benötigt, um die Starre des Grabenkrieges zu überwinden. Stattdessen drückten die immer wiederkehrenden Attacken eine gewisse Ratlosigkeit der Führung aus, die zwar um die Problematik solcher Frontalangriffe wusste, aber nichts anderes $\mathrm{zu}$ tun in der Lage war. Allerdings wurden die Ziele der Operationen Schritt für Schritt nach unten korrigiert.

Für das osmanische Heer und Liman von Sanders war die Situation nicht weniger deprimierend. Oft waren die Verteidiger an das Limit ihrer Möglichkeiten gebracht worden, die Tatsache, dass die alliierten Angriffe aber meist nach ein bis zwei Tagen abebbten, ließ sie weiter ausharren. Liman von Sanders beschreibt diesen Umstand später wie folgt: „Es war für uns ein großes Glück, daß die englischen Angriffe niemals durch längere Tage hintereinander fortgesetzt wurden, sondern immer bald eine mehrtägige Kampfpause eintrat. Anderenfalls wäre es gar nicht möglich gewesen, mit unserer Artilleriemunition durchzuhalten. “171

Es standen sich auf Gallipoli zwei durchaus ebenbürtige Armeen gegenüber, die mit ähnlichen Problemen zu kämpfen hatten. Autoren wie Masefield stellten die Heldenhaftigkeit des Kampfes in den Mittelpunkt ihrer Darstellung, da „keine Armee der Geschichte jemals eine heldenhaftere Attacke ausgeführt hat; keine Armee in der Geschichte hat jemals eine solche Aufgabe erhalten. Keine andere Gruppe von Männern in keinem anderen modernen Krieg war aufgefordert worden über Minen und mit Stacheldraht gesicherten Wassern und im Kreuzfeuer von Maschinengewehren zu landen. "172 Jedoch war der Alltag der Soldaten ein solcher, der von Not, Verzicht und stillem Leiden gekennzeichnet war. Das Klima und die Vegetation der Halbinsel sorgten dafür, dass die ersten Monate an Land von Hitze und Wassermangel geprägt waren, während der Winter mit eisigen Stürmen

169 Ebd., S. 195-203.

$170 \mathrm{Zu}$ den Angriffen siehe ebd., S. 209.

171 Sanders, Türkei, S. 104.

172 Masefield, Gallipoli, S. 33. 
aufwartete. ${ }^{173}$ Neben den natürlichen Gegebenheiten der Halbinsel mussten die Truppen auch mit der Realität des Krieges leben. Aufgrund der stetig abnehmenden Mannschaftsstärken der Einheiten, des Todes immer zahlreicherer eigener Kameraden sank die Moral der Truppe auf der Halbinsel zusehends. ${ }^{174}$ Diese Erfahrung machte beispielsweise eine deutsche Pionierkompagnie, die Ende Juni 1915 auf dem Kriegsschauplatz eintraf, deren Schicksal Liman von Sanders beschreibt:

Diese Pionierkompagnie, welche eine Stärke von 200 Mann erreichen sollte, wurde bei der Südgruppe gegenüber Seddulbar eingesetzt. Infolge der Einwirkung des überaus heißen Klimas und der ungewohnten türkischen Nahrung, sowie durch die starken blutigen Verluste sank ihre Kopfzahl in kurzer Zeit auf einige vierzig Mann. Diese fanden nunmehr als Vorarbeiter, auf die beiden Fronten verteilt, Verwendung. ${ }^{175}$

Nachdem sich die Operation zu einem reinen Ausharren in den eigenen Schützengräben entwickelt hatte, stieg die Lethargie und Melancholie der Truppen, die sich auf langes Warten einstellen mussten, das lediglich durch erneute Angriffe unterbrochen werden würde. Das Leben der einzelnen Soldaten spielte sich im Mikrokosmos des Schützengrabens ab, sodass sich die Erfahrung der GallipoliVeteranen durchaus mit der derjenigen deckte, die in Belgien und Frankreich ähnliches erlebt hatten. ${ }^{176}$ Langeweile am Tag wechselte sich ab mit erhöhter Bereitschaft in der Nacht, in der normalerweise Angriffe des Gegners erwartet wurden. Durchbrochen wurde die Eintönigkeit durch gelegentlichen Beschuss durch feindliche Artillerie oder den Versuch eines Scharfschützen, den sonst unsichtbaren Gegner aus der Distanz zu Fall zu bringen. Die Tatsache, dass der Feind sehr oft nicht sichtbar war, legte sich ebenfalls schwer auf die Moral der kämpfenden Truppe:

Das Unbekannte, das der wirkliche Zerstörer der Courage ist, lag schwerer auf den Alliierten als auf den Osmanen, denn diese jungen Männer waren weit von zu Hause entfernt, und die meisten von ihnen hatten ein behüteteres Leben geführt als die anatolischen Bauern und nun, bei der ersten Begegnung mit dem Krieg, waren sie diejenigen, die aufstehen und sich ins offene Feld begeben mussten, sich selbst zur Schau stellen mussten, während die Osmanen in der sicheren Umgebung eines Schützengrabens bleiben konnten. ${ }^{177}$

173 Zur Geographie und zum entsprechenden Klima auf Gallipoli vgl. Doyle u. Bennett, Geography, S. $17 \mathrm{f}$.

174 Hamilton, Diary, Bd. 1, S. 315.

175 Sanders, Türkei, S. 103.

176 Bean, History, S. 51.

177 Moorehead, Gallipoli, S. 124. 
Viele alliierte Soldaten fühlten sich wie in einer Falle, aus der es kein Entkommen zu geben schien. Vor ihnen spannte sich das Netz aus feindlichen Schützengräben, im Rücken war die See, aus der sich die britischen Schiffe nach den Angriffen des deutschen U-Bootes zurückgezogen hatten. Ein Gefühl der Einsamkeit, des Verlassenseins stellte sich nicht zu Unrecht ein.

Ebenfalls negativ wirkte sich die Erfahrung des Todes aus, der bei Gallipoli reiche Ernte eingefahren hatte. Wann immer ein Angriff erfolgte, mussten die Soldaten über offenes Gelände auf die gegnerischen Stellungen zustürmen, wobei nur wenige die knappe Minute ohne Deckung überlebten. Diejenigen, die es schafften, bis zu den Stellungen des Feindes zu gelangen, fielen dann oft durch ein Bajonett. Besonders schlimm war die Erfahrung aller Beteiligten nach den Nachtangriffen der Osmanen seit dem 18. Mai, denn die Toten und Verwundeten lagen danach hilflos im Niemandsland zwischen den Schützengräben, um in der Sonne zu verdursten und einsam und hilflos zu sterben. Keiner wagte sich aus den Stellungen, um den Verwundeten beizustehen oder die Toten zu bestatten. In der Hitze verbreitete sich schnell ein Gestank, der den noch Lebenden ein ähnlich grausames Schicksal verhieß. Das Wimmern und Jammern derer war zu vernehmen, die zwar noch am Leben waren, sich aber selbst nicht retten konnten. Schließlich wurde für den 24. Mai eine Waffenruhe vereinbart, um die Leichen und Verwundeten zu bergen. Für neun Stunden arbeiteten Osmanen und ANZACTruppen zusammen, um den Anblick zu beseitigen, für den ihr eigenes Handeln verantwortlich war. Dabei kamen die Gegner erstmals persönlich miteinander in Kontakt, tauschten unter anderem Zigaretten und Essen aus. Es waren diese Begegnungen, die die rassistisch aufgeladenen Stereotype, wie sie auf beiden Seiten bestanden haben, in Frage stellten. Besonders die ANZAC-Truppen akzeptierten die osmanischen Soldaten ab diesem Zeitpunkt als gleichwertigen und respektablen Feind. Nach dem Ende der Generalangriffe legte sich eine Monotonie auf das Schlachtfeld, die lediglich durch lange Gespräche mit Kameraden, manchmal aber auch sportliche Aktivitäten unterbrochen wurden. So spielten die Alliierten beispielsweise Fußball am Strand und wurden dabei von den Osmanen nicht unterbrochen, von denen behauptet wurde, dass sie nicht das Feuer eröffneten, weil sie das Spiel, auf welches sie gewettet hätten, beobachten wollten. ${ }^{178}$ Was sich allerdings schwer auf das Gemüt der ANZAC-Truppen legte, war das Gefühl, von den eigenen Politikern in der Heimat vergessen worden zu sein. ${ }^{179}$

Darüber hinaus litten die Soldaten vor allem unter den Fliegen, die auf der Gallipoli-Halbinsel überall zu sein schienen, die Nahrung und das Wasser der

178 Ebd., S. 176-180.

179 Ebd., S. 225. 
Soldaten mit Krankheitserregern verseuchten und zur Verbreitung von Krankheiten beitrugen. ${ }^{180}$ Die Tatsache, dass Leichen, die Exkremente der Transporttiere sowie Essensabfälle zunächst unbeachtet blieben, trug dazu bei, dass die Erkrankungen von Soldaten zunahmen und in der Mitte 1915 eine große Zahl der Männer für den aktiven Dienst ausfiel. Anfang Juli notierte die australische Feldambulanz beispielsweise, dass immer mehr Soldaten kollabierten und heftiger Durchfall unter den Truppen grassierte. ${ }^{181}$ Erst verschärfte Maßnahmen zur Regulierung des Latrinenwesens sowie eine Vermeidung einer unnötigen Verschmutzung des Geländes durch Essensreste oder die Leichname von Transporttieren wirkten den steigenden Krankenzahlen entgegen. Dafür war beispielsweise am ANZAC-Strandabschnitt eine 30 Mann starke Hygiene-Einheit ins Leben gerufen worden. Hinzu traten Maßnahmen, das Trinkwasser der Truppen zu sterilisieren. ${ }^{182}$ Dieses Vorgehen war besonders wichtig, da die Sanitätsschiffe nur eine geringe Anzahl von Soldaten aufnehmen konnten.

Mit der zunehmenden Dauer des Stillstandes an der Front, wuchs die Kritik an Hamilton, der weithin als Hauptverantwortlicher für die schlechte Lage der Alliierten galt. Hamilton selbst sollte später eher die offiziellen Berichterstatter dafür verantwortlich machen, dass nur wenig öffentliches Interesse an der GallipoliKampagne bestanden habe und deshalb die so wichtigen Nachschublieferungen ausblieben. ${ }^{183}$ Kritisiert wurde zu Recht, dass Befehlshaber und Soldaten in unterschiedlichen Welten lebten. Während die Kommandierenden über weit entfernte Operationsziele debattierten, konnte es für den Soldaten im Schützengraben nur zwei Ziele geben: die feindlichen Linien $\mathrm{zu}$ erreichen und dabei zu überleben. Hamilton war immer noch nicht bereit, dies zu akzeptieren und konnte sich bei Kitchener nicht durchsetzen, um beispielsweise Verstärkungen oder Nachschub einzufordern. Daran hinderten ihn die militärischen Hierarchien, seine Loyalität zu Kitchener, eine pragmatische Zurückhaltung, die aus der Erfahrung der Zusammenarbeit mit dem Kriegsminister herrührte, eine gewisse Angst vor dem Vorgesetzten sowie ein Groll gegen Kitchener, der Hamiltons Wünsche nicht selten zu ignorieren schien. Letztlich war bis Mitte 1915 der einzige Erfolg der Operation darin zu sehen, dass die Truppen überhaupt gelandet werden konnten. Ein schnelles Vorstoßen und die Einnahme der Halbinsel war ausgeblieben. Es stellte sich vielmehr ein Stellungskrieg ein, der ähnlich ausweglos war, wie der an der Westfront, den die Gallipoli-Kampagne eigentlich zu beenden helfen sollte.

180 Carlyon, Gallipoli, S. 20; Moorehead, Gallipoli, S. 214-216.

181 Bean, History, S. $366 \mathrm{f}$.

182 Ebd., S. 370 - 373.

183 Hamilton, Diary, Bd. 1, S. 339. 


\subsection{Die Suvla-Operation und die späte Einsicht}

Nach vier Monaten der Gallipoli-Kampagne hatten die Alliierten rund 47.000 Mann an Gefallenen, Verwundeten oder Vermissten zu beklagen und es war klar, dass die Operation entweder abgebrochen oder verstärkt werden musste. Die osmanische Armee hatte zwar mit etwa 68.000 Mann ebenfalls schwere Verluste $\mathrm{zu}$ verzeichnen und doch hielt sie stand und hatte bisher keinen wirklichen Raumgewinn auf Seiten der Angreifer zugelassen. Die Offensiven der osmanischen Armee waren allerdings nach den herben Verlusten vom Mai 1915 eingestellt worden und die Militärführung fokussierte sich nun auf die Sicherung der Höhenzüge, um den strategischen Vorteil weiterhin in den eigenen Händen zu behalten. Dabei erwiesen sich die osmanischen Soldaten als ebenbürtige Gegner, deren Wille nicht zu brechen schien, wenn es darum ging, die Wellen der Angreifer, u. a. während der Schlachten um Krithia, abzuwehren. ${ }^{184}$

Hamilton und sein Stab kämpften derweil mit Nachschubproblemen, die alle Schrecken einer mangelhaften Logistik offenbarten. So waren beispielsweise neue Geschosse eingetroffen, allerdings benötigte man Sicherungsschlüssel zur Nutzung derselben, die erst einen Monat später eintrafen. Hamilton machte vor allem die politische Führung in London verantwortlich, die die Truppen bei Gallipoli im wahrsten Sinne des Wortes verheizte, denn es wurde stets zu Gunsten der Westfront gespart. Die Halbherzigkeit, mit der sich die Regierung mit Gallipoli befasste, wurde dem Kommandeur von Tag zu Tag bewusster und offensichtlich auch mehr und mehr zuwider. ${ }^{185}$ Die Kommunikation mit London frustrierte ihn, da von dort Rechnungen über Soll-Stärken nach Angaben auf Papieren gemacht wurden, die nur wenig widerspiegeln konnten, was wirklich auf der Halbinsel geschehen war. Darüber hinaus beklagte Hamilton immer wieder, dass sich Maxwell weigerte, Truppen bereitzustellen, die er unter dem Vorwand der Verteidigung Ägyptens zurückhielt, wo diese doch gar nicht so dringend benötigt worden waren. ${ }^{186}$ Es schien dem Oberkommandierenden fast so, als wäre es Teil des Planes, „zu warten bis ein Teil der Truppen getötet worden wäre, bevor man den anderen Teil der Truppen aufbrächte.“187

Am 7. Juni 1915 traf sich zum ersten Mal das sogenannte Dardanellen-Komitee, eine Untersuchungskommission, die einberufen worden war, um die Ereignisse im Zuge der Gallipoli-Operationen genauer zu untersuchen. Trotzdem wurden

184 Erickson, Strength, S. $1009 \mathrm{f}$.

185 Hamilton, Diary, Bd. 2, S. 28-30.

186 Ebd., S. 34.

187 Ebd., S. 48. 
noch einmal drei Divisionen Verstärkungen für das Landungsunternehmen bewilligt, um eine erneute Offensive zu starten. Darüber hinaus entsandte die Marine erneut Schiffe der Monitor Klasse - relativ kleine Kriegsschiffe, die weder schnell noch stark gepanzert, dafür aber mit unverhältnismäßig großen Kanonen ausgestattet waren - sowie einige Beetles, spezielle Landungsfahrzeuge, die bis zu 500 Mann fassen konnten. ${ }^{188}$ Diese sollten einen neuen Plan des GallipoliKommandos unterstützen, im Zuge dessen am 6. August neue Truppen bei Suvla, also zwischen dem ANZAC-Strandabschnitt und Bulair im Norden gelandet werden sollten. Die Landung der frischen Truppenkontingente sollte einen zeitgleichen Angriff der australisch-neuseeländischen Truppen auf die Höhenzüge von Sari Bair unterstützen. Ziel war es, durch die gemeinsame Operation möglichst weit ins Innere vorzustoßen und die Höhen einzunehmen, von denen aus im Anschluss daran weitere Offensivoperationen erfolgen konnten. ${ }^{189}$

Die Suvla-Episode sollte als „Beispiel träger Inkompetenz“190 in die britische Militärgeschichte eingehen und schrieb deshalb die Tragik Gallipolis fort. Die ANZAC-Offensive war ebenfalls viel $\mathrm{zu}$ ambitioniert geplant worden, denn es wurde „zu viel von den Truppen verlangt und es sollte daher nicht verwundern, dass sie scheiterten. " ${ }^{191}$ Die Verstärkungen, die Hamilton erhalten hatte, waren in gutem Zustand und ähnlich enthusiastisch wie diejenigen, die Mudros im April 1915 verlassen hatten, um an der Küste der Gallipoli-Halbinsel zu landen. ${ }^{192}$ Erneut war Hamilton zuversichtlich.

Am Nachmittag des 6. August 1915, um 15:30 Uhr, begann der Beschuss von Kap Helles durch die Marine, wobei der Geschosshagel in erster Linie dazu bestimmt war, die osmanischen Soldaten im Süden zu binden und davon abzuhalten, Verstärkungen gegen die nördlichen Operationen $\mathrm{zu}$ entsenden, wo um 17:30 Uhr der Angriff der Australier und Neuseeländer einsetzte. Am Abend begann die Landungsoperation von knapp 20.000 Mann bei Suvla, die zuvor in Imbros (10.000), Mudros (6.000) und Mytilene (4.000) gestartet waren. ${ }^{193} \mathrm{Am}$ Morgen des 7. August offenbarte sich dabei erneut das Chaos, das auf der Gallipoli-Halbinsel, zumindest auf Seiten der Alliierten so allgegenwärtig war.

188 Moorehead, Gallipoli, S. 229.

$189 \mathrm{Zu}$ den Operationen bei Suvla siehe Moorehead, Gallipoli, S. 230-232; Prior, Gallipoli, S. 190 -209; Travers, Gallipoli, S. 179-219. Für die Operationen im ANZAC-Gebiet vgl. Prior, Gallipoli, S. 169-189; Travers, Gallipoli, S. 145-177.

190 Prior, Gallipoli, S. 190.

191 Ebd., S. 185.

192 Ebd., S. 54.

193 MacKenzie, Gallipoli, S. 354. 
Diesmal war zumindest die Landung geglückt und die Männer waren nicht wieder von Maschinengewehrsalven in Empfang genommen worden, sobald sie den ersten Fuß an den Strand setzten. Von daher konnte Hamilton zumindest über den Beginn der Operation optimistisch sein. ${ }^{194}$ Allerdings gab es andere Probleme. Zum einen wurden erneut einige Truppenteile im falschen Landungsgebiet abgesetzt und zum anderen eröffneten zwei Brigaden der 11. Division im Dunkeln das Feuer aufeinander. Teilweise waren Einheiten erneut über verschiedene Landungsplätze verstreut worden, sodass sie sich erst wieder sammeln mussten, was große Verwirrung schuf. Hinzu kam, dass die niederen Offiziere teilweise widersprüchliche Befehle erhalten hatten. Ganz besonders gefährlich war die Tatsache, dass nicht ausreichend Wasser mit an Land gebracht worden war, sodass ein Gros der Truppen unter der extremen Hitze litt und sich vor Durst kaum in der Lage sah, einen Angriff zu unternehmen. ${ }^{195}$ Die Inkompetenz der Kommandeure wurde erneut dafür kritisiert, dass keine konkreten Angaben zu Zielen gemacht wurden und die Befehle oft Spielraum zur Fehlinterpretation boten. ${ }^{196}$ Bei einigen Einheiten waren Soldaten und Offiziere getrennt worden, sodass die Führung fehlte. Dadurch sank die Moral, aber wesentlich schlimmer als das war der Verlust der Möglichkeit, einen koordinierten und vor allem zeitnahen Angriff einzuleiten.

Schließlich - und das ist erneut bezeichnend für die Tragik der gesamten Gallipoli-Kampagne - konnte sich Hamilton nicht durchsetzen, als ein Streit zwischen ihm und dem für die Landungen zuständigen Offizier die Initiative versanden ließ, bevor auch nur ein echter Angriffsversuch unternommen worden war. Generalleutnant Frederick Stopford (1854-1929) war der kommandierende Offizier, der für das Unternehmen in Gallipoli eingetroffen war. Allerdings sollte die Landung bei Suvla für den 61-Jährigen das erste Kommando über Truppen in einer Schlacht sein. Zuvor hatte er den Tower in London geleitet und war während des Burenkrieges ein Militärsekretär gewesen. Hier schien schon bei der Wahl der Offiziere deutlich zu werden, wie wenig Bedeutung man der Gallipoli-Kampagne von Seiten der politischen Führung noch beimaß. Stopfords Verhalten bei der Landungsoperation von Suvla war in erheblichem Maße dafür verantwortlich, dass der zwar vergleichsweise gelungene Beginn der Operation nicht in einen militärischen Erfolg umgesetzt werden konnte. Von seinen Zeitgenossen und den folgenden Generationen der britischen Militärgeschichtsschreibung wurden ihm

194 Hamilton, Diary, Bd. 2, S. 55.

195 Travers, Command, S. 421.

196 Major Crookenden an Aspinall, 28. Januar 1931, CAB 45/241, PRO zitiert nach ebd., S. 424. 
Vorwürfe gemacht, er habe eine gute Gelegenheit vertan, die Kampagne doch noch zum Erfolg zu führen. ${ }^{197}$

Stopford selbst erklärte seine Untätigkeit und die Tatsache, dass er nicht direkt nach der Landung der Truppen einen Angriffsbefehl erteilte, damit, dass die Männer erschöpft gewesen seien, nicht ausreichend Wasser zur Verfügung stand und er deshalb die Einnahme der Höhenzüge verschoben habe. ${ }^{198}$ Hamilton wies ihn deshalb darauf hin, dass ,wir die Höhen sofort einnehmen müssen. Es ist zwingend, dass wir jetzt [...] [dorthin] gelangen!“199 Stopford hingegen, der an Bord eines Kommandoschiffes geblieben war und sich dort über die Lage informieren ließ, wiederholte seine Bedenken bezüglich des mangelnden Wasservorrates. Zudem wollte er zunächst mehr Geschütze an Land haben und betonte, dass vor allem der Mangel an schwerer Artillerie zum Schutz der Angriffsoperation gegen schnelle Vorstoßversuche sprachen. ${ }^{200}$ Das Gros derselben war aber, so die anonyme Schilderung eines Offiziers, der an der Landung bei Suvla beteiligt gewesen war, aus unerfindlichen Gründen in Ägypten gelassen worden. ${ }^{201}$ Hamilton wurde klar, dass Stopford nicht willens war, eine Attacke vor dem 9. August einzuleiten, was seiner Meinung nach zu spät war, um eines der gesetzten Ziele zu erreichen. Er weigerte sich zudem, einen Nachtangriff auszuführen. Hamilton begab sich daraufhin selbst nach Suvla, um vor Ort einzugreifen und sich mit dem dortigen Kommandeur der Truppen, Generalmajor Frederick Hammersley (18581924), abzustimmen, beorderte Stopford jedoch nicht, ihn zu begleiten. ${ }^{202}$ Anstatt also einen direkten Befehl auszusprechen, hoffte Hamilton in dieser Situation, dass seine höheren Offiziere seine Wünsche aufnehmen würden, wie er selbst das vielleicht bei Kitchener getan hatte. Seine Annahme war aber falsch, sodass er für die mangelhafte Koordination zwischen Oberkommandierendem und höheren Offiziere und damit für viele der missglückten Operationen verantwortlich zu machen ist.

Hamilton begab sich am 8. August an Land und ordnete einen Nachtangriff an. Obwohl sich ein Teil der Truppen mittlerweile wieder in die richtige Ordnung zurückgefunden hatte, konnte er erst am nächsten Morgen ausgeführt werden. Andere Brigaden waren nämlich immer noch auf der Suche nach ihren Offizieren und hatten deshalb keinen Führungsoffizier, der sich mit den Befehlen oder den

197 Erickson, Strength, S. 1005.

198 Hamilton, Diary, Bd. 2, S. 62.

199 Ebd. S. 63

200 Ebd.

201 Anonym, With the Field Artillery Brigade at Suvla Bay Landing, Compiled from a diary by „X“, TNA-CAB 45/244, S. 1.

202 Travers, Command, S. 426. 
geographischen Verhältnissen vor Ort auskannte. ${ }^{203}$ Suvla war folglich ebenso hastig geplant worden, wie die ersten Landungen. Es war versäumt worden, die Vorbereitungen akkurat auszuführen. Hinzu kam, dass auch Hammersley nicht gewillt war, aktiv vorzugehen, solange die Wasserversorgung nicht geklärt war und zudem nicht mehr Geschütze bereit gestellt wären. Er hatte Hamilton darüber hinaus darauf hingewiesen, dass dessen Wunsch nach einer schnellen Attacke aufgrund der verstreuten Einheiten in der Nacht, noch dazu in unwegsamem Gelände unmöglich war. ${ }^{204}$ Am Ende bettelte Hamilton schon beinahe bei seinen Offizieren, dass diese seinen Wünschen doch endlich nachkämen. ${ }^{205}$ Neben den logistischen Schwierigkeiten und dem mangelhaften Durchsetzungsvermögen des Oberkommandierenden, verwirrenden Plänen ohne konkrete Zielvorgaben für einen Vormarsch, hatte Hamilton auf die Geheimhaltung seiner Landungspläne bestanden, die so weit ging, selbst die eigenen Offiziere bis kurz vor den eigentlichen Landungen nicht über Details zu informieren, was später für die schlechte Ausführung der geplanten Operation mitverantwortlich gewesen sein könnte.

So wusste beispielsweise Stopford bis drei Wochen vor Beginn der erneuten Landungen nichts über die konkreten Ablauf bzw. die zu erreichenden Ziele. Zudem erhielt er lediglich die Anweisung, so weit vorzurücken wie möglich, was angesichts der besseren Stellungen der osmanischen Verteidiger für einen vorsichtigen Kommandeur viel Freiraum schuf. Der „Exzess an Vorsicht“206 ging so weit, dass die niederen Offiziere erst drei Tage vor den Landungen über Details der Operation informiert wurden. Sie konnten sich also nicht umfassend vorbereiten, sondern mussten ad hoc reagieren. Mit ausreichend Freiheiten ausgestattet, konnte schließlich ein jeder Befehlshaber selbst entscheiden, was er aus der Situation machen würde. Die meisten waren Realisten und froh darüber, dass zumindest die Landungen erfolgreich verlaufen waren. Bei allem, was über die bisherigen Operationen bekannt war, war klar, dass eine Offensive ohne breite Artillerieunterstützung gegen gut verschanzte osmanische Verteidiger in einem Blutbad enden musste.

Die Operationen am ANZAC-Abschnitt verfehlten ebenfalls ihr Ziel, da dort das Terrain immer noch zu Ungunsten der Angreifer gestaltet war. Ein Drittel der Soldaten, die an der Suvla-Operation beteiligt war, wurde entweder verwundet oder getötet. Insgesamt betrachtet war damit der Tiefpunkt der Gallipoli-Kam-

203 John Still (Adjutant, 6th East Yorks Regiment) to Hamilton, 19 September 1923, 6/7, Hamilton Papers, Liddell Hart Centre for Military Archives, King's College, London University, ansonsten zit. nach ebd.

204 Hamilton, Diary, Bd. 2, S. 66.

205 Ebd., S. 78.

206 Moorehead, Gallipoli, S. 235. 
pagne erreicht. ${ }^{207}$ Die Chance, das Blatt doch noch zu wenden, war den Alliierten aus den Händen geglitten, da keine der beiden Operationen dazu in der Lage war, die gesteckten Ziele zu erreichen. Die Höhenzüge und strategisch wichtigen Hügel - abgesehen von Chocolate Hill - blieben in Feindeshand. Erneut zeigte sich, dass die Ambitionen und Ziele eher dem Wunschdenken der militärischen Führung als den Wirklichkeiten der Gallipoli-Halbinsel entsprungen waren. ${ }^{208}$ Zudem bot sich geradezu ein Bild eines Rückzuges, denn während des Vorstoßes kamen immer wieder Männer auf der Suche nach Wasser von Richtung der Frontlinie zurück an den Strand. Ihre Zungen hingen heraus, geschwärzt vom Durst in der Hitze dieser Augusttage. ${ }^{209}$ Die Lage war konfus. Keiner wusste wirklich, wo das Hauptquartier war, wo genau die einzelnen Truppenteile zu finden waren und so ,jagten die Truppen nach Wasser, die Offiziere jagten die Truppen, und die osmanischen Scharfschützen jagten nach ihrem Ruhm. “210 Die Verwirrung ging so weit, dass ganze Einheiten - nämlich das 1/5 Norfolk Bataillon ${ }^{211}$ - einfach verschwanden.

Die Kämpfe in der Suvla- und ANZAC-Zone wurden zwar teilweise noch bis in die letzte Augustwoche fortgesetzt, insgesamt wurden aber lediglich kleine Raumgewinne bei hohen Verlusten erzielt. Stopford blieb eisern, wenn es darum ging, untätig zu bleiben, sodass sich am Ende bei Suvla ebenfalls ein Grabensystem formierte und zum Stellungskrieg übergegangen wurde. Insgesamt mussten mehrere Tausend Verwundete auf einmal versorgt werden, worauf die Sanitätsschiffe immer noch nicht eingestellt waren, sodass erneut viele Soldaten an Ort und Stelle ihrem Schicksal überlassen blieben. ${ }^{212}$ Die weitere Kampagne war vom Tunnelgraben, Minenlegen, Scharfschützen-Aktionen und kleineren Scharmützeln bestimmt.

Eines wurde durch die Operation bei Suvla deutlich: Der Gedanke, dass mehr Soldaten, mehr Material, mehr Geschütze und vor allem mehr Geschosse darüber entscheiden konnten, ob der Sieg davonzutragen war oder nicht wurde auf britischer Seite hier ebenso gehegt wie mit Blick auf die Westfront. Es wurde gar nicht versucht, eine echte Fehleranalyse durchzuführen, sondern schlichtweg davon ausgegangen, dass der Sieg möglich gewesen war, aber aufgrund des materiellen Mangels nicht erreicht werden konnte. Die Moral der Soldaten litt unter den kontinuierlichen Niederlagen und dem Versagen ihrer Offiziere. Die Verwirrung bei den Landungen, die Verstreuung von Einheiten, Kommandierenden und

207 Ebd., S. 275.

208 Ashmead-Bartlett, Dardanelles, S. 185.

209 Ebd., S. 186.

210 Ebd., S. 190.

211 Zum Fall dieser Einheit vgl. Travers u. Celik (Norfolk Battalion).

212 Moorehead, Gallipoli, S. 289. 
Mannschaften war nicht spurlos an den Soldaten vorbeigegangen, die sich von den Entscheidungsträgern in London und dem eigenen Oberkommando hintergangen fühlten. Es wurde offensichtlich, dass es keine neuen Ideen gab, die verfahrene Situation zu lösen, sondern lediglich befohlen worden war, erneut eine aussichtslose Attacke auszuführen, die so viele junge Männer ihr Leben kosten musste. $^{213}$ Die Kritik an Hamilton wuchs, zumal er sich von seinen Offizieren vorführen ließ. Jeder machte, was er wollte, solange es ihm beliebte. Mit dieser Art der „Personalführung“ war es tatsächlich schwierig, das Vertrauen der Soldaten zu erhalten. ${ }^{214}$

Als der Schlachtenlärm bei Suvla verhallte, erkannte die Regierung in London nicht sofort, was das für das Unternehmen Gallipoli bedeutete. Hamilton selbst meldete seinen Plan, noch im Verlauf des August 1915 weiter gegen die osmanischen Stellungen vorzugehen. Auch er scheint also nicht wirklich wahrgenommen zu haben, wie schwerwiegend das Scheitern Anfang des Monats tatsächlich war. Immerhin machte er klar, dass noch einmal eine hohe Zahl - 100.000 Mann - an Verstärkungen notwendig sei, um die Kampagne zum Sieg zu führen. ${ }^{215}$ Die Dardanellen-Kommission wies ihm im Gegenzug an, seine Stellungen lediglich zu halten, doch das war bereits der Anfang vom Ende, denn auch in London sollte die Kritik am Oberbefehlshaber zunehmend lauter werden.

\subsection{Evakuierung und Ende}

Die Moral der alliierten Truppen war bereits vor den Operationen von Suvla erheblich gesunken. Dies betraf ebenfalls die Verwundeten, die nach Lemnos gebracht worden waren, um sich von den Strapazen der Gallipoli-Kampagne zu erholen. Als dort die Verstärkungen eintrafen, die Anfang August 1915 Verwendung finden sollten, herrschte große Verwunderung über die melancholische Stimmung derer, die zuvor das „Privileg“ genossen hatten, als erste auf der Halbinsel zu landen und dem osmanischen Feind entgegenzutreten. ${ }^{216}$ Die hohen Verluste, der Beginn des Grabenkrieges und die Enttäuschung über die eigenen Politiker und Offiziere taten ihr Übriges, um diesen Gemütszustand innerhalb der Truppe zu verbreiten. Nach der fehlgeschlagenen Augustoffensive setzte allgemeine Ernüchterung ein, bis erneut Hoffnung aufkam: Am 1. September hatte die französische Regierung vorgeschlagen, noch einmal vier Divisionen für die Ope-

213 Travers, Command, S. 430.

214 Erickson, Strength, S. 1004.

215 Bean, History, S. 766.

216 Calder, Head, S. 113. 
ration auf der Gallipoli-Halbinsel zur Verpflegung zu stellen, sofern die britische Marine den Transport organisieren könne. Das Angebot war ungewöhnlich, zumal die Entscheidungsträger in Paris die Ressourcen bisher lieber an der Westfront gesehen hatten. Es wurde nicht hinterfragt, wie es in Frankreich zu diesem Sinneswandel gekommen war, sondern erneut keimte die Hoffnung auf, die GallipoliKampagne doch noch $\mathrm{zu}$ einem siegreichen Ende $\mathrm{zu}$ führen. ${ }^{217}$ Zudem wurde befürchtet, dass die Zeit knapp wurde, bevor Bulgarien auf Seiten der Mittelmächte aktiv in den Krieg eingriffe und damit den Weg für deutsche Verstärkungen an den Bosporus öffnen würde. Die Diskussionen über dieses französische Angebot verliefen im Sande, zumal in London bereits Umdenken herrschte und immer mehr Mitglieder der Dardanellen-Kommission wie auch die Militärs, die den Fokus lieber auf die Front in Frankreich legen wollten und ein Ende der Kampagne bei den Dardanellen forderten.

Kitchener informierte Hamilton über diese Diskussionen und die Kritik an den Operationen in einem Telegramm am 4. Oktober 1915. Einen Tag später folgte ein weiteres Telegramm, in dem der Kriegsminister darauf hinwies, dass die Dardanellen-Kommission der Meinung sei, dass Hamilton in jedem Falle defensiv agieren würde, also keine baldige Wendung des Kriegsglückes zu erwarten sei. ${ }^{218}$ Der Oberkommandierende war sich durchaus bewusst, dass man in London von Sollstärken seiner Divisionen ausging und sich wunderte, weshalb er mit so vielen Soldaten keine Erfolge erzielte, doch von den ursprünglichen Truppen waren ihm bloß die Hälfte geblieben, von denen wiederum etliche Männer wegen Erkrankung ausfielen. Am 11. Oktober fragte Kitchener in einem weiteren Telegramm direkt, mit welchen Verlustzahlen Hamilton bei einer Evakuierung der Truppen von der Halbinsel rechnen würde. ${ }^{219}$ Kitcheners ehemaliger Stabschef war schockiert über diese Anfrage: „Wenn sie das tun, dann machen sie die Dardanellen[-Kampagne] zur blutigsten Tragödie der Welt! Selbst wenn wir ohne einen Kratzer entkämen, würde man unserer Kampagne den Stempel der blutigsten aller Tragödien aufdrücken!‘ ${ }^{220}$

Im Hinblick auf eine zeitnahe Evakuierung war Hamilton skeptisch. Was würde passieren, wenn die Evakuierung aufgrund des Wetters unterbrochen werden müsste? Die verbliebenen Truppen hätten dann keine Aussicht auf Erfolg, wenn es darum ging, den osmanischen Angreifern etwas entgegenzusetzen, denn „wir würden ein Desaster erhalten, dass in der Geschichte nur dem der Athener

217 Bean, History, S. 768.

218 Hamilton, Diary, Bd. 2, S. 235-237.

219 Ebd., S. 248 f.

220 Ebd., S. 249. 
bei Syrakus gleichkäme: ein Desaster, von dem sich das Britische Empire nur schwer zu erholen hoffen könnte.“221 Hamilton meldete deshalb an Kitchener, dass er von mindestens 50\% Verlusten ausgehen müsse, um die Truppen von der Halbinsel zu evakuieren. Zwar nahm er in Wirklichkeit an, dass etwa 35-40\% an Verlusten einkalkuliert werden müssten, meldete aber in Abstimmung mit seinen Offizieren den höheren Wert nach London, da er hoffte, dass eine so schockierende Zahl vielleicht zu der Einsicht führte, es doch noch einmal mit einer größer angelegten Offensive zu versuchen. ${ }^{222}$ Er hatte sich dabei jedoch getäuscht, denn die Dardanellen-Kommission beschloss am 11. Oktober 1915, dass alle in den Mittleren Osten entsandten Truppen sich zunächst in Ägypten einzufinden hatten, bis endgültig entschieden war, was weiter geschehen würde. Hinzu kam, dass Hamilton nicht mehr unangefochten war, besonders da Berichterstatter wie Ashmead-Bartlett oder der australische Journalist Keith Murdoch (1885-1952) seinen Führungsstil heftig kritisierten. ${ }^{223}$ Hamilton hatte $\mathrm{zu}$ diesem Konflikt durchaus beigetragen, da er, so Ashmead-Bartlett, die abgehenden Berichte der Berichterstatter zensieren ließ, oder gar nicht erst sendete. ${ }^{224}$

Am 16. Oktober erhielt Hamilton schließlich die Entscheidung des War Councils, der entschieden hatte, seine bisherigen Leistungen $\mathrm{zu}$ würdigen, aber sich dafür aussprach, ihn abzuberufen und in London über die Ereignisse befragen zu lassen. ${ }^{225}$ Auf seinem Rückweg war Hamilton angewiesen worden, erneut in Saloniki und Ägypten halt zu machen, um sich über die dortige Lage ein Bild zu machen und anschließend daran, vor dem War Council zu berichten. In seinem Tagebuch kommentierte er diesen Auftrag zynisch: „Welchen Wert um alle Welt konnte meine Ansicht über Saloniki und Ägypten für die Menschen haben, die keine Verwendung für meine Ansichten über mein eigenes Fachgebiet haben!“226 Hamilton war sich sicherlich bewusst, was ihn erwarten würde. Als Oberkommandierender war er der Hauptverantwortliche für die Entwicklungen seit April 1915 und selbst wenn er noch an eine Wende geglaubt haben mag, so dürfte ihm die zunehmende Kritik nicht entgangen sein. Er begab sich folglich in die Höhle des Löwen, wohl wissend, dass man ihn nicht mit Blumen und Willkommenswünschen empfangen würde, sondern dass vielmehr unangenehme Fragen auf ihn warteten.

221 Ebd., S. 252.

222 Ebd., S. 253; Moorehead, Gallipoli, S. 296.

223 Hamilton, Diary, Bd. 2, S. 263-270; Moorehead, Gallipoli, S. 297-303.

224 Ashmead-Bartlett, Dardanelles, S. 58.

225 Hamilton, Diary, Bd. 2, S. 272.

226 Ebd. 
Ersetzt wurde Hamilton durch General Charles Monro (1860 -1929), einen Befürworter der alleinigen Fokussierung auf die Westfront. Über seinen Nachfolger schreibt Hamilton: „Er war mit einer anderen Geisteshaltung als ich geboren worden. Wenn er von Beginn an hierher entsandt worden wäre, hätte er die Dardanellen niemals angerührt, und diejenigen, die so viel realisiert haben, könnten zu dem Schluss kommen, dass er jetzt aufräumen wird.“227 Bis zum Eintreffen Monros übernahm Birdwood in Vertretung das Kommando über die Truppen.

Hamiltons Nachfolger wurde in erster Linie nach Gallipoli entsandt, um sich vor Ort ein Bild über die Lage zu machen, wobei von Beginn an klar, war, dass er der dortigen Landung nicht sonderlich gewogen war. Für Monro war es „ein Akt des Glaubens geworden, Deutsche zu töten: Osmanen zählten für ihn nicht.“228 Zehn Tage nachdem Hamilton abgereist war, traf der neue Befehlshaber am 28. Oktober in Gallipoli ein und besuchte umgehend alle Landungszonen. ${ }^{229}$ Einen Tag später ließ er nach London melden, dass er empfehle, die Operation abzubrechen und zu evakuieren, was die Politiker der Regierung bestürzte. So viele Soldaten waren auf dem Altar der Dardanellen-Kampagne geopfert worden, um dem Gott der Versuchung zu huldigen und nun sollte das alles umsonst gewesen sein, ja sogar noch einmal bis zu 40.000 Verluste kosten, um die verbliebenden Truppen zu evakuieren: „[S]ie hatten den professionellen Experten um seine Meinung gefragt, und nun hatten sie sie erhalten: und es war unvorstellbar. “230 Hamilton hingegen, der in London eingetroffen war, versuchte ebenso wie Keyes wiederum für die Fortsetzung der Operationen zu werben. Kitchener sei als Oberbefehlshaber der britischen Armee sicher in der Lage, einige Kontingente und vielleicht sogar Flugzeuge von der Westfront abzuziehen, um die Operation gegen das Osmanische Reich erfolgreich beenden zu können. ${ }^{231}$ Kitcheners Name allein würde genügen, Angst und Schrecken zu verbreiten, denn zumindest das erkannte der abberufene General: „Meine eigene Chance ist vorüber. Es gibt keinen Grund warum mein alter Chef sich nicht selbst gut machen sollte. “232 Zudem vertraute Hamilton auf Keyes, der zwei Tage nach ihm eintreffen würde, um dem Kabinett vorzuschlagen, zumindest noch einen letzten Streich gegen den Gegner zu führen, bevor man die Flagge streiche. Keyes war sehr aktiv und fand tat-

227 Ebd., S. 273.

228 Moorehead, Gallipoli, S. 306.

229 Prior, Gallipoli, S. $217 \mathrm{f}$.

230 Moorehead, Gallipoli, S. 308.

231 Hamilton, Diary, Bd. 2, S. 273 f.

232 Ebd., S. 274. 
sächlich einige Unterstützer, da viele, unter anderem Kitchener, noch nicht bereit waren, die auch politisch heikle Niederlage anzuerkennen. ${ }^{233}$

Ähnlich den Kommandeuren an der Westfront, ignorierten Keyes und Hamilton alle Zweifel, dass ihre Methoden und Ansichten vielleicht falsch seien. Die Gründe für das Scheitern wurden stets im Mangel an Soldaten, Munition, oder Unterstützung für das Unternehmen gesucht. Es konnte nicht zu Ende sein, denn das würde bedeuten, dass alles bisher Erreichte nutzlos war, dass man der britischen Öffentlichkeit den Tod so vieler junger Männer erklären musste und schließlich dass ein Eingeständnis zu erfolgen hatte, das alle Beteiligten als leichtgläubig, naiv und überheblich entlarven würde. In der bisherigen GallipoliForschung wurde immer wieder auf das Versagen einzelner Personen - v. a. Hamilton oder Stopford - hingewiesen, es ist jedoch von einem Kollektivversagen in Konsequenz mangelnder Alternativen zu sprechen.

Im Oktober 1915 wurde innerhalb des britischen Militärs fortwährend über eine Fortsetzung der Operationen auf der Halbinsel diskutiert. Eine Fraktion wollte unbedingt mit der Dardanellen-Kampagne fortfahren und immense Verstärkungen senden, weil sie immer noch daran glaubten, dass die August-Offensive lediglich am Mangel an Reserven gescheitert war. Die Gegner eines solchen Vorgehens votierten für das Ende der Operationen und plädierten stattdessen dafür, die Armee an einen anderen Schauplatz zu verlagern, wobei vor allem Saloniki zur Eröffnung einer gemeinsamen Operation mit Serbien, gegen die Gefahr eines Angriffs Österreich-Ungarns und Bulgariens, im Gespräch war. Eine dritte Gruppe votierte schließlich für die weitere Stärkung der Westfront. ${ }^{234}$ Es dauerte lange, bis eine endgültige Entscheidung getroffen wurde. Zwar war der letzte Angriff auf der Halbinsel am 21. August 1915 erfolgt, das Kabinett entschied sich aber erst am 7. Dezember 1915 endgültig dafür, Gallipoli zu evakuieren. „Für fünf Monate wurde die Armee in den Gräben gelassen, um zu verrotten“ “235, was die Moral der dortigen Truppen weiter schwinden ließ.

Neben den Militärs sprachen sich ebenfalls die Berichterstatter AshmeadBartlett und Murdoch, nachdem sie nach London zurückgekehrt waren, für das Ende der Kampagne und die Abberufung Hamiltons aus. Ersterer war sich sicher, dass man „ein [...] in der englischen Geschichte nie dagewesenes Desaster riskierte, wenn [man] [...] während des Winters [dort] verbleiben würde.“"236 Zunächst galt es aber, eine Zeitung zu finden, die bereit war, unzensierte Artikel abzudru-

233 Moorehead, Gallipoli, S. 309-314.

234 Ashmead-Bartlett, Dardanelles, S. 251.

235 Ebd.

236 Ebd. 
cken, allerdings schien klar, dass der einzige Weg, Druck auf die militärische Führung und die Regierung auszuüben, über die öffentliche Meinung führte. Ashmead-Bartlett hatte nach eigener Aussage nichts mehr zu verlieren und war willens, „den Krieg in das Lager des Gegners zu tragen. “237 Die London Sunday Times erklärte sich schließlich einverstanden, seine kritischen Schilderungen zu veröffentlichen, nachdem deren Eigentümer sich über die Form des Artikels, der schließlich als Interview erscheinen würde, geeinigt hatten. Am Sonntag, den 17. Oktober 1915 erschien es und löste nach Aussagen Ashmead-Bartletts eine Sensation aus. ${ }^{238}$ Am Montag wurde das Interview in fast allen wichtigen Zeitungen abgedruckt und Keith Murdoch stellte sicher, dass es auch die australische Presse erreichte. ${ }^{239}$ Ungeachtet dessen gab es immer noch Verfechter der GallipoliKampagne, wie beispielsweise Winston Churchill, der wirklich an die Möglichkeit eines Sieges auf diesem Kriegsschauplatz glaubte. Er wurde nicht müde zu betonen, dass die Flotte es schaffen könne, die Durchfahrt durch die Meerengen zu erzwingen. Ashmead-Bartlett, der Churchill in London getroffen hatte, nannte dies ,einen Fetisch, der von seinen [Churchills] Gedanken Besitz ergriffen hatte, der ihn für Fakten blind machte und der sein Gehirn mit Illusionen füllte.“240

Letzten Endes erzwang das Zusammenspiel militärstrategischer Kritik, politischer Zweifel und des Drucks der öffentlichen Meinung die Entscheidung gegen eine Fortsetzung der Kampagne. Am 19. und 20. Dezember wurden die ANZACTruppen und die bei Suvla ausharrenden Soldaten evakuiert. Am 23. Dezember entschied das Kabinett schließlich über die Zukunft von Kap Helles, wo die Truppen am 8. Januar 1916 von der Halbinsel evakuiert werden sollten. Monro hatte sich also mit einer schnellen und klaren Entscheidung durchgesetzt, etwas, das Hamilton in seiner gesamten Zeit als kommandierender Offizier der GallipoliKampagne nicht gelungen war.

Nachdem die aktiven Operationen nach und nach erloschen waren und sich der Grabenkrieg eingestellt hatte, gab es im Winter 1915 kaum noch Veränderungen im Hinblick auf die Aufstellungen der osmanischen Armee. ${ }^{241}$ Gleiches galt für die Alliierten, die sich, nachdem Kitchener noch einmal selbst am 9. November die Truppen inspiziert hatte, keine Verstärkungen mehr erhielten. Nachdem der Beschluss gefasst war, ging man auf Seiten der Alliierten daran, den Abzug zu planen, wobei schlechtes Wetter die Evakuierung verzögerte. Mit der Entscheidung des Kabinetts vom 8. Dezember war, „soweit es die Politiker betraf,

237 Ebd., S. 256.

238 Ebd., S. 258.

239 Ebd.

240 Ebd., S. 257.

241 Kannengießer, Gallipoli, S. 251-253. 
das Gallipoli-Abenteuer beendet. Alles, was übrig blieb, war die Aufgabe des Militärs, die Wünsche [des Kabinetts] umzusetzen.“242 Vier Tage nach diesem Beschluss wurden die Truppen bei Suvla und im ANZAC-Landungsbereich über die Evakuierung informiert, wobei diese Mitteilung zunächst für einen „Moment der Verblüffung“243 sorgte. Nur trotzig ging man daran, die Maßnahmen zum Verlassen der Gallipoli-Halbinsel, auf der so viele Kameraden ihr Leben gelassen hatten, vorzubereiten.

Im Gegensatz zur Landung wurden diese Vorbereitungen aber gut durchdacht, mit Vorsicht geplant und zielsicher ausgeführt, sodass es sich bei der Evakuierung wohl um die erfolgreichste aller Aktionen im Zuge der GallipoliKampagne handelte, bei der im ANZAC-Bereich lediglich zwei Verwundete zu beklagen waren. ${ }^{244}$ Während Kitcheners Besuch im November hatte ein kleiner Stab aus Armee- und Marineoffizieren den Plan für den Abzug der gesamten Truppen von der Halbinsel erarbeitet. Die Operation wurde dabei in drei Phasen aufgeteilt, bei der die erste bereits ausgeführt wurde, bevor es eine offizielle Entscheidung in London gegeben hatte. Die Truppenstärke wurde dabei zunächst nur soweit verringert, dass eine effektive Winterkampagne noch möglich war. Die zweite Phase einer weiteren Reduktion der Soldaten war vorgesehen, sobald die Politik die Evakuierung beschlossen hatte. Dabei sollten Mannschaften und Material derart reduziert werden, dass nur noch eine Grundbesatzung der Grabenanlagen zurückblieb. In der dritten und letzten Phase sollten dann die verbliebenen Kontingente so schnell wie möglich abgezogen werden, wobei das verbliebene Material zurückgelassen werden konnte, selbst wenn es so dem Feind in die Hände fiele. ${ }^{245}$ Um die Verteidigung in der letzten Phase zu gewährleisten, sollten zwei Schützen pro Yard (91,4 Zentimeter) und ein Drittel der Artillerie auf der Halbinsel zurückbleiben. Es war deshalb vorgesehen, in der letzten Phase etwa 26.000 Mann bei Suvla und im ANZAC-Abschnitt zu behalten, wohingegen man bei Kap Helles mit ca. 18.000 auszukommen gedachte.

\begin{tabular}{llll}
\hline Strandabschnitt & Truppenstärke in Phase 1 & Truppenstärke in Phase 2 & Truppenstärke in Phase 3 \\
\hline Suvla & 50.807 & 43.160 & 25.753 \\
\hline ANZAC & 41.218 & 35.786 & 26.195 \\
\hline Kap Helles & 42.697 & 29.139 & 18.556 \\
\hline
\end{tabular}

242 Prior, Gallipoli, S. 220.

243 Moorehead, Gallipoli, S. 333.

244 Ebd., S. 333-339.

245 Bean, History, S. 853. 
John Graham Gillam beschreibt die Vorbereitungen auf den Abzug in der dritten Phase seit Anfang Dezember 1915 und die Evakuierung selbst in seinem Tagebuch. Am 2. Dezember notiert er noch, dass es Flutwarnungen gibt und dass das Wetter den Abzug noch verzögern könnte, da Fluten und Blizzards eine Operation der Marine erschweren würden. Ungeachtet dessen verliefen die Vorbereitungen zur Evakuierung jedoch recht gut, wobei sich Gillam fragte, ob die osmanischen Soldaten sie dabei wohl beobachteten. ${ }^{246}$ Am 6. Dezember beschossen sich die osmanische Armee und die Alliierten den ganzen Tag, allerdings gab es nur wenige Gefallene zu beklagen, da mittlerweile gute Deckungen bestanden und es sich bei den Geschossen nicht um Schrapnelle handelte. Am Folgetag beschossen die Osmanen die alliierten Stellungen erneut. Wie es schien, war auf der Seite des Feindes endlich Munitionsnachschub eingetroffen. ${ }^{247}$ Am 9. Dezember wurde die Evakuierung dann Realität, als die letzte Abzugsphase begann. Am 20. Dezember notiert er dann, dass „Suvla wieder osmanisch ist“, wobei alle Truppen evakuiert wurden und kein einziger Soldat gefallen war. ${ }^{248}$

In diesem Fall hatten die Planer also alles richtig gemacht. Die Einzelheiten waren nicht vorgegeben worden, sondern sollten von den Korpsoffizieren direkt vor Ort, auf Basis ihrer genauen Einschätzung der jeweiligen Situation getroffen werden. Es gab klare Richtlinien und einen dezidierten Zeitplan, an den sich alle zu halten hatten. ${ }^{249}$ Hier funktionierten zum ersten Mal die Kommandostrukturen einwandfrei, zumal die Pläne eingehend studiert werden konnten, bevor es an deren konkrete Umsetzung ging. ${ }^{250}$ Die Vorbereitungen mussten mit äußerster Vorsicht erfolgen, damit die osmanischen Soldaten nichts von denselben erfuhren, schließlich wäre ein Sturmangriff auf die sich zurückziehenden Truppen fatal gewesen. Vielleicht war es die Erfahrung der Landungen, die die Soldaten und ihre Offiziere in dieser Situation zu extremer Vorsicht antrieben, diese lohnte sich aber, denn die geringen Verlustzahlen können durchaus als Erfolg verstanden werden.

Die Frontlinie musste trotzdem bis zum Ende gehalten werden, um sicherzustellen, dass die Evakuierung nicht zu früh entdeckt wurde. An Freiwilligen für diese Aufgabe mangelte es nicht. Hier wurde die Grundlage für weitere Heldengeschichten geschaffen, die später einen großen Anteil an der Etablierung der ANZAC-Legende und den Erzählungen über den australischen Heldenmut bei

246 Gillam, Diary, S. 282.

247 Ebd., S. 285.

248 Ebd., S. 299.

249 Vgl. dazu etwa 3rd Australian Light Horse Brigade, Brigade Operation Order, Gallipoli, 19. Dezember 1915, TNA-WO95/4288-1.

250 Bean, History, S. 856. 
Gallipoli hatten. John Masefield nannte sie in seiner Darstellung der GallipoliKampagne beispielsweise trotz ihrer Niederlage „die feinste Gruppe junger Männer, die jemals in unseren modernen Zeiten zusammengebracht worden waren. Aufgrund ihrer physischen Schönheit und ihrer noblen Haltung übertrafen sie alle Männer, die ich je bisher gesehen hatte; sie gingen und sahen aus wie die Könige in alten Gedichten. “251 Ungeachtet dessen litten die Alliierten vor dem Abzug genauso stark unter dem kalten Winter, wie der osmanische Gegner selbst. $^{252}$

Diejenigen, die sich an die Strände begaben, um dort die Boote zu bemannen, hatten die ganze Zeit damit gerechnet, dass die osmanischen Soldaten sie entdecken und den Angriff aufnehmen würden, aber nichts dergleichen geschah. Eine Serie von Memoranden war im Zuge der Evakuierungsvorbereitungen ausgegeben worden, um die Truppe auf das Verlassen der Halbinsel vorzubereiten. Für viele war es eine Enttäuschung, nach so vielen Opfern unverrichteter Dinge abzuziehen. Das Gros der Männer war überzeugt, dass die osmanische Armee selbst sich gerade auf den Rückzug vorbereitete und man wollte deshalb die Verteidigungsanlagen, deren steter Besitz mit so vielen Soldatenleben erkauft worden war, nicht einfach aufgeben. ${ }^{253}$

Lieutenant General Birdwood, der die endgültige Niederlage und das Ende der Operation akzeptiert hatte, war dennoch unwillig, kriegswichtiges Material, das während der gesamten Kampagne knapp bemessen gewesen war, nun einfach in den Händen des Feindes zurückzulassen. Ihm genügte es daher nicht, die Geschütze lediglich untauglich zu machen, er wollte sie zerstört wissen, damit sie nicht als Trophäe in den Händen osmanischer Truppen landen konnten. ${ }^{254}$ In der letzten Nacht wurden daher an allen Kanonen Sprengladungen angebracht, die von den letzten abziehenden Soldaten zu zünden waren, damit nichts übrig blieb.

Später liefen ähnliche Geschehnisse bei Kap Helles ab. „Nicht ein Mann wurde zurückgelassen“ ${ }^{255}$ und alles lief bestens, wie von der Führung geplant. Auch im Süden bestätigte sich, dass die Evakuierung der Truppen wohl die am besten geplante Aktion der Gallipoli-Kampagne war. Warum genau die osmanische Armee nicht eingegriffen hat, bleibt unklar, auch wenn Liman von Sanders mit Blick auf den Erfolg der alliierten Aktion bemerkte, dass „die sehr geschickte Einleitung und Durchführung der Räumung [...] ein frühzeitiges Erkennen an der

251 Masefield, Gallipoli, S. $25 \mathrm{f}$.

252 Ebd., S. $229 \mathrm{f}$.

253 Bean, History, S. 880 f.

254 Ebd., S. 884.

255 Moorehead, Gallipoli, S. 348. 
vordersten türkischen Front verhindert[e]. “256 Anerkennend fügt er hinzu, dass „[d]er Abzug [...] außerordentlich sorgfältig vorbereitet und geschickt durchgeführt worden [war]."257 Als die osmanischen Soldaten sich den aufgegebenen Stellungen näherten, war die Freude über den schlussendlichen Sieg und die Vertreibung der Alliierten groß, besonders, da trotz aller Bemühungen des britischen Gegners noch viel wertvolles Material zurückgelassen worden war: „Die Kriegsbeute war [...] außerordentlich groß. Wagenparks verschiedener Art und ein großer Automobilpark, sowie ganze Berge von Waffen, Munition und Schanzzeug erstanden aus der Beute. Auch hier waren die großen Zeltlager und Baracken stehengeblieben, zum Teil [mit] voller Einrichtung. “258 Ein Gros der Nahrungsmittel war nur durch das Übergießen mit einer „scharfen Lösung“"259 unbrauchbar gemacht und die Pferde und Maultiere der Alliierten waren vor Abzug erschossen worden, aber die osmanischen Truppen fanden ausreichend Material, um ihren Sieg zu feiern, sodass man „,[i]n der nächsten Zeit [...] die türkischen Soldaten auf der Halbinsel in den unglaublichsten Bekleidungen, die sich aus allen nur denkbaren Uniformstücken zusammengestellt hatten [sah]. Sie waren wie die Kinder. Sogar die englischen Gasmasken trugen sie zum Vergnügen.“260

Militärisch war die Gallipoli-Kampagne beendet, politisch sollte sie noch einige Nachwehen erzeugen. 1917 legte die Dardanellen-Kommission ihren Zwischenbericht vor, der sich „,ausschließlich mit dem Ursprung und dem Beginn des Angriffes auf die Dardanellen befasst.“261 Die zehn Kommissionsmitglieder waren 1916 durch den Special Commissions Act ernannt worden, um die GallipoliKampagne einer genauen Analyse zu unterziehen, wobei alle Aspekte der Operationen genauestens untersucht wurden. Dabei ging es vor allem um die Frage der Schuld, also die nach der Verantwortlichkeit für das Scheitern, über das es in der Öffentlichkeit verschiedene Meinungen gab. Die Kommission sollte sich im Gegensatz dazu ausschließlich auf Fakten stützen und herausfinden, welche Rolle dem War Council und den Offizieren am Ort des Scheiterns tatsächlich zukam. Es wird im Zwischenbericht festgestellt, dass Churchill den Plan erstmals am

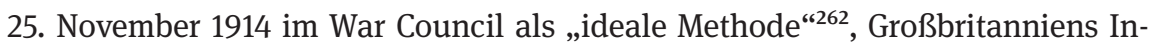
teressen in Ägypten zu verteidigen, vorgestellt hatte. Schließlich kann festgestellt werden, dass alle Mitglieder gegen eine alleinige Attacke der Marine waren, die

256 Sanders, Türkei, S. 127.

257 Ebd., S. 128.

258 Ebd., S. 134.

259 Ebd.

260 Ebd.

261 Dardanelles Commission, First Report, S. 1.

262 Ebd., S. 41. 
jedoch von Churchill aufgrund einer „gewissen halbherzigen und zögernden Expertenmeinung ${ }^{\text {“263 }}$ beworben wurde. Die Kommission kam schließlich zu dem Ergebnis, dass der War Council ohne sich vorher umfassend zu informieren oder weitere Meinungen einzuholen, am 13. Januar eine fahrlässige Entscheidung getroffen hatte. Zudem wird konstatiert, dass der Plan selbst, sofern in einer kombinierten Aktion von Marine und Heer mit dem entsprechenden Überraschungsmoment ausgeführt, erfolgversprechend war. Allerdings wurde durch die Entscheidung, einen alleinigen Angriff der Marine auszuführen zu lassen, eine gute Möglichkeit, den Krieg zum Wohle Großbritanniens zu beeinflussen, ver$\tan ^{264}$ In dem 1919 vorgelegten Abschlussbericht der Kommission, in dem die Mitglieder ihre abschließende Bewertung der Ereignisse bekannt gaben, wird moniert, dass die Pläne nicht ausreichend durchdacht und vorbereitet worden waren, um eine solche Operation mit Erfolg durchführen zu können. ${ }^{265}$ Die Schwierigkeiten waren „stark unterschätzt“266 worden und die Verantwortlichen gingen davon aus, dass kaum ein Widerstand von Seiten des Feindes erfolgte. Die Kommission „sieht [jedoch] keine ausreichenden Belege für diese Annahme.“267 Es war bekannt, dass die osmanischen Truppen von deutschen Offizieren kommandiert würden und es gab daher keinen Grund, nicht anzunehmen, dass sie nicht reagierten, zumal sie die Verteidigung übernahmen. ${ }^{268}$ Stopford wurde für das Scheitern des Vorstoßes bei Suvla verantwortlich gemacht, da die Aktionen, der ihm zugewiesenen Truppen als „nicht zufriedenstellend“ $\mathrm{zu}$ bewerten waren. ${ }^{269}$ Besonders seine Untätigkeit und das Unterlassen, sich selbst mit akkuraten Informationen an Land zu versorgen, wurden bemängelt. Dagegen wurde Hamilton im Gegensatz dazu bloß partiell für das Scheitern der Kampagne verantwortlich gemacht, selbst wenn „die Fähigkeiten eines Kommandeurs im Krieg danach bewertet werden sollten, was er erreicht. “" ${ }^{270}$ Kritisiert wurde vor allem Hamiltons Haltung zu Kitchener, den er eher als einen Vorgesetzten und nicht als einen Minister betrachtete. ${ }^{271}$

263 Ebd., S. $41 \mathrm{f}$.

264 Ebd., S. 42.

265 Dardanelles Commission, Final Report, S. 86.

266 Ebd.

267 Ebd.

268 Ebd.

269 Ebd., S. 87

270 Ebd.

271 Ebd., S. 88 
A.C. Temperley, der selbst als Offizier an den Landungen der ANZAC-Truppen beteiligt gewesen war, schrieb am 27. Oktober 1930 an Aspinall-Oglander, ${ }^{272}$ der an der offiziellen Geschichte der Schlacht von Gallipoli arbeitete und erklärte in seinem Brief die Gründe für das Scheitern aus Sicht der ANZAC-Führung noch einmal im Detail: „es gibt drei Hauptgründe wegen derer die Operationen scheiterten“"273, nämlich

1. die viel $\mathrm{zu}$ ambitionierten Ziele der Operation,

2. die sinnlose Aufteilung der Truppen und die unzureichende Versorgung derselben mit Nachschub, sowie

3. die Unerfahrenheit der britischen Truppen, die von den geographischen und klimatischen Bedingungen überfordert worden waren. ${ }^{274}$

Die Kritik richtete sich hier allerdings ebenfalls eher gegen die Führung als gegen die Soldaten, die nach Kräften versucht hatten, die ambitionierten Forderungen ihrer Befehlshaber umzusetzen.

Neben Hamilton war es aber vor allem Churchill, der in der Kritik stand und der schon im Mai, nachdem der Konflikt mit Fisher wieder ausgebrochen war, gezwungen wurde, seinen Posten in der Admiralität zu räumen. Während der spätere Premierminister nämlich eine weitere Flottenoperation durchzusetzen versuchte, war Fisher nicht länger bereit, den Konflikt zu entschärfen, zumal Churchill mit derlei Plänen die wertvollen Ressourcen der Britischen Marine gefährdete. Letztgenannter wurde in der Folge politisch degradiert und zum Kanzler des Herzogtums Lancaster ernannt. Seinen einflussreichen Posten hatte Churchill damit verloren und diese Entscheidung markierte seinen schwersten politischen Fall innerhalb seiner Karriere. ${ }^{275}$ Trotz dieser Maßnahme und der Berichte der Dardanellen-Kommission waren einige Beobachter nicht zufriedengestellt worden und bezogen öffentlich Position gegen diejenigen, die sie für das Scheitern der Gallipoli-Kampagne für schuldig erklärten. Ashmead-Bartlett drängte darauf, Kitchener und Hamilton stärker zur Rechenschaft zu ziehen. ${ }^{276}$ Besonders tragisch hält er das Scheitern der Operation - Ashmead-Bartlett gehört zu denen, die

272 Aspinall-Oglander stand im Zuge seiner Arbeit an der Geschichte der Schlacht von Gallipoli mit etlichen Teilnehmern derselben in Kontakt und bat diese unter anderem um Detailwissen sowie deren Meinung zu seinem Manuskript. Überliefert sind diese Korrespondenzen in TNA-CAB 45/241-245.

273 Brief von A.C. Temperley an Cecil F. Aspinall-Oglander, London, 27. Oktober 1930, TNA-CAB 45/245, S. 3.

274 Ebd., S. 4.

275 Moorehead, Gallipoli, S. 162.

276 Ashmead-Bartlett, Dardanelles, S. 11. 
an der Idee eines möglichen Gelingens festhielten - , da eine Einnahme der Gallipoli-Halbinsel und die Etablierung einer Versorgungslinie nach Russland die Russische Revolution hätten verhindern können. ${ }^{277}$ Churchill macht er dafür verantwortlich, dass er ,den großen Preis erblickte und versuchte, diesen mit unzureichenden Maßnahmen zu erlangen.“278

Ebenso kritisch weist der Kriegsberichterstatter darauf hin, dass der Kampf zwischen den einzelnen Fronten um Nachschub und Truppen dazu geführt hatte, dass die Operation bei Gallipoli oft halbherzig ausgeführt worden war und infolgedessen scheitern musste. Die Kampagne war für einen kurzen Moment diejenige, die von den Entscheidungsträgern favorisiert wurde, doch sobald das Interesse abebbte, versanken die Soldaten vor Ort in der Vergessenheit des politischen Tagesgeschäftes, wobei sie von anderen und als wichtiger betrachteten Fronten überschattet wurden. ${ }^{279}$ Persönlich macht Ashmead-Bartlett Ian Hamilton für das Desaster Gallipoli verantwortlich, der Frontalangriffe gegen schwer zu verteidigende Stellungen angeordnet hatte, die lediglich hohe Verluste, jedoch keinen Raumgewinn einbrachten. ${ }^{280}$ Betrachtet man die Auseinandersetzung mit den Operationen bei den Dardanellen genauer, so wurden doch einige Lehren, vor allem mit Blick auf mögliche Landungsoperationen, gezogen. Das Überraschungsmoment sowie die Notwendigkeit der Geheimhaltung von Operationsdetails wurden in militärischen Lehrbüchern stärker betont. Gewiss hatte Gallipoli einen negativen Effekt, denn Landungen von Truppen wurden in der Zukunft oft vermieden, weil sich die Entscheidungsträger zu stark an die Ereignisse von 1915 erinnert fühlten. ${ }^{281}$ Die Erfahrung Gallipoli erklärt folglich zumindest partiell Churchills Zögern bei den Vorbereitungen zur Landung großer Truppenkontingente in der Normandie, schließlich hatte eine ähnliche Operation schon einmal seine Karriere beinahe beendet. Gallipoli bleibt bis in die Gegenwart ein hoch interessantes Thema, zumal die Diskussion um die Fehler der Kampagne seit 1916 nie abgebrochen ist. Dabei ist es müßig, den oder die Schuldigen zu suchen, gerade bei einer Operation, die einfach nicht, zumindest nicht mit so wenigen Truppen, gewonnen werden konnte. Die Regeln des modernen und technisierten Krieges, in Verbindung mit dem für die osmanischen Verteidiger günstigen Terrain machten einen alliierten Erfolg unmöglich.

277 Ebd., S. 12.

278 Ebd., S. 14.

279 Ebd., S. 16.

280 Ebd., S. 20 f.

281 MacGregor, Use, S. 607 f. u. S. 615. 


\subsection{Exkurs: Die französischen Operationen}

Die französischen Operationen sollen im Folgenden nur kurz und exkursartig dargestellt werden, zumal es auch keine konkreten Planungen gab, die das Zusammenspiel aus britischen und französischen Kontingenten regelte. Zwar war aufgrund eines von den beiden Entente-Mächten in London am 6. August 1914 unterzeichneten Abkommens vorgesehen, dass Admiral Augustin Boué de Lapeyrère (1852-1924) das Kommando der britisch-französischen Flotte im Mittelmeer führen sollte. Doch stimmte im Januar 1915 der französische Marineminister Victor Augagneur (1855-1931) zu, dass Frankreich im Zuge der GallipoliOperationen lediglich eine assistierende Position zukäme. Der französische Präsident Raymond Poincaré (1860 - 1934), den der Würzburger Historiker Rainer F. Schmidt in einem kürzlich erschienen, mitunter „revisionistischen“ Artikel in der Historischen Zeitschrift, zuweilen etwas unausgewogen betrachtet und bescheinigt, dieser habe den Ersten Weltkrieg gegen Deutschland geplant und provoziert, ${ }^{282}$ stand dem Landungsvorhaben - wohl ungewöhnlich für den nach Schmidt sonst so aggressiv-expansiven Stil des französischen Regierungschefs ebenfalls kritisch gegenüber, da ihm die Planungen in London zu schnell vonstattengingen und zu wenig Zeit für konkrete Vorbereitungen zur Verfügung stand. Wenn einer Beteiligung zugestimmt wurde, dann aus französischer Perspektive vor allem deshalb, um die Bündnisverpflichtung gegenüber Russland wahrzunehmen, selbst wenn die Expedition in erster Linie, und das wusste man auch in Frankreich, dazu dienen sollte, die britischen Positionen in Ägypten und Indien zu sichern.

Aufgrund der also schon zu Beginn negativen Haltung der französischen Militärs zu Gallipoli, verwundert es nicht, dass diese Kreise nicht gewillt waren, mit den Operationen, besonders nach dem Debakel der Phase nach den Landungen der alliierten Truppen, identifiziert zu werden. Des Weiteren wurde die Kampagne als nicht genuin französisch betrachtet, besonders da sich Frankreich mit einem wesentlich kleineren Kontingent an Schiffen - nur vier von 15 - und Truppen - nur zwei Divisionen, im Gegensatz zu sieben britischen - an der Ausführung des Planes beteiligte. ${ }^{283}$ Darüber hinaus wurde weder eine große militärische Persönlichkeit des französischen Stabes bestellt, um sich an den

282 Vgl. Schmidt (Revanche). Der Artikel wurde von einer durchaus polemischen Replik in der Historischen Zeitschrift kritisiert. Vgl. Moore (Legende). Für eine etwas ausgewogenere Bewertung, die darauf hinweist, dass Schmidts Standpunkt durchaus dem der 1920er Jahre, auf Basis dessen einer deutschen Kriegsschuld widersprochen wurde, entspreche, vgl. das Interview mit Gerd Krumeich in Kellerhoff (Argumentation).

283 Dutton, Supernumerary, S. 89. 
Operationen $\mathrm{zu}$ beteiligen, noch gab es einen Politiker, wie etwa Churchill im britischen Lager, der sich explizit mit dem Vorhaben identifizierte. In vielen späteren Memoiren wurde auf Seiten der Franzosen schließlich oft darauf verwiesen, dass die Regierung sich nur aufgrund der Bündnispflicht gegenüber Großbritannien bereit erklärt hätte, ein Unternehmen zu unterstützen, welches von vornherein nur wenig erfolgversprechend gewesen sei. ${ }^{284}$

Gallipoli blieb ein Minimalprojekt des französischen Militärs, das die Schaffung einer zweiten Front im Jahre 1915 klar ablehnte. ${ }^{285}$ Die einflussreichen Offiziere in Frankreichs Heer lehnten eine Landung bei den Dardanellen zudem mit der Begründung ab, dass sie dem eigentlichen Ziel, das Osmanische Reich von Süden her zu attackieren, entgegenstand. Die Operation blieb deshalb eine halbherzige. Nachdem die französischen Kontingente erfolgreich bei Kum Kale gelandet waren, um die osmanischen Verteidiger von den Zielen der britischen Landungsoperationen abzulenken, verblieben sie die meiste Zeit der Kampagne in dieser Position, auch wenn sie im Hinblick auf die erreichten Vormarschdistanzen vergleichsweise gut abschnitten. Am 5. Mai 1915 ernannte der französische Kriegsminister Alexandre Millerand (1859-1943) schließlich General Henri Gouraud (1867-1946) zum Befehlshaber des Corps Expéditionnaire Français aux Dardanelles, dessen Stab aufgrund seiner Erfahrungen in den französischen Kolonien und als Befehlshaber von Frankreichs Kolonialarmee einem „who-is-who der Kolonialkrieger Frankreichs“ glich - zu nennen wären etwa Marie François Adolphe Gabriel Ganeval (1853-1915) sowie Pierre Girodon (1869-1916). ${ }^{286}$

Mit seinen Offizieren und Soldaten agierte Gouraud aber weitestgehend unabhängig vom Rest der Landungstruppen und bildete sozusagen ein Expeditionskorps im Expeditionskorps. Konkrete Planungen zum Zusammenspiel französischer und britischer Truppen hatte es nämlich, wie oben bereits erwähnt, nicht wirklich gegeben. Russland, Frankreich und Großbritannien hatten sich zwar darauf verständigt, keinen Separatfrieden mit dem Deutschen Kaiserreich zu schließen, allerdings wurden keine formellen Abmachungen getroffen, die die gemeinsame diplomatische Linie in eine koordinierte militärische Strategie umgemünzt hätte. Die Soldaten und deren militärische Führer schienen vor Ort jedoch ungeachtet solcher Defizite recht gut miteinander auszukommen. Gourauds Plan, den französischen Vorstoß bei Kum Kale nach Norden voranzutreiben, um die osmanische Armee von beiden Seiten der Meerengen $\mathrm{zu}$ attackieren und in

284 Ebd.

285 Andurain, Gouraud.

286 Ebd. 
einer Zangenbewegung einzuschließen, stieß allerdings trotzdem auf taube Ohren.

Vor Ort waren die Franzosen, wie alle anderen Truppenteile, ebenfalls in die Kampfhandlungen eingebunden und dadurch mit den damit einhergehenden Problemen konfrontiert. Bereits beim Angriff der Flotte auf die osmanischen Befestigungsanlagen am 19. Februar 1915 waren vier französische Kriegsschiffe Gaulois, Charlemagne, Bouvet und Suffren - beteiligt, von denen letztgenanntes mit 600 Mann Besatzung sank. Die französische Armee war später während der Landungsoperationen genauso an vorderster Front beteiligt, wobei deren Einsatz, wie oben beschrieben, eher der Ablenkung als der Erreichung echter militärischer Ziele dienen sollte. Während die Landung per se und ein anfänglicher Vormarsch weitestgehend problemlos verliefen und Kum Kale schnell eingenommen werden konnte, sahen sich die Landungstruppen in der Nacht zahlreichen Gegenoffensiven der osmanischen Armee ausgesetzt. ${ }^{287}$ Die Probleme, die sich dann in der Folgezeit einstellten, glichen denen der britischen Truppen: Wassermangel, unzureichende Logistik, das Klima und die damit verbundenen Krankheiten. Zudem waren die geographisch höher gelegenen Stellungen vom Gegner besetzt, sodass die Situation der französischen Soldaten kaum besser war als die der australischen an der Anzac Cove. Während die osmanischen Scharfschützen in erhöhter Position mit ausreichend Wasser beobachten und sich gemütlich zurücklehnen konnten, schienen die Franzosen nach dem erfolgreichen ersten Tag ebenso in die Falle gelaufen zu sein wie ihre Kameraden im Norden. ${ }^{288}$

Berichte der französischen Veteranen stehen den Schilderungen der britischen Seite in nichts nach, gerade wenn die klimatischen Bedingungen als schwerwiegendes Problem beschrieben werden. ${ }^{289}$ Mit mehr als 10.000 Toten und einer wesentlich höheren Zahl an Verwundeten - nur ein Drittel der entsandten Soldaten kam unverwundet zurück - hatte Frankreich ebenfalls einen hohen Blutzoll im Zuge der Dardanellen-Expedition entrichtet. ${ }^{290}$ Einzig die enormen Gefallenenzahlen der großen Schlachten der Westfront (Somme, Marne, Verdun etc.) ließen solche Zahlen gering erscheinen und in Vergessenheit geraten, wobei diese in späteren Diskussionen, im Gegensatz zum positiven Verhältnis während des Krieges, oft Großbritannien zum Vorwurf gemacht wurden. ${ }^{291}$ Frankreich war im Gegensatz zu Gallipoli wesentlich mehr an der Saloniki-Front interessiert, die von französischen Militärs und Strategen gleichermaßen gefordert wurde. Mit der

287 Cochet, L'armée, S. 95.

288 Valluy, Guerre, S. 184 zitiert nach Cochet, L’armée, S. 98.

289 Beispielhaft etwa der Bericht Vassal, Dardanelles.

290 Dutton, Supernumerary, S. 87.

291 Vgl. etwa Mordal, L’Expédition. 
Befürwortung dieser Operation war das Ende Gallipolis besiegelt worden und die Franzosen, die schlussendlich mit der Etablierung dieses Nebenkriegsschauplatzes das Ende der Mittelmächte einleiteten, proklamierten ihren eigenen Sieg und damit gleichzeitig eine Wiedergutmachung des Desasters bei den Dardanellen. ${ }^{292}$

Der amerikanische Historiker George H. Cassar konnte zwar in seinem Werk The French and the Dardanelles (Die Franzosen und die Dardanellen) ${ }^{293}$ vor etwa viereinhalb Jahrzehnten belegen, dass die Franzosen kein völlig passiver Partner der Gallipoli-Operation der Briten gewesen sind, aber die öffentliche Wahrnehmung in Frankreich konnte diese Untersuchung kaum beeinflussen. Hinzu kommt, dass offenbar auf britischer Seite kein echtes Interesse an der französischen Beteiligung bestand, da die Kooperation „,weder angefragt, noch besonders gewünscht war.“294 Das mag daran gelegen haben, dass die politische und militärische Führung, wie oben detailliert geschildert, die eigenen Möglichkeiten bei den Dardanellen kolossal überschätzt hatte. Ungeachtet dieser ungerechtfertigten Einschätzung war Frankreichs Anteil an den Operationen alles andere als vernachlässigungswürdig und im Zuge der Jahrhundertjubiläen sind in Frankreich etliche Werke erschienen, die die Zusammenhänge im Hinblick auf die Geschichte(n) des Ersten Weltkrieges eingehender analysieren. ${ }^{295}$ Im Zuge des damit verbundenen Diskurses bleibt zu hoffen, dass einige Fehlannahmen der vergangenen Jahrzehnte im Hinblick auf die Bedeutung Gallipolis für Frankreich revidiert werden können, etwas, das in Großbritannien, ob des großen Interesses an der Geschichte der Ereignisse von 1915 und 1916, nicht erst eines hundertjährigen Jubiläums bedurfte.

292 Dutton, Supernumerary, S. 94. Zur Salonikifront siehe Palmer, Gardeners.

293 Cassar, French.

294 Dutton, Supernumerary, S. 95.

$295 \mathrm{Zu}$ nennen wäre hier etwa Le Naour (1915). Der Autor hat für jedes Kriegsjahr einen eigenen Band vorgelegt und die Ereignisse dadurch sehr detailliert und anschaulich darstellen können. 